
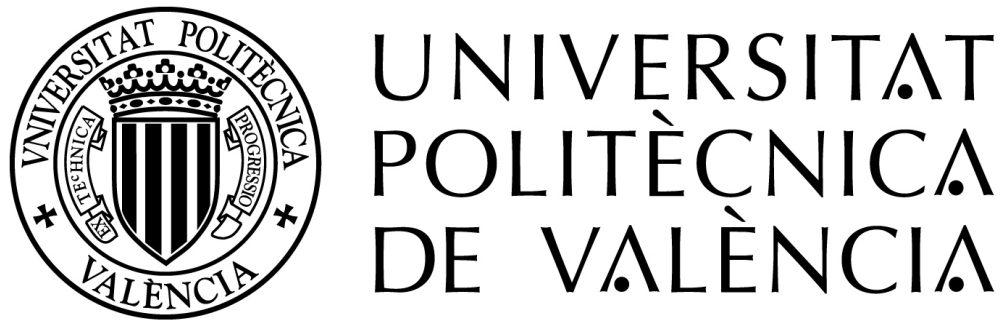

Universitat Politècnica de València

Departamento de Sistemas Informáticos y Computación

\title{
Ph.D. Thesis \\ An immersive virtual reality task with physical movement for the assessment of spatial memory
}

July, 2018

Author: David Rodríguez Andrés

Supervisors: Prof. M. Carmen Juan Lizandra

Dr. Magdalena Méndez López 



\section{Abstract}

Virtual Reality (VR) has not yet been exploited in the assessment of spatial memory. Current VR systems for the assessment of spatial memory include interaction by using traditional devices (e.g., computer screens, mouses or keyboards). This classical type of interaction with the system is ineffective because the user's sense of presence is very poor. If the user does not have the feeling of "being there" in the virtual environment, the spatial memory may not be assessed correctly. The user's physical movement can contribute to a high level of presence. Therefore, by developing a system that allows the participants to become active in a virtual environment, spatial memory can be assessed as the same way it could be evaluated in a real environment.

The main objective of this thesis was to design, develop and validate an immersive VR system in which the user could interact by physical movements. The virtual environment was designed based on a city square. The cognitive task, based on this environment, comprised six levels: an interaction adaptation level, a habituation level, and four levels for the main task. The goal of the levels for the main task was to assess children short-term memory for object location in the virtual environment. The VR system incorporated two types of interaction. 1) A physical active condition (physically walking on a Wii Balance Board ${ }^{\mathrm{TM}}$ and changing the direction by turning a wireless steering wheel). 2) An inactive condition (stand up and use a gamepad). For the visualization of the task, a large stereo screen was used.

For the validation, two studies were carried out to determine the efficacy and utility of our task with regard to the performance outcomes, usability, emo- 
tional variables, fun, the displacement in the virtual environment, or the general satisfaction. The possible relationships between the variables collected during the performance were also analysed. The performance of our task was compared with traditional methods (the Corsi Block Tapping Test). We carried out two studies involving 212 children ( 5 to 12 years old). Correlations were found between our task and traditional methods (the Corsi Block Tapping Test (backward and forward versions)), indicating that our task has proven to be a valid tool for assessing spatial short-term memory in children. With regard to the interaction type, the results showed that there were no statistically significant differences regarding the score obtained in our task based on the interaction used (inactive condition vs. physical active condition). Although unexpected, this is a good result because it means that the task is well suited for the assessment of spatial memory and that the two interaction types can be used for this purpose. With regard to gender differences in the task score and the Corsi Block Tapping Test, the results indicated that there were no statistically significant differences for gender. With regard to usability and satisfaction, our studies have shown that the use of the inactive condition (gamepad) did not differ significantly from the physical active condition for the usability and satisfaction questions.

Previously to the development of the mentioned VR system, we developed a VR system, with Natural User Interfaces (NUI) and an autostereoscopic screen, for dental learning. The system included two modes: neutral and real world background. This system was validated with 33 dentistry students. With this first development, the required knowledge for facing the second development, core of the thesis, was acquired.

The following general conclusions were extracted from the two developments and the three studies: 


\section{Learning}

- Autostereoscopic VR systems, with different background modes and NUI, have proven to be effective tools for learning teeth morphology.

- With this type of systems, children can learn and at the same time, they can have a good time.

- Stereoscopy and NUI are appropriated for developing educational games and they can be exploited in their development.

\section{Spatial memory}

- VR systems, with stereoscopy and two different user interfaces (inactive and physical active conditions), have proven to be reliable and effective tools to assess spatial memory in children.

- With this type of systems, the children can be assessed meanwhile are having a good time.

- Our task and similar tasks could be used for assessment and training of spatial memory in children and adults. 



\section{Resumen}

La Realidad Virtual (RV) aún no se ha explotado en la evaluación de la memoria espacial. Los sistemas actuales de RV para la evaluación de la memoria espacial incluyen interacción mediante el uso de dispositivos tradicionales (por ejemplo, pantallas, ratones o teclados). Este tipo de interacción clásica con el sistema es ineficaz porque la sensación de presencia del usuario es muy pobre. Si el usuario no tiene la sensación de "estar ahí" en el entorno virtual, es posible que la memoria espacial no se evalúe correctamente. El movimiento físico del usuario puede contribuir a un nivel de presencia alto. Por tanto, desarrollar un sistema que permita a los participantes estar activos en el entorno virtual, podría evaluar la memoria espacial de la misma forma que se puede evaluar en un entorno real.

El objetivo principal de esta tesis fue diseñar, desarrollar y validar un sistema inmersivo de RV en el que el usuario pueda interactuar mediante movimiento físico. El entorno virtual se diseñó a partir de una ciudad con forma cuadrada. La tarea cognitiva, basada en dicho entorno, constaba de seis niveles: un nivel de adaptación a la interacción, un nivel de habituación y cuatro niveles para la tarea principal. El objetivo de los niveles para la tarea principal era evaluar la memoria a corto plazo de los niños para la localización de objetos en el entorno virtual. El sistema de RV incorporó dos tipos de interacción. 1) Una condición física activa (caminar físicamente sobre una Wii Balance Board ${ }^{\mathrm{TM}}$ y cambiar la dirección girando un volante inalámbrico). 2) Una condición inactiva (estando de pie y usando un gamepad). Para la visualización de la tarea, se utilizó una pantalla grande y estéreo. 
Para la validación, se realizaron dos estudios para determinar la eficacia y utilidad de nuestra tarea con respecto a resultados de rendimiento, usabilidad, variables emocionales, diversión, desplazamiento en el entorno virtual o satisfacción general. También se analizaron las posibles relaciones entre las variables almacenadas durante la realización de la tarea. El rendimiento de nuestra tarea se comparó con métodos tradicionales (Corsi Block Tapping Test). Se llevaron a cabo dos estudios con 212 niños (de 5 a 12 años). Se encontraron correlaciones entre nuestra tarea y los métodos tradicionales (Corsi Block Tapping Test (versiones hacia atrás y hacia adelante)), lo que indica que nuestra tarea ha demostrado ser una herramienta válida para evaluar la memoria espacial a corto plazo en niños. Con respecto al tipo de interacción, los resultados mostraron que no hubo diferencias estadísticamente significativas con respecto a la puntuación obtenida en nuestra tarea y en función de la interacción utilizada (condición inactiva vs. condición física activa). Aunque inesperado, éste es un buen resultado porque significa que la tarea es adecuada para la evaluación de la memoria espacial y que los dos tipos de interacción se pueden utilizar para este fin. Con respecto a las diferencias de género en la puntuación de la tarea y Corsi Block Tapping Test, los resultados indicaron que no hubo diferencias estadísticamente significativas para el género. Con respecto a facilidad de uso y satisfacción, nuestros estudios han demostrado que el uso de la condición inactiva (gamepad) no difirió significativamente de la condición física activa para las preguntas de usabilidad y satisfacción.

Previamente al desarrollo del sistema de RV mencionado, desarrollamos un sistema de RV, con interfaces de usuario naturales (NUI) y una pantalla autoestereoscópica, para aprendizaje dental. El sistema incluye dos modos: fondo neutro y mundo real. Este sistema fue validado con 33 estudiantes de especialidades dentales. Con este primer desarrollo, se adquirió el conocimiento necesario para poder afrontar el segundo desarrollo, núcleo de la tesis.

Las siguientes conclusiones generales se extrajeron de los dos desarrollos y los tres estudios:

\section{Aprendizaje}

- Los sistemas de RV con autoestereoscopía, con diferentes fondos y NUI, han demostrado ser herramientas eficaces para aprender la morfología dental.

- Con este tipo de sistemas, los niños pueden aprender y, al mismo tiempo, pueden divertirse. 
- La estereoscopía y NUI son apropiadas para el desarrollo de juegos educativos y pueden ser explotadas en su desarrollo.

\section{Memoria espacial}

- Los sistemas de RV, con estereoscopía y dos interfaces de usuario diferentes (condiciones inactiva y física activa), han demostrado ser herramientas fiables y efectivas para evaluar la memoria espacial en niños.

- Con este tipo de sistemas, los niños pueden ser evaluados mientras se divierten.

- Nuestra tarea y tareas similares podrían usarse para evaluación y entrenamiento de la memoria espacial en niños y adultos. 



\section{Resum}

La Realitat Virtual (RV) encara no s'ha explotat en l'avaluació de la memòria espacial. Els sistemes actuals de RV per a l'avaluació de la memòria espacial inclouen interacció mitjançant l'ús de dispositius tradicionals (per exemple, pantalles, ratolins o teclats). Aquest tipus d'interacció clàssica amb el sistema és ineficaç perquè la sensació de presència de l'usuari és molt pobre. Si l'usuari no té la sensació de "ser-hi" en l'entorn virtual, és possible que la memòria espacial no siga avaluada correctament. El moviment físic de l'usuari pot contribuir a un nivell de presència alt. Per tant, desenvolupar un sistema que permeta als participants estar actius en l'entorn virtual, podria avaluar la memòria espacial de la mateixa manera que es pot avaluar en un entorn real.

L'objectiu principal d'aquesta tesi va ser dissenyar, desenvolupar i validar un sistema immersiu de RV en el qual l'usuari puga interactuar mitjançant moviment físic. L'entorn virtual es va dissenyar a partir d'una ciutat amb forma quadrada. La tasca cognitiva, basada en aquest entorn, constava de sis nivells: un nivell d'adaptació a la interacció, un nivell d'habituació i quatre nivells per a la tasca principal. L'objectiu dels nivells per a la tasca principal era avaluar la memòria a curt termini dels xiquets per a la localització d'objectes en l'entorn virtual. El sistema de RV va incorporar dos tipus d'interacció. 1) Una condició física activa (caminar físicament sobre una Wii Balance Board ${ }^{\mathrm{TM}}$ i canviar la direcció girant un volant inalàmbric). 2) Una condició inactiva (estar dret i fent servir un gamepad). Per a la visualització de la tasca, es va utilitzar una pantalla gran i estèreo. 
Per a la validació, es van realitzar dos estudis per a determinar l'eficàcia i utilitat de la nostra tasca pel que fa a resultats de rendiment, usabilitat, variables emocionals, diversió, desplaçament en l'entorn virtual o satisfacció general. També es van analitzar les possibles relacions entre les variables emmagatzemades durant la realització de la tasca. El rendiment de la nostra tasca es va comparar amb mètodes tradicionals (Corsi Block Tapping Test). Es van dur a terme dos estudis amb 212 xiquets (de 5 a 12 anys). Es van trobar correlacions entre la nostra tasca i els mètodes tradicionals (Corsi Block Tapping Test (versions cap enrere i cap endavant)), el que indica que la nostra tasca ha demostrat ser una eina vàlida per avaluar la memòria espacial a curt termini en xiquets. Pel que fa al tipus d'interacció, els resultats van mostrar que no hi va haver diferències estadísticament significatives respecte a la puntuació obtinguda en la nostra tasca i en funció de la interacció utilitzada (condició inactiva vs. condició física activa). Encara inesperat, aquest és un bon resultat perquè significa que la tasca és adequada per a l'avaluació de la memòria espacial i que els dos tipus d'interacció es poden utilitzar per a aquest fi. Pel que fa a les diferències de gènere en la puntuació de la tasca i Corsi Block Tapping Test, els resultats van indicar que no hi va haver diferències estadísticament significatives per al gènere. Pel que fa a facilitat d'ús i satisfacció, els nostres estudis han demostrat que l'ús de la condició inactiva (gamepad) no va diferir significativament de la condició física activa per a les preguntes d'usabilitat i satisfacció.

Prèviament al desenvolupament del sistema de RV esmentat, vam desenvolupar un sistema de RV, amb interfícies d'usuari naturals (NUI) i una pantalla autoestereoscòpica, per aprenentatge dental. El sistema inclou dos tipus de fons: fons neutre i món real. Aquest sistema va ser validat amb 33 estudiants d'especialitats dentals. Amb aquest primer desenvolupament, es va adquirir el coneixement necessari per poder afrontar el segon desenvolupament, nucli de la tesi.

Les següents conclusions generals es van extraure dels dos desenvolupaments i els tres estudis:

\section{Aprenentatge}

- Els sistemes de RV amb autoestereoscòpia, amb diferents fons i NUI, han demostrat ser eines eficaces per a aprendre la morfologia dental.

- Amb aquest tipus de sistemes, els xiquets poden aprendre i, al mateix temps, poden divertir-se. 
- La estereoscòpia i NUI són apropiades per al desenvolupament de jocs educatius i poden ser explotades en el seu desenvolupament.

\section{Memòria espacial}

- Els sistemes de RV, amb estereoscòpia i dues interfícies d'usuari diferents (condicions inactiva i física activa), han demostrat ser eines fiables i efectives per avaluar la memòria espacial en xiquets.

- Amb aquest tipus de sistemes, els xiquets poden ser avaluats mentre es diverteixen.

- La nostra tasca i tasques similars podrien usar-se per avaluació i entrenament de la memòria espacial en xiquets i adults. 



\section{Acknowledgments}

Firstly, I would like to express my sincere gratitude to my supervisors Prof. M. Carmen Juan and Dr. Magdalena Méndez López for the continuous support of my Ph.D. thesis and related research, for their patience, motivation, and immense knowledge. Their guidance helped me during the realization of this Ph.D.

I would also like to extend my thanks to my lab mates of the Universitat Politècnica de València: Lucian Alexandrescu, Juan Fernando Martín, Vicente Broseta, Gustavo Rovelo and David Furió. Thanks to all of them. They have made me feel as at home.

I also thank to Elena Pérez Hernández. Without her participation and input, the validation survey could not have been successfully conducted.

I wish to thank Mara Chinea for her assistance in this thesis, and her help in my good and bad times.

Finally, I wish to thank my parents for their support and encouragement throughout my studies. 



\section{Contents}

Abstract $\quad$ iii

Contents xvii

I Introduction 1

1 Introduction 3

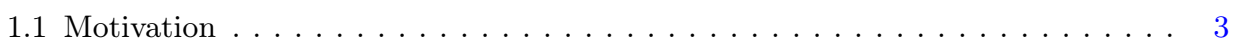

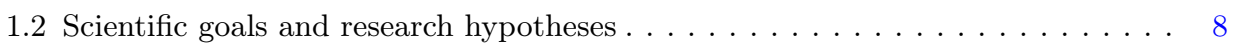

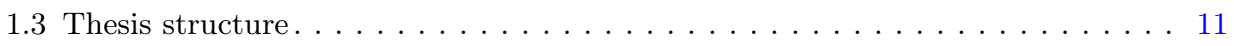

II Selected papers 13

2 3D Serious Dental Game $\quad 15$

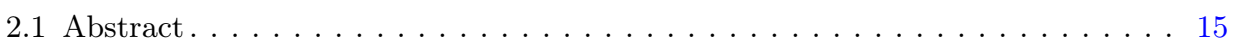

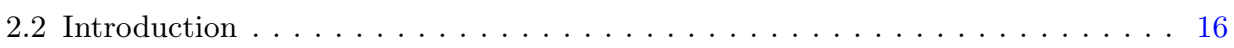

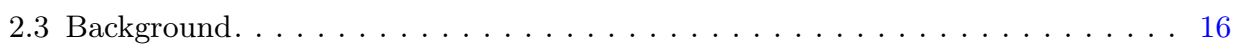




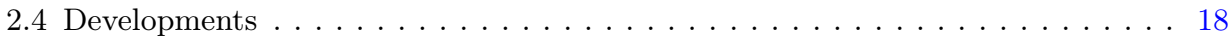

2.5 Study. . . . . . . . . . . . . . . . . . . . . . . . . 20

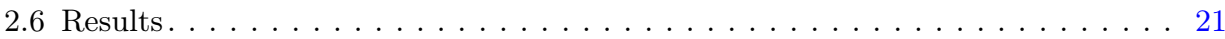

2.6 .1 Knowledge outcomes . . . . . . . . . . . . . . . . . . . . . . . . . 21

2.6.2 Usability, Depth Perception, and Satisfaction Outcomes . . . . . . . . . . . 22

2.6 .3 Preferences about the Game Background . . . . . . . . . . . . . . . . 23

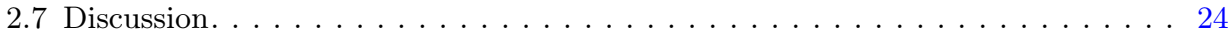

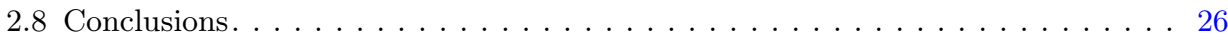

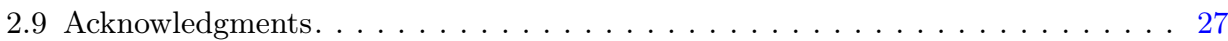

3 MnemoCity Task 29

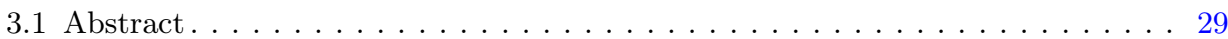

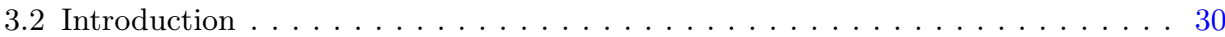

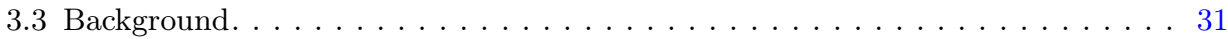

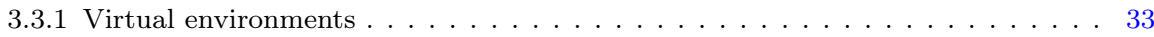

3.3 .2 Natural User Interfaces. . . . . . . . . . . . . . . . . . . . . . . . . . . . 34

3.3 .3 Stereoscopy . . . . . . . . . . . . . . . . . . . . . . . . . . . . . 35

3.3 .4 Short-term memory . . . . . . . . . . . . . . . . . . . . . . 35

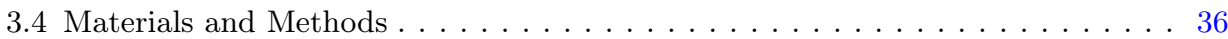

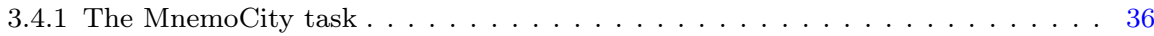

3.4.2 Development . . . . . . . . . . . . . . . . . . . . . . . . . 41

3.4 .3 Interaction . . . . . . . . . . . . . . . . . . . . . . . . 43

3.4 .4 Software and Hardware. . . . . . . . . . . . . . . . . . . . . . . . . . . 45

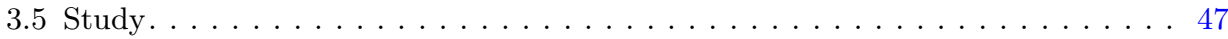

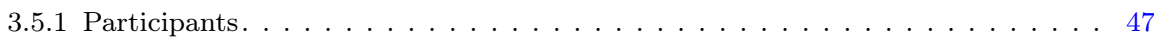

3.5 .2 Measurements . . . . . . . . . . . . . . . . . . . . . . . 48

3.5 .3 Procedure . . . . . . . . . . . . . . . . . . . . . . . . . 49

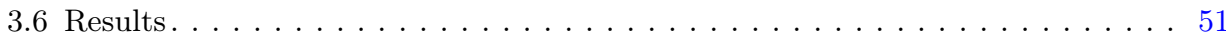

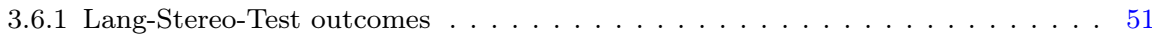

3.6 .2 Interaction outcomes . . . . . . . . . . . . . . . . . . . . 52

3.6 .3 Gender outcomes . . . . . . . . . . . . . . . . . . . . . . 53

3.6.4 Preference and depth perception outcomes . . . . . . . . . . . . . . . 54

3.6.5 Short-term memory outcomes. . . . . . . . . . . . . . . . . . . . 55

3.6 .6 Usability and satisfaction outcomes . . . . . . . . . . . . . . . 56 


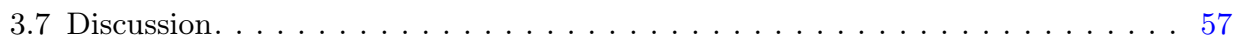

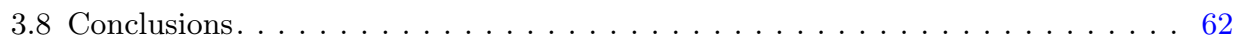

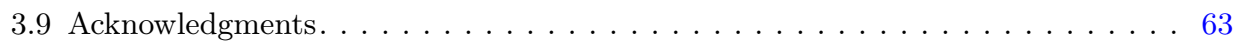

4 A Virtual Object-Location Task for Children 65

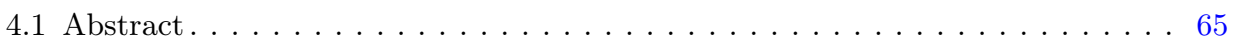

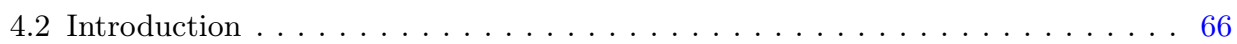

4.3 Materials and Methods . . . . . . . . . . . . . . . . 70

4.3 .1 Participants. . . . . . . . . . . . . . . . . . . . 70

4.3.2 The Testing Room and Instrumentation for the VOL Task . . . . . . . . . . 70

4.3 .3 The VOL Task . . . . . . . . . . . . . . . . . . . . . . . . . . . . 71

4.3.4 Videogame Exp., 3D Perception, Satisfaction, and Usability Questionnaires . . 76

4.3 .5 Spatial Ability Tests . . . . . . . . . . . . . . . . . . . 77

4.3 .6 Emotional and Behavioral Rating Scale. . . . . . . . . . . . . . . 77

4.3 .7 Procedure . . . . . . . . . . . . . . . . . . . . . . . . 77

4.3 .8 Data Analysis . . . . . . . . . . . . . . . . . . . 78

4.4 Results . . . . . . . . . . . . . . . . . . . . . . . . . . 79

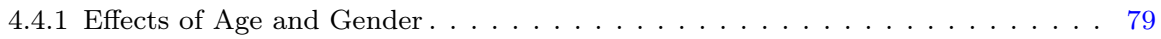

4.4 .2 Usability, Satisfaction and 3D Perception. . . . . . . . . . . . . . . 81

4.4.3 Relationship between Performance on the VOL Task and the Participant's

Outcomes . . . . . . . . . . . . . . . . . . . . . . . . . 84

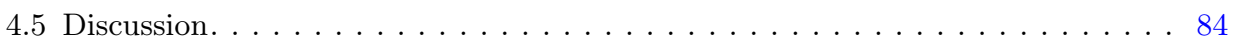

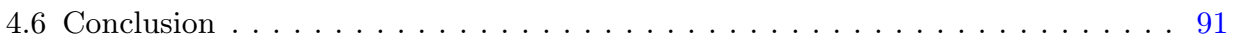

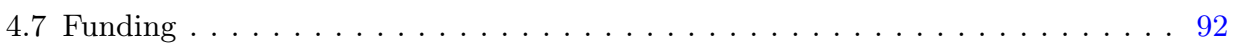

4.8 Acknoledgments. . . . . . . . . . . . . . . . . . . . . . . . . . 92

$\begin{array}{ll}\text { III Discussion } & 93\end{array}$

5 Discussion 95

5.1 VR system for the assessment of spatial memory . . . . . . . . . . . 95

5.2 VR system for dental learning . . . . . . . . . . . . . . . . . 99 
$\begin{array}{ll}\text { IV Conclusions } & 101\end{array}$

6 Conclusions 103

6.1 Conclusions. . . . . . . . . . . . . . . . . . . . . . . . . . 103

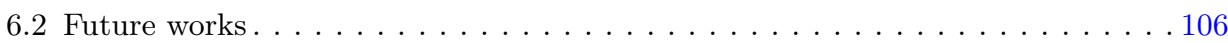

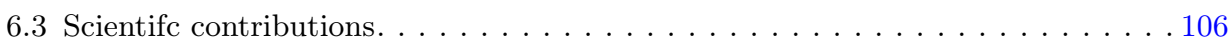

6.3 .1 Papers in journals indexed in JCR . . . . . . . . . . . . . . . . . 106

6.3 .2 Papers in conferences indexed in CORE $2017 \ldots \ldots$. . . . . . . . . . . . 107

6.3 .3 Papers in other conferences . . . . . . . . . . . . . . . . . . . . . 107

6.3 .4 Other difusions. . . . . . . . . . . . . . . . . . . . . . . . . . . 107

$\begin{array}{ll}\text { Bibliography } & 109\end{array}$ 


\section{List of Figures}

1.1 A child performing the Corsi Block Tapping Test . . . . . . . 7

2.1 Screen view of the real-background mode. . . . . . . . . 17

2.2 Zoom of a tooth. . . . . . . . . . . . . 18

3.1 Stereoscopy scheme. . . . . . . . . . . . . . . . . 32

3.2 General scheme of MnemoCity task. . . . . . . . . . . 37

3.3 A child performing the interaction adaptation level. . . . . . . . 39

3.4 The progression bar screen. . . . . . . . . . . . . . . 41

3.5 One of the objects that appears on the MnemoCity task. . . . . 42

3.6 The MnemoCity environment. . . . . . . . . . . . . . . . . 42

3.7 System architecture. . . . . . . . . . . . . . . 44

3.8 Virtual representation of the MnemoCity testing room. . . . . . 46

3.9 The Wii Balance Board ${ }^{\mathrm{TM}}$ and Wii Mote ${ }^{\mathrm{TM}}$ used to create the NUI interaction. . . . . . . . . . . . . 46

3.10 The gamepad used to create the standard interaction. . . . . 47 
3.11 Procedure of the task. . . . . . . . . . . . . . . . 49

3.12 The Correlation plot. . . . . . . . . . . . . . . 55

3.13 The Matrix plot for correlations between traditional tests and the MnemoCity task. . . . . . . . . . . . . . 60

4.1 The testing room for the VOL task. . . . . . . . . . 71

4.2 The VE in the mountains in the adaptation phase. . . . . . . 72

4.3 The VE in the mountains in the adaptation phase. . . . . . . 74

4.5 The paths made by the children in the testing phases of the four levels. . . . . . . . . . . . . . . 85

4.6 The paths made by the children in the testing phases of the four levels. . . . . . . . . . . . . . 86

5.1 Left, the real-world background version. Right, the neutral background version. . . . . . . . . . . . . . . 99 


\section{List of Tables}

2.1 Q2 and Q3 questionaries. The Q2 questionnaire includes Q1Q11 questions. The Q3 questionnaire includes Q12-Q20 questions. 22

2.2 Mann Whitney $\mathrm{U}$ test for Q2 questions. . . . . . . . . . 24

2.3 Chi-squared test for Q3 questions. . . . . . . . . 25

3.1 Gender and age distribution of the participants of the MnemoCity task. . . . . . . . . . . . . . . . . . . 4 48

3.2 Questions of the Q1 questionnaire. . . . . . . . . 50

3.3 Questions of the Q2 questionnaire. . . . . . . . . 51

3.4 Multifactorial Kruskal-Wallis test results for stereo vision. . . . 52

3.5 A Multifactorial Kruskal-Wallis test was conducted on the influence of four independent variables (Gender, Usability, Satisfaction and MnemoCity Score) for the Type of interaction. "**" indicates the statistical significance at level $\alpha=0.05$. "-" indicates that there was no statistical significance. . . . . . . . 53 
3.6 A Multifactorial Kruskal-Wallis test was conducted on the influence of four independent variables (Interaction, Usability, Satisfaction and MnemoCity Score) for gender. "**" indicates the statistical significance at level $\alpha=0.05$. " $-"$ indicates that there was no statistical significance. . . . . . . . . . . . 53

3.7 Interaction and 3D preferences. Mann-Whitney U tests about the preferences. . . . . . . . . . . . . . 54

3.8 Multifactorial Kruskal-Wallis test results for depth perception. . 55

3.9 Descriptive data of the MnemoCity score. . . . . . . . . . 56

3.10 Usability and satisfaction questions. . . . . . . . . . 56

3.11 Interaction preferences. . . . . . . . . . . . . . 57

4.1 Mean scores (standard deviations) for the variables of the VOL task, videogame experience, 3D perception, satisfaction, and usability questionnaires $(N=52) \ldots \ldots \ldots \ldots$

4.2 Mean scores (standard deviations) for the spatial ability tests and the subscales of the Parent Report form of the BASC-2 used in the study $(N=52)$. CBTT $=$ Corsi Block Tapping Test. $\mathrm{BC}=$ Block Construction subtest from the Nepsy-II. PRfBASC $=$ Parent Report form of the Behavioural Assessment Scale for Children. . . . . . . . . . . . . . . .

4.3 The results of the Kruskal Wallis tests for the variables related to the performance of the VOL task. The tests that reached significance are displayed in bold type. . . . . . . . . . . 82

4.4 Multifactorial Kruskal Wallis tests for the Usability, Satisfaction, and 3D Perception variables. . . . . . . . . . 83

4.5 Partial Spearman correlations $(N=52) \ldots \ldots \ldots \ldots$ 
Part I

Introduction 



\title{
Chapter 1
}

\section{Introduction}

\author{
"Science is a way of thinking much more than it is a body of \\ knowledge" -Carl Sagan
}

\section{Motivation}

Virtual Reality (VR) can be defined as an artificial world or a virtual environment, created by computer, in which the user has the impression of being and the ability to navigate and manipulate objects in it (Manetta and Blade 2015). The environments are usually computer-generated 3D worlds or virtual representations of environments in the real world. To visualize the virtual worlds, the user must use special visualization devices. These visualization devices induce the user's sense of presence in the virtual world. The term presence refers to a user's subjective psychological response to a VR system (Bowman and McMahan 2007). The term immersion is interchangeably used. However, the term immersion refers to the objective level of sensory fidelity a VR system provides (Bowman and McMahan 2007). Accordingly, the level of immersion of a VR system depends only on the system's rendering software and display technology. Immersion is objective and measurable. By contrast, presence is an individual and context-dependent user response, related to the experience of "being there". Different users can experience different levels of presence with the same VR system. A user might experience different levels of presence with the same system at different times (Bowman and McMahan 2007). Immersion, defined in technical terms, is capable of producing the sense of presence, the sensation of "being there" (Mestre and Vercher 2011). In an ideal VR system, 
the users would not be able to distinguish whether the environment is real or virtual. The main objective of a VR system is that the user experiences the sensation of being in the VR environment.

One of the aspects that influences this sense of presence is to perceive the virtual environment as a user perceives a real environment, that is, having the depth perception. To have this depth perception, the displays must be stereoscopic. According to Balram (2016), traditional stereoscopic displays can be classified into two main types: with glasses and without glasses. Current large screen consumer 3D systems are based on glasses, which are classified into two types: 1) Passive glasses: wavelength-based, polarization based; 2) Active glasses: electronically controlled liquid crystal shutters.

Other well-known devices are the Head Mounted Displays (HMD), which are devices that are attached to the user's head. These HMDs have two small displays that are a few centimetres from the user's eyes. Two different perspectives are rendered onto the two displays individually. The HMDs usually have optical adjustment lenses to be able to focus the display.

To interact in the most natural way possible in a VR system, the user can use gestures (Natural User Interfaces). Therefore, both the depth perception and the gestural interaction help the user to have a sensation as close as possible to reality.

According to some experts, VR has the potential to become one of the top breakthrough technologies of the next decade (Markets and Markets 2016). The VR market is expected to grow from USD 1.37 billion in 2015 to USD 33.90 billion by 2022, at an annual growth rate of $57.8 \%$ between 2016 and 2022 (Markets and Markets 2016). The conclusions of this report indicate that the major factors driving the VR market are the increasing use of HMDs in the entertainment and gaming sector, declining prices of displays and other hardware components of HMDs, and use of VR for training and simulation in the defense sector. According to the report published by Markets and Markets in November 2017 (Markets and Markets 2017), the augmented and virtual reality in healthcare market was valued at USD 504.5 million in 2016 and is expected to reach USD 4,997.9 million by 2023, at an annual growth rate of $36.6 \%$. Health market in which the developments of this thesis would be included.

Since the creation of the first HMD in 1960 (Heilig 1960) until now, VR has tried to transfer the user to an artificial world. The possibility of transferring the user to a virtual world created specifically for him/her, has allowed 
this technology to be very useful in many fields. For example, in education, to improve the students' training process (Wu et al. 2013; Merchant et al. 2014), in psychology (Foreman 2010), for the treatment of phobias such as arachnophobia (Carlin, Hoffman, and Weghorst 1997), in medicine as well as for rehabilitation of patients with motor problems (Jack et al. 2001; da Silva Cameirão et al. 2011). It has also been useful for the training of doctors, to improve their techniques of surgery (Ahlberg et al. 2007; Gurusamy et al. 2008). VR technology has proven to be useful for improving other fields in which the use of a controlled virtual environment can be an advantage.

VR systems transfer the user inside an artificial environment of our choice. In this way, there are no limits in the creation of the environment or its characteristics. Thanks to this fact, it is possible to create environments adapted to the needs and specifications required for each specific system. For example, a flight simulator can allow the training of pilots or new cadets without the risk of doing it in a real environment (Lam and de Vries 1983), and thus, in addition to improve their safety, the instructors can control a multitude of parameters in real time and in this way to improve the instruction of the pilots (Valverde 1973). Other virtual scenario is a virtual operating theatre, that can be used by surgeons in specific operations for training without endangering the patient's life (Aggarwal and Shishodia 2006).

Within the applications that are developed with VR, there are a set of applications where the objective of the task is well defined and identified by the user. For example, a flight simulator (Hays et al. 1992) aims to evaluate the flight capacity of a pilot in a controlled environment. In this case the pilot knows that the system will evaluate the ability to pilot an airplane. But, in other types of applications, the purpose of the task is not showed to the user, the task tries to be hidden behind a game. These games are called serious games (Michael and Chen 2006). In a serious game the user must complete a task or a goal to finish the game. While the user performs this task, the assessment or training is carried out, but in such a way that the user is not aware of this fact. An example of a serious game could be a game about cave painting in a prehistoric cave. Its main function would be to teach the colours with which these paintings were made and in what type of walls. But, the users only perceived that it is a game about painting.

In some serious games, the objective of the game is hidden in the user's eyes. The goal to complete the game is totally different to the final objective of the task. This is the case, for example, in rehabilitation applications. In these applications, the goal of the user can be to explode balloons or to score goals. This objective motivates the user to perform movements to overcome the 
game. These applications are calibrated so that the movements that users make during the performance are the same they need to carry out for rehabilitation purposes.

One of the most critical cognitive abilities in humans is storing the representation of stimuli that was experienced at some time in the past. Hence, memory can be divided into short-term and long-term memory (Burgess and Hitch 2005). The short-term memory can be defined as the capacity for holding a small amount of information in mind in an active, readily available state for a short period of time. By contrast, in the long term memory, the information to be memorized is relevant to be stored in a stable manner for any future need. Spatial memory has the capacity to store representations of spatial stimuli. Spatial memory allows us to find a place that was visited previously, remember the place where we left our belongings or follow a route after consulting a map (Burgess et al. 2001a).

Traditionally, the evaluation of spatial memory in children has been done through pencil and paper tests. In these tests, the children must answer a series of questions or point objects in an established order (Kessels et al. 2000). One of this test is the Corsi Block Tapping Test (Corsi 1972; Kessels et al. 2000)(Figure 1.1), that consists of blocks positioned on a board. The evaluator points out a series of blocks in a certain order and the child must reproduce the sequence. The child may be asked to repeat the movements in the same order (i.e, forward condition) or in reverse order (i.e., backward condition).

However, VR is an alternative technology for the assessment of spatial memory. The environment and the task can be designed according to the key elements for a specific problem. In this way, the users fell the same sensations that they would experience in an analogous situation in the real world. The virtual environment can be made as specific or wide as needed. In this way, a specific environment can be obtained for children with spatial needs or for a specific age group. In addition, as a computer-based system, storage and tracking capacities can be exploited. It allows to save information regarding the behaviours, the route or the objects that the user has looked during the task. These methods, compared to the traditional ones, facilitate and speed up the subsequent work of analysis and personalized evaluation of the users.

Since the nineties, VR environments have been incorporated to the field of psychology for different purposes. For example, for the treatment of phobias and other psychological disorders. In those treatments, VR has shown to be as or more effective than traditional methods such as exposure in vivo (Rothbaum et al. 2000; Emmelkamp et al. 2001; North, North, and Coble 2002; 


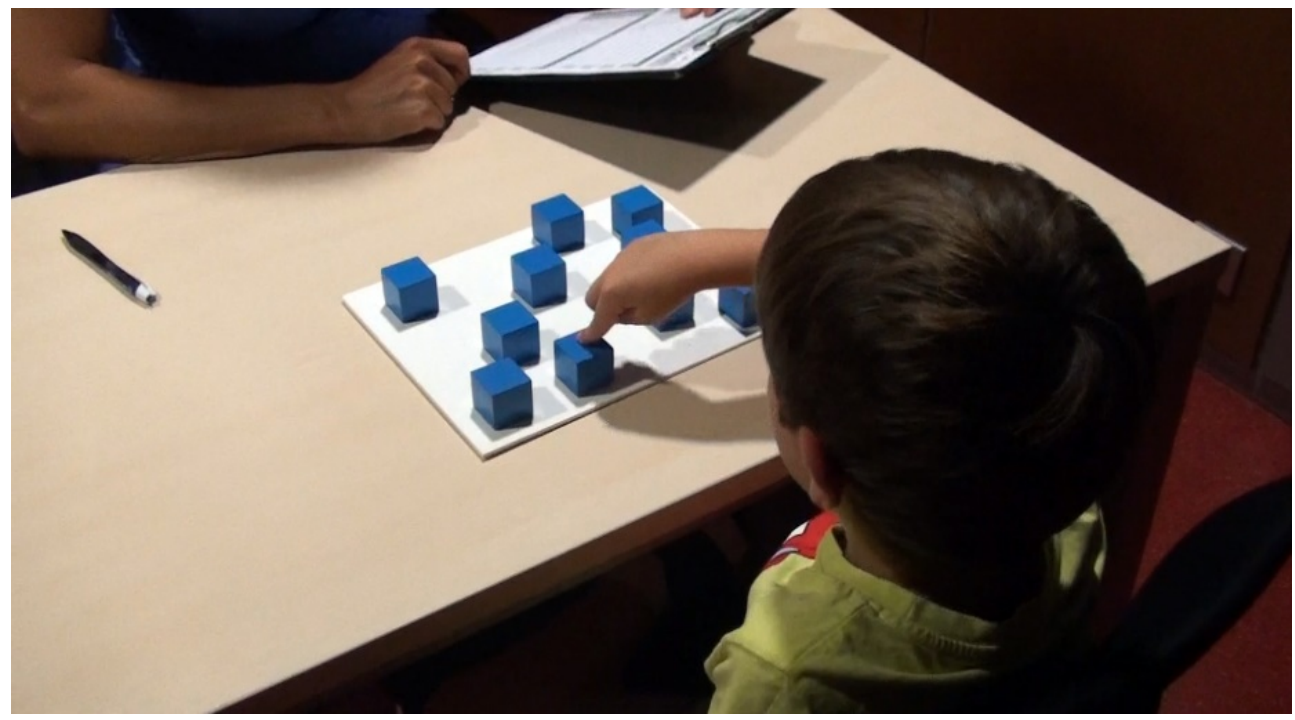

Figure 1.1: A child performing the Corsi Block Tapping Test.

Emmelkamp et al. 2002; Rothbaum et al. 2002; Botella et al. 2004). Later, VR has also been incorporated for the assessment and training of cognitive processes such as spatial memory. In spatial memory tasks, generally, the user goes through the environment and must remember certain objects that are in the virtual world. In a second travel, the user must remember where were the objects. Although previous virtual systems used a basic form of interaction (e.g., a keypad or joystick) that did not induce the required sense of presence to the user (e.g., Picucci, Caffò, and Bosco 2011; Cimadevilla et al. 2014; Walkowiak, Foulsham, and Eardley 2015). This classical type of interaction with the computers is ineffective because the user's sense of presence within the environment is very poor. In spatial memory user's movement is important (Ruddle and Lessels 2006). If the user does not have the feeling of being inside the virtual environment, the spatial memory may not be assessed correctly. Therefore, by creating a system that allows children to become active within a virtual environment, spatial memory can be evaluated as the same way it could be evaluated in a real environment.

This thesis is part of the National Spanish Project "CHILDMNEMOS" (TIN 2012- 37381-C02-01). In CHILDMNEMOS, different VR and AR (Augmented Reality) systems to assess spatial memory were designed, developed and validated. Handheld Augmented Reality was used for developing the ARSM task 
(Juan et al. 2014; Mendez-Lopez, Perez-Hernandez, and Juan 2016). The ARSM task showed virtual objects in a physical location and the children had to remember where they were. In another work, a task that combined Natural User Interfaces and smart devices for assessing spatial memory using auditory stimuli was designed, developed and tested with children and adults (Loachamín-Valencia et al. 2017; Loachamín-Valencia et al. 2018). The Virtual Maze Task was also developed (Cárdenas-Delgado et al. 2017a; CárdenasDelgado et al. 2017b). This VR task incorporated two types of interaction: 1) Inactive condition, with no physical movement in which a gamepad was used (B-Move Gamepad BG Revenge); 2) Active condition, involving physical movement (a real bicycle). For visualization, the task used a VR HMD (Oculus Rift). There are three main differences with the current thesis. 1) The visualization system and the device used for the physical movement were different. 2) The virtual environment was different. In the Virtual Maze Task, the environment was a maze and the spatial cues were proximal to the user. The spatial cues of the studies of this thesis were: proximal and distal. 3) The sample was different. The participants of the studies of this thesis were children and the participants of the studies of the Virtual Maze Task were adults.

As far as we know, there are no specific and adapted instruments that allow to know the development of memory and spatial orientation in children with an immersive VR system and involving physical movement. This thesis aims to investigate the possibilities of these systems for the assessment of spatial memory. Our system will facilitate that the children feel motivated during the performance. Moreover, the system storages information about the participants' performance. These data can be analysed as well as the questionnaires filled out by the participants. The performance with the task is compared with the results obtained using traditional methods.

\section{Scientific goals and research hypotheses}

The main objective of this thesis was the design, development and validation of an immersive Virtual Reality system that includes physical movement for the assessment of short-term spatial memory in children. We compared the system with other classical tests to check if our system correctly evaluates short-term memory. We also studied how several factors affect the assessment of spatial memory. We analysed aspects such as usability, emotional variables, fun, the displacement in the virtual environment, or the general satisfaction. The pos- 
sible relationships between the variables collected during the performance were also analysed.

To achieve this objective, the following activities were carried out:

- A virtual environment was designed based on an open space (city square).

- A MnemoCity Task was designed and implemented using the previous environment. The cognitive task comprised six levels: an interaction adaptation level, a habituation level, and four levels for the main task. The goal of the levels for the main task was to assess children short-term memory for object location in the virtual environment.

- The VR system incorporated two types of interaction. 1) A physical active condition (physically walking on a Wii Balance Board ${ }^{\mathrm{TM}}$ and changing the direction by turning a wireless steering wheel). 2) An inactive condition (stand up and use a gamepad).

- For the visualization of the MnemoCity Task a large stereo screen was integrated in the VR system using Unity and developed libraries.

- The VR system was developed for having real-time interaction and depth perception, and therefore, to induce the highest possible level of presence.

Two different developments were carried out:

- An autostereoscopic display and gesture interaction for learning (Development 1).

- This development was the first contact with Natural User Interfaces and 3D visualization systems. We designed and developed a serious game that combined autostereoscopy and Natural User Interfaces for dental learning. The game included two modes: neutral and real world background. With this first development, the required knowledge for facing the second development, core of the thesis, was acquired.

- MnemoCity Task for assessing spatial memory (Development 2).

- We designed and developed a virtual environment for the assessment of spatial memory involving user's physical movement and depth perception. 
With these two developments, three different studies were carried out:

- Dental Learning in Higher Education (Study 1)

A total of 33 dentistry students participated in the study. There were 18 men and 15 women. They were specializing in two areas: Hygiene and Prosthesis.

The objective of this study was to test the capability of Natural User Interfaces and autostereoscopic displays for dental learning in higher education.

The first of our hypotheses (H1) was that users would increase their knowledge about the teeth morphology thanks to the 3D visualization of the models. Our second hypothesis (H2) was that since the real-world background offers more cues about the environment than the neutral background, there would be a statistically significant improvement in knowledge in favor of the real-world background.

- MnemoCity Task for assessing spatial memory (Study 2)

A total of 160 children ( 5 to 10 years old) participated in the study. There were 91 boys and 69 girls.

The objective of this study was to test the capability of the MnemoCity Task to assess spatial short-term memory in children involving physical movement and depth perception. The participants' performance on the MnemoCity Task and traditional neuropsychological tests were evaluated and compared.

The third hypothesis (H3) was that there would be statistically significant differences for the score obtained in the MnemoCity task using natural interaction when compared with standard interaction. The fourth hypothesis (H4) was that there would be no statistically significant difference for the performance of the task between genders. The fifth hypothesis (H5) was that the MnemoCity task could evaluate short-term spatial memory in children like traditional tests applied in psychology.

- MnemoCity Task. Gender and videogame experience influence navigation; Age impacts memory and completion time (Study 3)

A total of 52 typically-developing children aged 5-12 years participated in the study. 
The objective of this study was to analyze participants' age, gender, and previous videogame experience as potential variables that could influence success on the task and the way of exploring the virtual environment. We also examined relationships among the variables in performance on the task and visuospatial, emotional, and behavioral outcomes.

The sixth hypothesis (H6) was that age would affect performance in the MnemoCity Task. The seventh hypothesis (H7) was that a higher ability for recalling objects in the MnemoCity Task would be linked with higher visuospatial skills on small-scale tests. The eighth hypothesis (H8) was that the displacements made across the interaction area of the MnemoCity Task during performance of the task would be related to emotional and behavioral outcomes.

\section{Thesis structure}

The thesis document is structured as follows:

Part 1 introduces the thesis and includes the thesis motivation, the scientific goals, the research hypotheses, the developments and studies carried out and this explanation of the thesis structure.

Part 2 contains a selection of the most representative papers supporting this thesis which were published in journals indexed in JCR and conferences indexed in CORE 2017. Specifically, it includes three papers.

- Paper 1. A 3D Serious Game for Dental Learning in Higher Education. It describes the first development and study of the thesis for dental learning.

- Paper 2. MnemoCity Task: assessment of children's spatial memory using stereoscopy and virtual environments. It describes the second development (MnemoCity Task) and the second study of the thesis for assessing spatial memory. The performance in the task and traditional methods were compared.

- Paper 3. A Virtual Object-Location Task for Children: Gender and Videogame Experience Influence Navigation; Age Impacts Memory and Completion Time. It describes the third study (a second study with MnemoCity Task) of the thesis for assessing spatial memory. The performance in the task and traditional methods were compared. Also, in- 
dividual and emotional factors were related to the performance in the task.

Part 3 discusses the results of the thesis, summarizes the work with the general conclusions and future works, and enumerates the publications derived from this thesis. 
Part II

Selected papers 



\title{
Chapter 2
}

\section{A 3D Serious Game for Dental Learning in Higher Education}

Rodríguez-Andrés, D.; Juan, M.C.; Mollá R.; Méndez López, M. (2017). A 3D Serious Game for Dental Learning in Higher Education. The 17th IEEE International Conference on Advanced Learning Technologies (ICALT2017), pp. 111-115. DOI: 10.1109/ICALT.2017.29, CORE B

\begin{abstract}
Natural User Interfaces and advanced displays can be combined to provide rich learning experiences. In this paper, we present the development and validation of a serious game that combines autostereoscopy and Natural User Interfaces for dental learning in higher education. The game includes two modes: neutral and real-world background. A comparative study to check different aspects was carried out. A total of 33 dentistry students participated in the study. From the results, the students increased significantly their knowledge about teeth morphology. Most of the students preferred the neutral background for dental learning. The real-world background was identified as being more suitable for leisure activities.
\end{abstract}




\section{Introduction}

The rapid development of new technologies has provided many new systems that were unimaginable just a few years ago. Natural User Interfaces (NUI) have become more and more common. They facilitate our interaction with systems without having to use extra devices; we can use some parts of our body to communicate with the systems. Another technology to consider is autostereoscopy, which is a method for displaying stereoscopic images without the use of special glasses on the part of the viewer.

Dentistry students do not usually have any 3D virtual model to help them learn about teeth morphology. They usually have real models made of plaster or 3D models drawn on paper. From our point of view, a 3D virtual model could help in this learning process. If the virtual model was also presented in 3D with autostereoscopy, the 3D visualization could further improve the learning process. If the interaction is as natural as possible (for example, using NUI), the learning process could also be more natural and intuitive. The users of this type of visualization do not need to wear or manipulate any physical device to interact with the system. The virtual elements are perceived in 3D as real elements and the manipulation is performed with gestures. Following this idea, we have developed a dental learning game that includes NUI and autostereoscopy. To validate the game, we measured the influence of the self-representation and the NUI. We compared the real-world background (the users can see themselves as in a mirror) with a neutral background. Our first hypothesis was that users would increase their knowledge about the teeth morphology thanks to the 3D visualization of the models. Our second hypothesis was that since the real-world background offers more cues about the environment than the neutral background, there would be a statistically significant improvement in knowledge in favor of the real-world background.

\section{Background}

NUI allow users to be the controller of themselves by detecting the position of the different parts of their body. According to Fishkin (2004), NUIs facilitate the acceptance of an application by users. Roman (2010) pointed out "The mouse's days are numbered", the current trend in new devices, games, and consoles is to get rid of all gamepads, joysticks, and other input methods.

NUI are being incorporated in different types of applications, for example, learning (Chang, Chen, and Chuang 2011a), assessment of short-term memory 


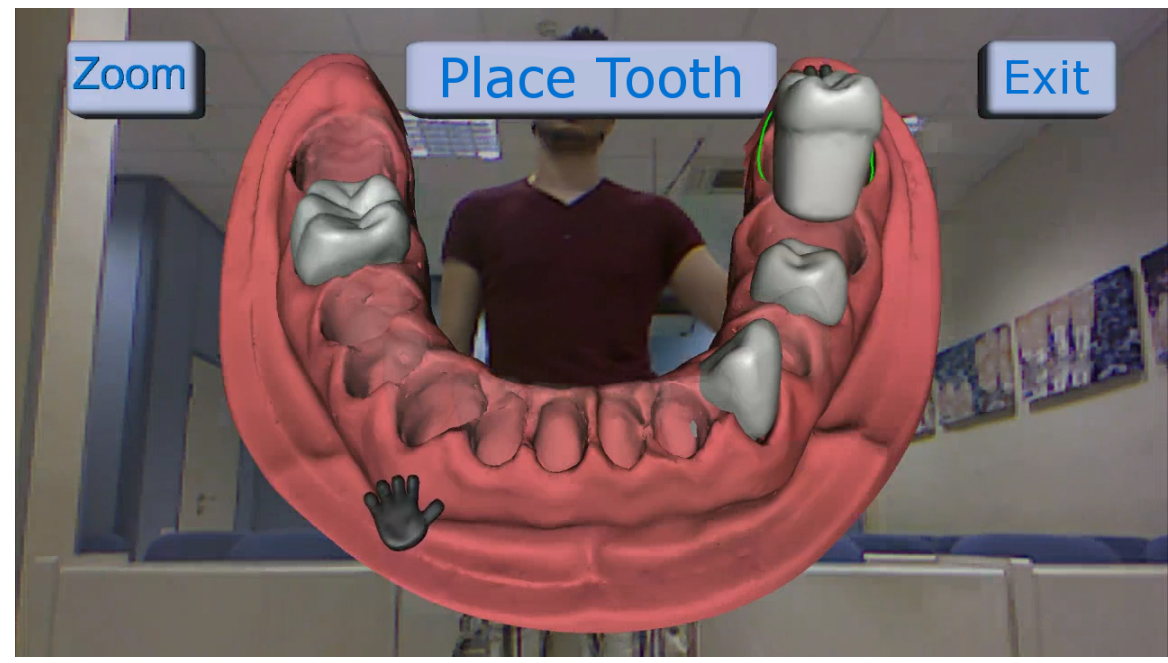

Figure 2.1: Screen view of the real-background mode.

(Rodríguez-Andrés et al. 2016); training individuals with cognitive impairments (Chang, Chen, and Chuang 2011b); or transforming a paper based process to a NUI process in a chronic care hospital (Anacleto, Fels, and Silvestre 2012).

Since the publication of the first papers about stereoscopy in the 1990s (Halle 1997), several works have been presented related with this technology. For example, a virtual reality immersive experience utilizing 35" LCD 3D displays that used the parallax barrier technique (Sandin et al. 2005). An application with Kinect ${ }^{\mathrm{TM}}$ Fusion that captured a 3D image of a realworld scene which was reproduced in an autostereoscopic display (Maimone et al. 2012). Kim et al. (2012) used autostereoscopy combined with NUI making an autostereoscopic display for multi-user collaboration. Kim et al.'s study proposed an autostereoscopic platform for sharing visual data with two or more users, which uses two displays. Studies have also been carried out to compare augmented and virtual reality using autostereoscopic displays (Arino et al. 2014).

Several dental learning systems have been presented. However, most of them are pretty basic; some of them use web technologies (Meckfessel et al. 2011), or multimedia material. Grigg and Stephens (1998) studied the possibility to learn dentistry using computers. They evaluated the knowledge of their time in an objective manner to make some predictions such as that computer-asisted learning would have an impact not only on how dentists would be trained, but 


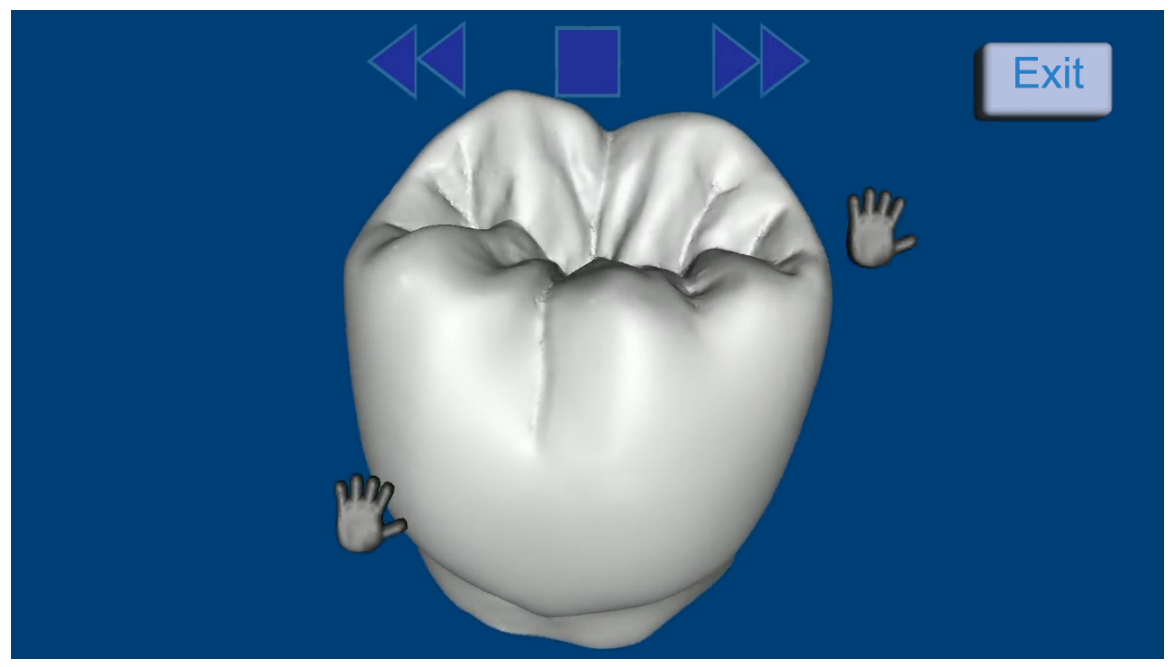

Figure 2.2: Zoom of a tooth.

also on the skills they would need to acquire in the future in order to keep up with new technologies. Computer-aided dental learning programs are either more effective than or equally effective as other methods of education (Walmsley 2003). The benefits of computer-assisted learning can be seen for example in self-paced and selfdirected learning and increased motivation (Welk et al. 2006). The effectiveness of computer-aided programs in dental education have also been analyzed (Rosenberg, Grad, and Matear 2003). Those authors concluded that computer-assisted learning can provide innovative and interactive ways of presenting material, and, therefore, should be used with conventional teaching or as a mean of self-instruction that can elicit a positive response from students and can motivate them. Following these recommendations and unlike previous works, we propose to combine stereoscopy and NUIs for dental learning.

\section{Developments}

Our game combines autostereoscopy and natural interaction. We use a Microsoft Kinect $^{\mathrm{TM}}$ device to capture the image of the real world and to track the user. We use an autostereoscopic display for the 3D perception. The user does not need to wear any extra devices to interact with the game. The virtual elements are objects with 3D perception. Students are able to interact with 
the game using gestures. The 3D display is on a table near a wall in front of the user. The Microsoft Kinect ${ }^{\mathrm{TM}}$ is placed on the table a few centimeters in front of the display and centered relative to the 3D display. The users should stand in front of the display two meters away. We developed two different versions of the game. The functionality is the same for the two versions. The only difference is the visualization of the background. In one version (the realworld background), the real world captured by the Kinect ${ }^{\mathrm{TM}}$ camera is shown as the background (Figure 2.1). Therefore, the users see the real world and they can also see themselves as in a mirror. In the second version (the neutral background), the background is a neutral blue color.

The main goal of the user in the two versions is to place each tooth in its correct position. In our game, seven teeth of the lower jaw have been included. Looking closely at the 3D models from all angles, the students can observe minimal details that help them to identify each tooth in order to place it in the right position. The game is divided into two principal stages (1. Learning stage and 2. Placement stage).

In the Learning stage, the user sees all of the 3D models for the teeth. The game shows and reproduces the scientific name of each tooth. The principal goal at this stage is for the users to observe each tooth and to learn about its morphology. The teeth are presented one after another. When all the teeth have been shown, the game changes to the next stage.

In the Placement stage, the game shows the lower jaw in the center of the screen with fourteen holes, one hole for each tooth. Three buttons appear in the upper area of the screen. When one of these buttons is selected, the related action will be carried out. Figure 2.1 shows a screenshot of this stage. The three buttons are:

- Zoom Button. When this button is selected, the game shows a detailed view of the tooth that the user is handling. The tooth is ten times bigger than the tooth visualized in the placement view. With this detailed view, the user can better appreciate the morphology of the tooth and know its correct placement in the jaw. Figure 2.2 shows an example. The options that appear in the center of this view work as follows: (a) $\mathbf{T}$ The tooth rotates counter-clockwise. (b) The tooth rotates clockwise. (c) This button stops the rotation of the tooth. The "Exit button" allows the user to go back to the previous view. The selection of these buttons is similar to the previous ones. The users only have to put their hand over the button to select them. 
- Place tooth button. This button allows a selected tooth to be placed in one of the fourteen holes. To achieve this, the user has to put the hand that holds the tooth over the hole of its correct position and with the other hand select the Place tooth button.

- The Exit button allows the user to exit the game.

\section{Study}

A total of 33 students from a School of Dentistry participated in our study. There were 18 men $(52.34 \%)$ and 15 women (47.66\%). They were specializing in two areas: Hygiene and Prosthesis. They were divided into two groups. Each group had participants from both specialties who were assigned to one of the following two groups:

- Group A: Participants that played with the real-world background configuration first, and afterwards played with the neutral background configuration. There were 17 participants $(9$ from Hygiene and 8 from Prosthesis).

- Group B: Participants that played with the neutral background configuration first, and afterwards played with the real-world background configuration. There were 16 participants ( 8 from Hygiene and 8 from Prosthesis).

To collect the data, we designed three different questionnaires. The Q1 (the knowledge questionnaire) to measure knowledge about teeth morphology. In this questionnaire, the students have to connect each tooth with its correct position using arrows in a paper with the images of the teeth and the jaw. The Q1 questionnaire evaluates the knowledge about teeth morphology. The Q2 questionnaire (Table 2.1) includes questions related to usability, experienced fun, depth perception, and perceived learning. The Q2 and Q3 questionnaires were based on the questionnaire used by Martín-SanJosé et al. (2014).The final questionnaire, Q3 (Table 2.1), which were designed to compare the two modes includes some questions about the users' preferences. In addition, the game stores information about the time users require to complete the game and the errors they have committed. The entire activity (Q1, Q2 and Q3 questionnaires and the two game modes) lasted around 30 minutes. The following protocol was used:

- The two groups filled out the Q1 questionnaire. 
- Group A played with the neutral-background version and group B played with the real-world background version.

- The two groups filled out the Q1 and Q2 questionnaires. The Q1 (knowledge questionnaire) is only filled out once after playing with the first version. In other words, the analysis about knowledge outcomes is an inter-subjects analysis (Group A vs. Group B).

- Each group played the game with the mode that they had not previously played.

- The two groups filled out the Q2 and Q3 questionnaires.

\section{Results}

\section{Knowledge outcomes}

To measure the initial or acquired knowledge, we used the Q1 questionnaire. The knowledge score ranges from zero to seven hundred. These scores were established by an expert professor of the School of Dentistry. The knowledge variable was created to condense the correct placement of the seven teeth. Several t-tests were performed to determine if there were statistically significant differences in the acquired knowledge. All tests are shown in the format: (statistic [degrees of freedom], $p$-value, Cohen's $d$ ); and the "**" character indicates statistical significance at level $\alpha=0.05$. First, we checked whether there were statistically significant differences for the initial knowledge of the students in the two groups. The initial scores of knowledge for Group A (mean $420.62 \pm 134.65)$ and for Group B (mean $380.88 \pm 168.8)$ showed that there was no statistically significant difference $(t[31]=-0.72, p=0.476, d=0.25)$. This result implies that there is no statistically significant difference between the two groups for the initial knowledge. For Group A, a paired t-test revealed that there was a statistically significant difference for the acquired knowledge (initial: $420.62 \pm 134.65$ ), (after playing: $526.26 \pm 84.07),(t[15]=-2.80$, $\left.p=0.014^{* *}, d=0.70\right)$. For Group B, a paired t-test revealed that there was also a statistically significant difference for the acquired knowledge, (initial: $380.88 \pm 168.8$ ), (after playing: $550.00 \pm 103.26),\left(t[16]=-4.21, p<0.001^{* *}\right.$, $d=1.02$ ). These results indicate that the students improved their knowledge about teeth morphology with the two modes. We also checked if there were statistically significant differences in acquired knowledge between the two groups, Group A $(526.26 \pm 84.07)$, Group B $(550.00 \pm 103.26),(t[31]=-0.69$, 
$p=0.495, d=-0.24)$. The t-test indicates that no statistically significant difference was found with regard to the acquired knowledge using the two modes.

Table 2.1: Q2 and Q3 questionaries. The Q2 questionnaire includes Q1-Q11 questions. The Q3 questionnaire includes Q12-Q20 questions.

\begin{tabular}{cl}
\hline \hline \# & Questions \\
\hline Q01 & How much fun did you have? \\
Q02 & How many of your classmates would you recommend this game to? \\
Q03 & What was the difficulty of the game? \\
Q04 & Did you understand the game rules? \\
Q05 & Was selecting the answers easy? \\
Q06 & How much did you like the images of the game? \\
Q07 & How much did you learn during the game? \\
Q08 & How often did you feel that the 3D models of the game looked like \\
& plaster models? \\
Q09 & Rate the sensation of viewing the teeth. Did they look like coming \\
& out of the screen? \\
Q10 & Did you have the feeling that you can touch the teeth? \\
Q11 & Rate the experience from 1 to 10. \\
\hline Q12 & Which game did you like the most? \\
Q13 & Which game is better for dental learning? \\
Q14 & Which game was easier to interact with? \\
Q15 & Which game was more comfortable? \\
Q16 & Which game did you have more control of? \\
Q17 & In which game did the images look better in? \\
Q18 & Which game was easier to interact with? \\
Q19 & Which game was more fun? \\
Q20 & Which game do you want your teacher to use in class? \\
\hline \hline
\end{tabular}

\section{Usability, Depth Perception, and Satisfaction Outcomes}

Several non-parametric tests were performed for the Likert questions (the Mann-Whitney U test for unpaired questions and the Wilcoxon Signed-rank sum test for paired questions) to determine if there were statistically significant differences in the opinions of the students depending on the game mode played. We applied tests to: 
- The answers to the Q2 questionnaire of the students that played the realworld version first versus the students that played the neutral version first.

- The answers to the Q2 questionnaire versus the answers to the Q2 questionnaire of the students that played the real-world version first.

- The answers to the Q2 questionnaire versus the answers to the answers to the Q2 questionnaire of the students that played the neutral version first.

- The answers to the Q3 questionnaire of the students that played the realworld version first versus the students that played the neutral version first.

No statistically significant differences were found in any of these tests. As an example, we only present the Mann-Whitney $U$ test for the first mentioned analysis, Q2 for GA vs. GB (Table 2.2).

With regard to the 3D sensation (Q08-Q10), the students thought that the models looked like real plaster models (Q08: $4.48 \pm 1.58$ over 7). The sensation that the teeth come out of the screen was considerable (Q09: $5.09 \pm 1.14$ over 7).

Finally, the last question asked was about rating the experience from 1 to 10. The students liked the game experience (Q11: $8.03 \pm 1.31$ over 10). Four professors also tested the game; they liked the game and they argued about the great possibilities of including this game in their classes. The professors expressed their satisfaction with the game and scored it with $8.20 \pm 1.79$. Most of them preferred the neutral-background version (75\%).

\section{Preferences about the Game Background}

To measure the students' preferences about the two modes, several chi-squared $\left(\chi^{2}\right)$ tests were performed. These tests show whether a group has a preference for the game mode. Table 2.3 shows the modes of questions and the result of the analysis. The $\chi^{2}$ test revealed that there was no statistically significant difference between the two different backgrounds. However, if percentages are considered, the following was observed. When asked about the best option for dental learning (Q213), 68\% preferred the neutral background; 63\% considered the neutral background to be easier to manipulate (Q214); 58\% considered the neutral background to be more comfortable (Q215); 64\% considered that the 
Table 2.2: Mann-Whitney $U$ tests about the $3 \mathrm{D}$ perception, usability and satisfaction. GA is Group A (plays the real-background first), and GB is Group B (plays the neutral background first). Means and standards deviation of the questions have also been included.

\begin{tabular}{cccrrcc}
\hline \hline \# & Mean GA & Mean GB & $U$ & $Z$ & $p$-value & $r$ \\
\hline Q01 & $4.12 \pm 0.68$ & $4.00 \pm 0.71$ & 148.0 & 0.47 & 0.773 & 0.082 \\
Q02 & $4.41 \pm 0.60$ & $4.69 \pm 0.58$ & 100.5 & -1.49 & 0.151 & 0.259 \\
Q03 & $3.71 \pm 0.75$ & $3.56 \pm 0.70$ & 150.5 & 0.57 & 0.596 & 0.100 \\
Q04 & $3.00 \pm 0.00$ & $2.94 \pm 0.24$ & 144.5 & 1.03 & 0.485 & 0.179 \\
Q05 & $3.24 \pm 0.81$ & $3.44 \pm 0.86$ & 121.5 & -0.58 & 0.574 & 0.101 \\
Q06 & $3.88 \pm 0.58$ & $4.00 \pm 0.50$ & 122.0 & -0.62 & 0.661 & 0.109 \\
Q07 & $3.71 \pm 0.67$ & $3.38 \pm 0.70$ & 163.0 & 1.07 & 0.287 & 0.186 \\
Q08 & $4.12 \pm 0.68$ & $4.00 \pm 0.71$ & 148.0 & 0.47 & 0.773 & 0.082 \\
Q09 & $4.41 \pm 0.60$ & $4.69 \pm 0.58$ & 100.5 & -1.49 & 0.151 & 0.259 \\
Q10 & $3.71 \pm 0.75$ & $3.56 \pm 0.70$ & 150.5 & 0.57 & 0.596 & 0.100 \\
Q11 & $3.00 \pm 0.00$ & $2.94 \pm 0.24$ & 144.5 & 1.03 & 0.485 & 0.179 \\
\hline \hline
\end{tabular}

images/models looked better in the neutral background (Q17). With regard to their recommendation for using the two versions at school (Q20), their preferences were the following: $55 \%$ selected the neutral background, $24 \%$ selected both, $14 \%$ selected the real-world background, and $7 \%$ selected neither of them. A total of $53 \%$ of the participants liked the real-world background the most (Q12). For the most fun mode (Q19), 43\% selected the real-world background, $37 \%$ selected both, and $20 \%$ selected the neutral background. From these percentages and the results of the $\chi^{2}$ test, we can deduce that although there were no statistically significant differences between the two modes, the dental students expressed their preference for the neutral background.

\section{Discussion}

The first of our hypotheses was that the students would increase their knowledge about teeth morphology. We compared their initial knowledge and their knowledge after playing. We found statistically significant differences that corroborate the first hypothesis $(p<0.05)$. Therefore, our results indicate that our game improves students' learning performance. This result is in line with previous conclusions that have argued for the great potential of educational computer games in helping students to improve their learning performance (Hwang and $\mathrm{Wu}$ 2012). However, the second hypothesis (the real-world back- 
Table 2.3: Chi-squared test for Q3 questions.

\begin{tabular}{cllccccc}
\hline \hline$\#$ & Mode GA & Mode GB & $\chi^{2}$ & $d f$ & $N$ & $p$ & Cramer's $^{\prime}$ \\
\hline Q12 & Neutral & Real-world & 1.087 & 1 & 32 & 0.297 & 0.184 \\
Q13 & Neutral & Neutral & 0.068 & 1 & 31 & 0.795 & 0.047 \\
Q14 & Neutral & Real-world & 1.807 & 1 & 27 & 0.179 & 0.259 \\
Q15 & Neutral & Real-world & 1.284 & 1 & 26 & 0.257 & 0.222 \\
Q16 & Neutral & Real-world & 1.200 & 1 & 32 & 0.273 & 0.194 \\
Q17 & Neutral & Neutral & 0.778 & 1 & 28 & 0.678 & 0.167 \\
Q18 & Neutral & Neutral & 0.268 & 3 & 30 & 0.875 & 0.094 \\
Q19 & Neutral & Real-world & 5.298 & 3 & 30 & 0.071 & 0.420 \\
Q20 & Neutral & Neutral & 1.503 & 3 & 29 & 0.682 & 0.228 \\
\hline \hline
\end{tabular}

ground will obtain better learning results) was not corroborated. Although unexpected, it is an excellent result because it means that the game is well suited for learning outcomes and that the two backgrounds can be used for this purpose.

For preferences regarding the background mode, even though there were no statically significant differences between the two modes the percentages and the results of the $\chi^{2}$ test indicated that, the dental students preferred the neutral background for learning activities (Table 2.3). For Q13 ("Which game is better for dental learning?"), the preferred option of the two groups was the neutral background. The same occurred for Q18 ("Which of the games would you recommend to your classmates?") and Q20 ("Which game do you want your teacher to use in class?"). Two of the students' arguments that support this preference are: "The real world in the game distracted me" and "With the neutral background, I could focus on the morphology of the teeth".

For the experienced fun, the students had fun playing the game (means of 4 on a scale from 1 to 5 ). Even though there were no statistically significant differences between the two backgrounds, the students assigned higher means to the real-world background. In related questions shown in Table 2.3, the preferred background mode for Group B was the real-world background (Q19 and Q12). These data, the opinion of the professors, and the comments of the students indicate that the real-world background was identified as being more suitable for leisure activities. One of the students' comments that support this argument is: "You can see yourself inside the TV and it is entertaining". 
For depth perception, the results showed that the 3D sensation (Q09) was greatly perceived and appreciated. This result is in line with a similar question answered by children in the study of Arino et al. (2014). Our results also revealed that autostereoscopy gave the students the feeling of being able to touch the 3D elements (Q10). These results are encouraging and can be exploited for the development of educational systems.

With regard to the time spent placing each tooth in its correct position, the students spent more time on some teeth whose morphology was difficult to distinguish. The opinion of the professors who participated in the study was that the game facilitates the correct identification of these teeth and that this identification is much more difficult to do using traditional methodologies. However, this aspect was not analyzed in our study.

Although the results are encouraging, the use of this technology in the classroom presents several drawbacks. First, there is the cost of the autostereoscopic display, which is more expensive than normal displays. However, cheaper 3D technologies could be used. Second, the use of Kinect ${ }^{\mathrm{TM}}$ for the interaction limits the number of students that can be behind the student who is using the game.

\section{Conclusions}

In this paper, autostereoscopy and Natural User Interfaces were used to develop a serious game with two background modes for dentistry students. The two different modes were developed for an educational game based on teeth morphology. The game allows the users to have a complete experience without having to carry devices or wires on their bodies. To our knowledge, this is the first time that a game of these characteristics has been presented for learning dentistry. Based on our study, we believe that using natural gesture interaction and having stereoscopic vision without wearing devices or wires provides an enhanced and richer user experience that is metaphorically similar to the real-world experience. In this situation, the selection of elements is done by using your hands and interacting directly without other devices. Moreover, according to our results, the neutral background is especially suitable for learning activities and the real-world background has been identified as being more suitable for leisure activities. With regard to future work, we have compared two modes, but other comparisons are also possible; for example, using a control group in which the students learn teeth morphology using traditional learn- 
ing method. Another possible comparison could consider autostereoscopic vs. non-autostereoscopic visualizations.

\section{Acknowledgments}

This work received financial support from the Conselleria d'Educació, Investigació, Cultura i Esport through the grant for consolidable research groups (2017-2018).

We would like to thank the following for their contributions:

- The School of Dentistry C.F. Folguera-Vicent (Alboraya, Spain).

- Fernando Folguera, Agustín Herrero, Sandra Albinyana, and Juan-Fernando Martín- SanJosé for their help.

- The undergraduate students, the Master's students and the employees of C.F. Folguera-Vicent who participated in the study.

- The reviewers for their valuable comments. 

Chapter 3

\title{
MnemoCity Task: Assessment of children's spatial memory using stereoscopy and virtual environments
}

Rodríguez-Andrés, D.; Juan, M.C.; Méndez-López, M.; PérezHernández, E.; Lluch, J. (2016). MnemoCity Task: Assessment of children's spatial memory using stereoscopy and virtual environments. PLOS ONE, 11(8): e0161858. DOI: 10.1371/journal.pone.0161858, Impact Factor: 2.806 in the year of publication (Q1)

\begin{abstract}
This paper presents the MnemoCity task, which is a 3D application that introduces the user into a totally 3D virtual environment to evaluate spatial short-term memory. A study has been carried out to validate the MnemoCity task for the assessment of spatial short-term memory in children, by comparing the children's performance in the developed task with current approaches. A total of 160 children participated in the study. The task incorporates two types of interaction: one based on standard interaction and another one based
\end{abstract}


on natural interaction involving physical movement by the user. There were no statistically significant differences in the results of the task using the two types of interaction. Furthermore, statistically significant differences were not found in relation to gender. The correlations between scores were obtained using the MnemoCity task and a traditional procedure for assessing spatial short-term memory. Those results revealed that the type of interaction used did not affect the performance of children in the MnemoCity task.

\section{Introduction}

One of the most critical cognitive abilities in humans is storing the representation of stimuli that were experienced at a certain time in the past. Hence, memory can be divided into short-term and long-term, depending on whether the memory formed has a limited time period or a longer and stable one (Burgess and Hitch 2005). Spatial memory generally refers to the ability to store representations of spatial stimuli. This type of memory allows us to find a place that was visited previously, follow a route after consulting a map or remember the place where we left our belongings, among other examples (Burgess et al. 2001b).

The use of computer-based technologies has increased in a variety of fields and may provide an advantage over traditional methods. This has already been demonstrated in fields like psychology or education (Martín-SanJosé et al. 2017; Juan and Calatrava 2011; Juan et al. 2006; Juan et al. 2014; Juan et al. 2005). In our work, the advances in these computer-based technologies have been used to develop an application to evaluate spatial short-term memory. Our application introduces the user into a virtual environment. The stereoscopy technology gives the user a greater sense of immersion. Our application was created in the field of psychological assessment, which is focused on testing a human cognitive ability, spatial short-term memory, from an ecological assessment perspective.

The use of virtual reality to assess spatial memory in humans has shown positive results (Koenig et al. 2011; Maguire, Nannery, and Spiers 2006; Cánovas et al. 2008; Cimadevilla et al. 2014). There are systems created for evaluating spatial memory in humans. Most of them are based on tasks that have been previously used in animal research (Cánovas et al. 2008; Cimadevilla et al. 2014; Cimadevilla et al. 2011). These systems introduce the user into a virtual environment, where the user can move and interact with the systems. However, the systems developed for humans used to include classical interac- 
tions (e.g., a computer screen, a mouse, or a keyboard). These systems were designed to assess spatial memory in adults. Our application was especially designed to assess spatial memory in children. Hence, the duration of the task, the type of stimuli, and the reinforcements used take this population into account. In addition, the human-computer interface of our system consists of a 120" stereoscopic screen and a Natural User Interface (NUI) to facilitate the children's interaction with the system, and to improve the immersion in the virtual environment. The objective of this application is to remember the spatial locations where objects have been previously presented.

To demonstrate the relation between the performance in this novel task and the performance on other classical pencil-paper tests which are commonly used to test spatial short-term memory, the children performed classical tests to assess spatial short-term memory. Therefore, correlations between the results on classical pencil-paper tests and the results of the application can be verified.

The main hypothesis is that there would be statistically significant differences for the score obtained in the MnemoCity task using natural interaction when compared with standard interaction. There are two sub-hypotheses derived from the main hypothesis. The first sub-hypothesis is that there would be no statistically significant difference for the performance of the task between genders. The second sub-hypothesis is that the preference of the user would be the natural user interface. The secondary hypothesis of this work is that the MnemoCity task can evaluate short-term spatial memory in children like the pencil-paper tests applied in psychology.

Section 3.3 introduces the state of the art for virtual environments and shortterm memory evaluation. Section 3.4 describes the development of the system. Section 3.5 explains the procedure for testing. Section 3.6 presents the results and Section 3.7 presents the discussion. Section 3.8 presents our conclusions.

\section{Background}

This section introduces virtual environments, Natural User Interfaces, and stereoscopy. We also describe how computer-based technologies have been previously used for the assessment of short-term memory. 


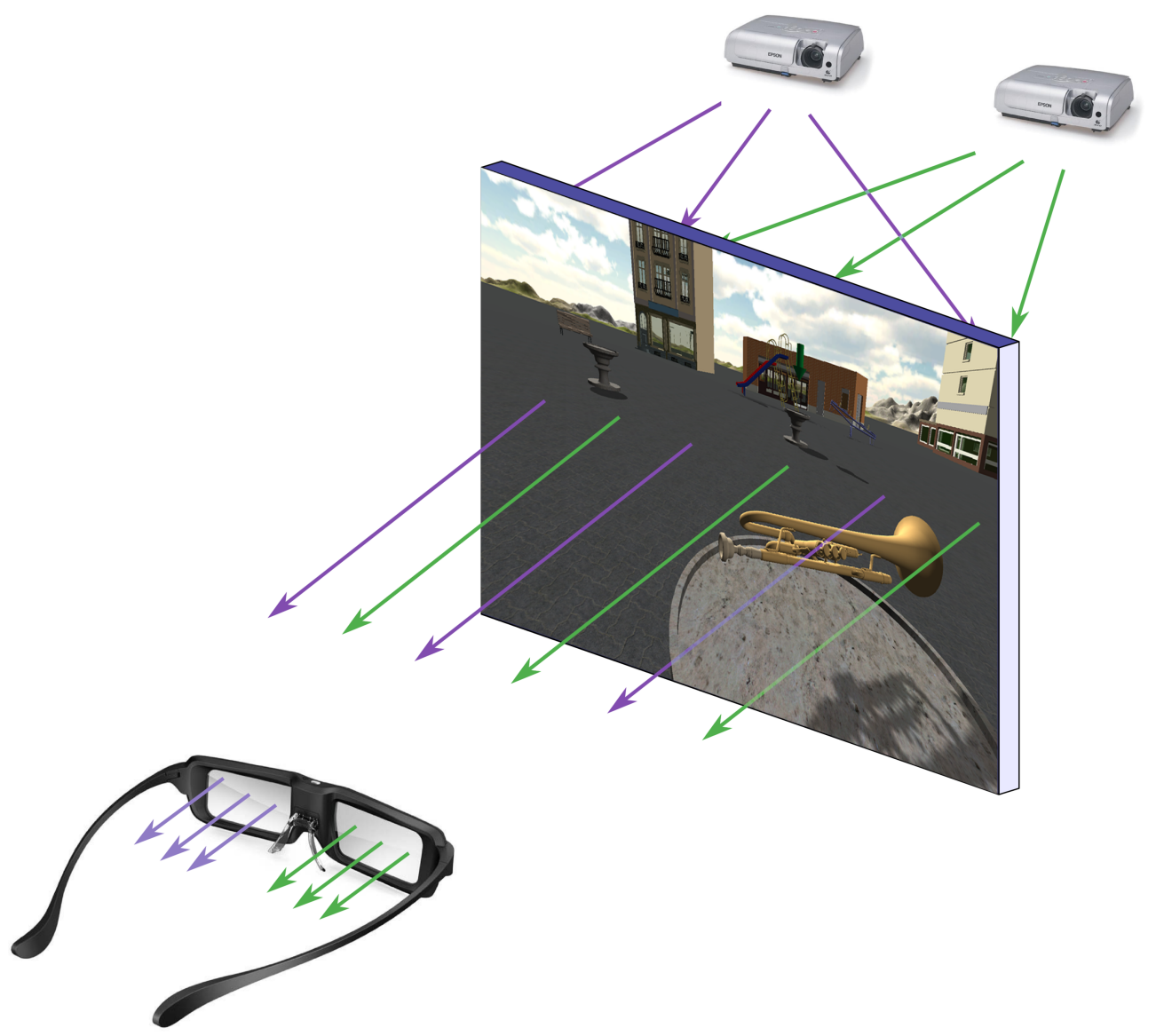

Figure 3.1: Stereoscopy scheme: The two projectors send polarized images to the screen. The filters placed in the glasses allow each eye to get the correct image. 


\section{Virtual environments}

New developments in virtual reality allow new applications for humans to be created. A virtual environment simulates physical presence in places in the real world or in imagined worlds and lets the user interact in that world. Virtual reality artificially creates sensory experiences, which can include sight, hearing, touch, smell, and taste. The benefits of using virtual environments (VEs) in psychology arise from the fact that movements in virtual space and accompanying perceptual changes are treated by the brain in much the same way as those in an equivalent real space (Foreman 2010).

VEs could be a great tool for specific areas like psychology (Loomis, Blascovich, and Beall 1999). In this area, the VEs are used to help with specific problems. For example, Holden (2005) did a survey of the virtual environment for motor rehabilitation. The benefits of VEs for children with disabilities were studied in Stanton, Foreman, and Wilson (1997) and McComas, Pivik, and Laflamme (1998). Hamilton, Driscoll, and Sutherland (2002) adapted a virtual adaptation of a behavioral paradigm for the study of spatial memory in rodents to be used for humans. The virtual scene was a circular pool inside a room with four walls. The user had to swing and observe different objects that appear on the walls (cues). Another virtual environment was developed by Moffat, Hampson, and Hatzipantelis (1998). In their study, the males were better than the females at using their egocentric orientation skill in terms of accuracy and speed. Cánovas et al. (2008) developed an application to study the effectiveness of a new virtual task to evaluate spatial learning in adults. The system was called the Boxes Room and the design of the task was based on the hole-board. This is a task that is well known in animal research in which the holes to be remembered by the rodent are rewarded with a pellet (Oades and Isaacson 1978; van der Staay, Nies, and Raaijmakers 1990). When translated into a virtual reality environment, the boxes that were used had to be opened to discover a possible reward inside. Cánovas, Fernández-García, and Cimadevilla (2011) also carried out a study to examine the influence of the number of cues and their location in adult spatial learning for the same task. The study by Koenig et al. (2011) proposes a spatial memory task with high ecological validity that can be integrated into any virtual environment. Environments and target objects can be individually designed for each user in order to provide a relevant context and high motivation for patients with cognitive deficits. Sturz and Bodily (2010) developed an application to evaluate spatial memory in adults using the valve engine. The results of their study provide empirical evidence for the encoding of variability of landmark-based spatial information and have implications for theoretical accounts of spatial learning. 
Almost all applications that are developed for the assessment of spatial memory are based on squared virtual environments; however, there are other works that have opted for environments with a different geometric shape. For example, Cimadevilla et al. (2011) chose a circular environment. With this circular wall, the users could not use the four walls of a squared environment to help their orientation.

In addition to these studies which focus on adult performance, there are other studies that use virtual environments to assess spatial memory in children. For example, Hamilton et al. (2003) used a virtual task called the Virtual Morris Water Maze with children. They demonstrated that children with Fetal Alcohol Syndrome have difficulties in spatial short-term memory. Even though all of these works demonstrate the possibility of using the VE to evaluate memory, these virtual environments have not been specifically designed for children, and the interaction with the system is not adapted to them. In addition, these environments are not natural for children and can contain elements that confuse them. For this reason, we have created an environment with familiar objects that children see in their houses.

In summary, the use of a virtual environment offers the possibility of introducing the user into a virtual world which allows the simulated situation of individuals to be assessed in their daily life.

\section{Natural User Interfaces}

NUI are defined as interfaces in which a person interacts with the system with his/her body (hands, legs or any other parts of the body). Another characteristic of the NUI is that the learning process is fast, and the user can move from novice to expert in a quick transition. These user interfaces have previously been used in studies to create an interface that is adapted to children obtaining good results (Martín-SanJosé et al. 2017; Xie, Antle, and Motamedi 2008). There are other studies that analyze the advantages and disadvantages of NUI and compare them with the standard interaction methods (Rauterberg 1997; Lacolina, Soro, and Scateni 2011). Rauterberg (1997) carried out a study to compare four different types of interaction: (1) a command language, (2) a mouse, (3) a touch screen, and (4) a custom-made Digital Playing Desk. They used an implemented version of the computer game "Go-bang". The user had to play the game by moving a real chip on the virtual playing field using the four different types of interaction. A total of 304 visitors rated the usability of all four different interactions on a bipolar scale. The touch interaction was rated as being the easiest to use, followed by the mouse, the Digital Playing Desk, and 
the command language interface. Lacolina, Soro, and Scateni (2011) compared two interactive systems for natural exploration of 3D models. They compared two natural interfaces: multitouch vs. free-hand gestures. They concluded that both interfaces provide a natural dual-handed interaction and at the same time free the user from the need to use a separate device. The natural interfaces have proven to be useful for certain purposes such as learning (Cantoni, Cellario, and Porta 2004; Martín-SanJosé et al. 2013) or rehabilitation (Rego, Moreira, and Reis 2011). Most systems developed (Cánovas et al. 2008; Hamilton, Driscoll, and Sutherland 2002; Moffat, Hampson, and Hatzipantelis 1998; Sturz and Bodily 2010) for evaluating spatial short-term memory which are described in the virtual environments section have simple interaction methods (based on a screen, a mouse, and a keyboard).

\section{Stereoscopy}

Stereoscopy is a technology that is currently being incorporated in many fields such as psychology (Juan et al. 2005) and education (Martín-SanJosé et al. 2014). Stereoscopy is based in collecting three-dimensional visual information and creating an illusion of depth. This can be obtained by showing a different image to each eye (Figure 3.1). In an ideal 3D application, the users perceive how the objects come out of the screen, and they have the illusion that the objects are in front of them. By adding this technology, a virtual environment can be improved by providing an immersive sensation, and making the users feel as if they were actually inside the virtual world (Loomis, Blascovich, and Beall 1999). This technique has been used to introduce users into the virtual environment and create the sensation that he/she is in a real place performing a real task. For example, Grantcharov et al. (2004) explained that there are differences between surgeons who were trained with a virtual reality simulator and surgeons that were not trained with it. This virtual task allows the surgeons to improve their skills in a simulated environment. Since it has been demonstrated that stereoscopy increases the immersive sensation of the user in the task, we have selected this technology for memory assessment.

\section{Short-term memory}

Spatial memory is a higher cognitive function that has been extensively probed using testing paradigms that were developed for animal models with the aim of understanding the neural basics of memory. Hence, there is a large body of knowledge about how our brain works to store information (i.e., to create memories) that is derived from the data about performance in tasks for spatial 
training (Byrne, Becker, and Burgess 2007). Spatial tasks of this type can be defined according to the type of memory trained (i.e., short-term or long-term) (Burgess and Hitch 2005). Spatial short-term memory is defined as the limited capacity of subjects to remember the locations of items for short periods of time (Baddeley 1992). In children, the spatial short-term memory ability is related to academic outcomes (Alloway and Alloway 2010). Therefore, it is interesting to assess this type of memory in children and to obtain information that could predict their academic achievements. Most of the tasks developed to test spatial short-term memory in children consist of showing very simple items or objects on a screen, a paper, or a board (e.g., Alloway 2012; Kessels et al. 2000; Reynolds, C. R. and E. D. Bigler 2001). In these tasks, the person is tested while sitting in a chair; however, spatial memory has a strong component of spatial orientation, which is only tested when the spatial items to be remembered are located in a more complex layout. Spatial orientation involves establishing a relationship between the spatial elements of a large environment, where the person and the spatial items are located. This problem can be solved by using virtual environments, which do not require a large interaction area.

Thanks to advances in virtual reality, several tests have been developed for the assessment of short-term memory for spatial locations (Juan et al. 2014; Cánovas et al. 2008; Cánovas, Fernández-García, and Cimadevilla 2011). However, to our knowledge, none of them have used the types of interaction that are used in our task, nor have they used stereoscopic visualization.

\section{Materials and Methods}

In this section, we describe the task that was developed to carry out our study. We also explain in detail how we developed the system and the software and hardware used.

\section{The MnemoCity task}

The main objective of the user in the MnemoCity task is to search for objects and remember their location. Figure 3.2 shows a general scheme of the MnemoCity task. The objects appear in the virtual environment. The MnemoCity task has six levels: an interaction adaptation level, a habituation level, and four levels for the main task. The objective of each level of the task is described below. 


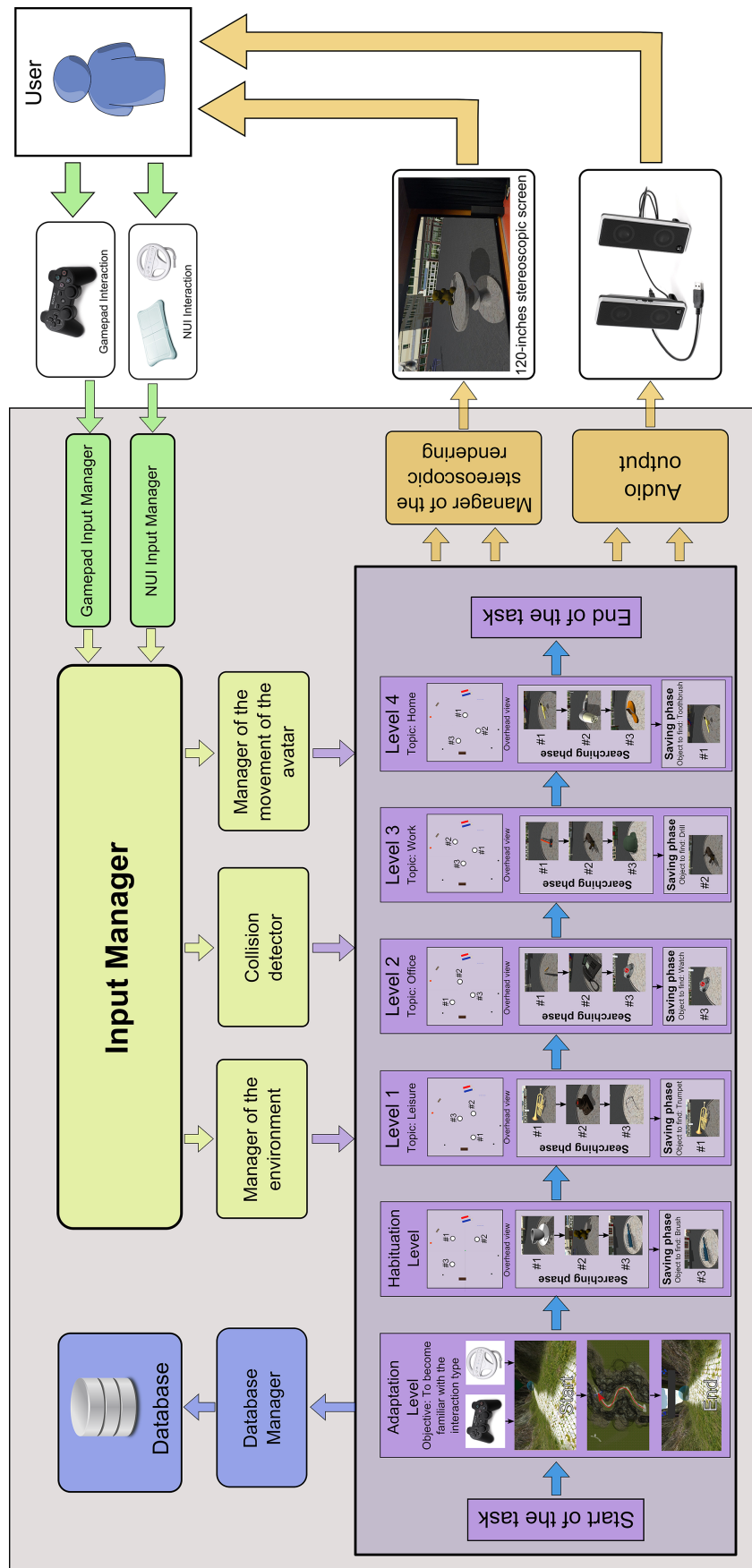

Figure 3.2: General scheme of MnemoCity task: An explanation of the elements that appear in overhead views can be found in Figure 3.6. 
The interaction adaptation level: This level aims to provide an initial experience with the system so that the user becomes familiar with the interaction for the main task. In this level, the user learns how to move inside the virtual environment using one of the two types of interactions.

The habituation level: This level is the tutorial level of the main task. In this level, the user learns what the goal of the task is and how to achieve it.

The main task: This task is composed of four different levels. The goal of these levels is to assess children short-term memory for object location. In this level, the task stores the information about the user's performance at each level, which reflects the spatial short-term memory ability of the user.

The interaction adaptation level consists of a path through mountains that the users must follow. There are arrows and bubbles along the path that help the user to find the direction to be followed. The path forward has several curves. The aim of these curves is for the user to follow the path as it curves from left to right and get used to the interaction. At the end of the path, there is a big sign that indicates the end of the level. Figure 3.3 shows a child performing the interaction adaptation level.

After completing the interaction adaptation level, the user is moved virtually to the practice level of the memory task: the habituation level.

In the habituation level and the four levels of the main task, the user is located in a virtual city. This environment consists of a city square that is surrounded by several buildings (distal cues), and eight visual cues inside the city square (proximal cues). Since the geometry of the land may or may not help user orientation (Hartley, Trinkler, and Burgess 2004), our environment was created in a square shape to help the participant navigate. Because the application was designed for children, an open space (city square) was chosen. This is to prevent the children from being in a virtual environment that is too closed or too dark and could frighten them. The visual cues help the user to orientate spatially.

The habituation level is similar to the rest of the levels of the main task. This level was designed so that the users could learn how to perform the task. Throughout all of the levels, a narrator guides the children with her voice and tells them what to do each time (e.g., "You have to put this object in its correct position", "Remember the location of the objects that you are going to see now", "Approach the table and push the button when it changes color"). 


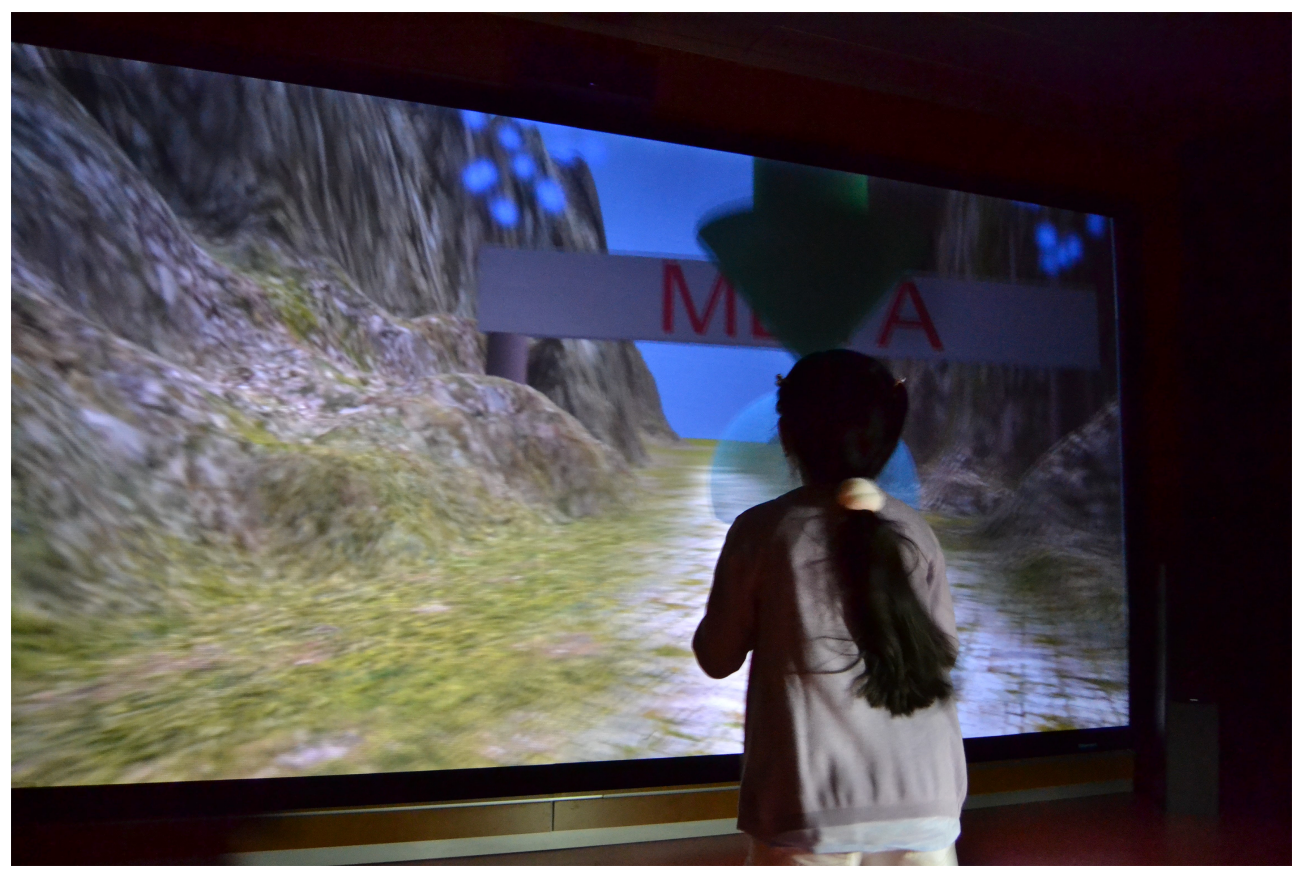

Figure 3.3: A child performing the interaction adaptation level. 
Each level is divided into two phases. In the first phase, called the searching phase, the users must move through the environment looking for a green arrow. This arrow is pointing to a white table. The child must walk to this table, and when the child is close enough, the table changes color from white to green, and the child can see the secret object on the table. The child must repeat this process two more times to discover a total of three objects. It is important to note that the children must remember the objects they saw and where the objects were placed. At the end of each search phase, the child returns to the center of the scene, and the virtual world is rotated $180^{\circ}$ from the original position before starting the second phase. Therefore, the idiothetic information cannot be used as a reference for orientation.

In the second phase, the saving phase, the screen shows an object and the narrator asks the user the position of that object. From a cognitive perspective, the searching phase refers to the formation of short-term memories for visuospatial items, whereas the saving phase refers to the retrieval of those items.

To keep the child motivated, the game includes a score screen. The child receives a star when he/she finishes the habituation level and the four levels of the main task, regardless of the quality of his/her responses. Hence, when the task is completed, the user has obtained five stars, which are shown on the score screen (Figure 3.4). From the perspective of the user, it does not matter whether or not he/she places the object on the correct table because, in all cases, the user goes on to the next level. This is to keep the child from becoming frustrated with an incorrect response that could affect another level. However, the selected object is stored in the database. Each level has three tables and three hidden objects to remember. To complete the game the participant must complete the interaction adaptation level, the habituation level, and the four levels of the main task. When the child is in the virtual environment of the city, all of the hidden objects of one level have a common theme. The objects and the theme of each level are the following:

- Habituation level: a coffee cup, a teddy bear (the object shown in 3.5), and a brush;

- Level 2 (Office level): a pen, a telephone, and a watch;

- Level 3 (Work level): a hammer, a drill, and a helmet;

- Level 4 (Home level): a toothbrush, a hairdryer, and a slipper. 


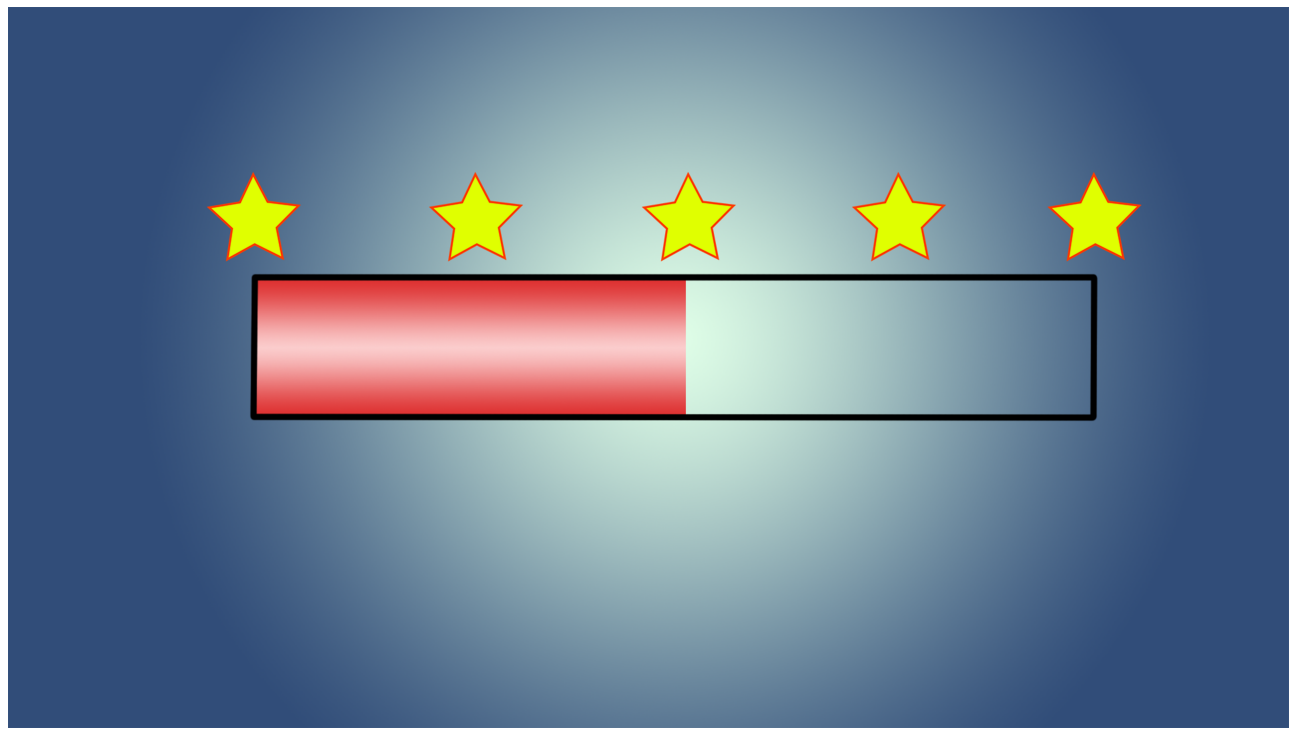

Figure 3.4: The progression bar with the five stars needed to complete the game.

The three objects that characterize each level and the object that the child is asked to locate are shown in Figure 3.2.

\section{Development}

The system is divided into three main components: the passive environment, the active environment and the user interaction. The passive environment was developed first. This passive environment consists of the objects that are static in the virtual world (e.g., buildings, the ground or the bench). To create all of these objects, we used a 3D model library called De Espona. These models were improved by using Blender and 3DS MAX to adapt the characteristics to the application requirements. The passive environment is composed by a city square surrounded by 16 visual cues including 8 buildings and 8 objects that are commonly found in a city (a streetlight, a bench, a trash can, a statue, a bin, a bus stop, a swing and a slide). The buildings are located distally, and the remaining visual cues are placed proximally to the city squared. Figure 3.6 shows the city square as seen from above.

The interaction area of the virtual environment limits the movement of the child (Figure 3.6 pink dashed lines in front of buildings). These limits are used so that the children will not try to walk inside the buildings and be 


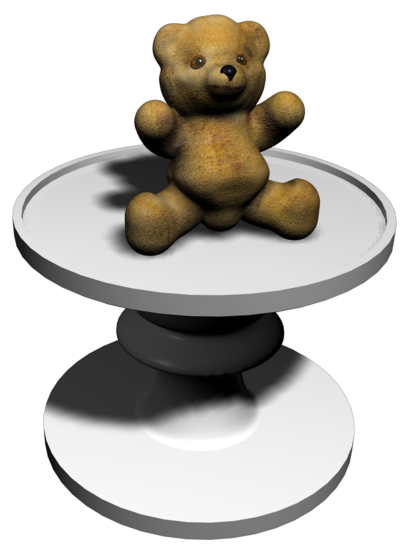

Figure 3.5: An example of one of the objects that appears on the table.

\section{$---\quad$ Interaction area \\ IU User avatar \\ $\square$ Tables \\ Proximal clues \\ Distal clues}

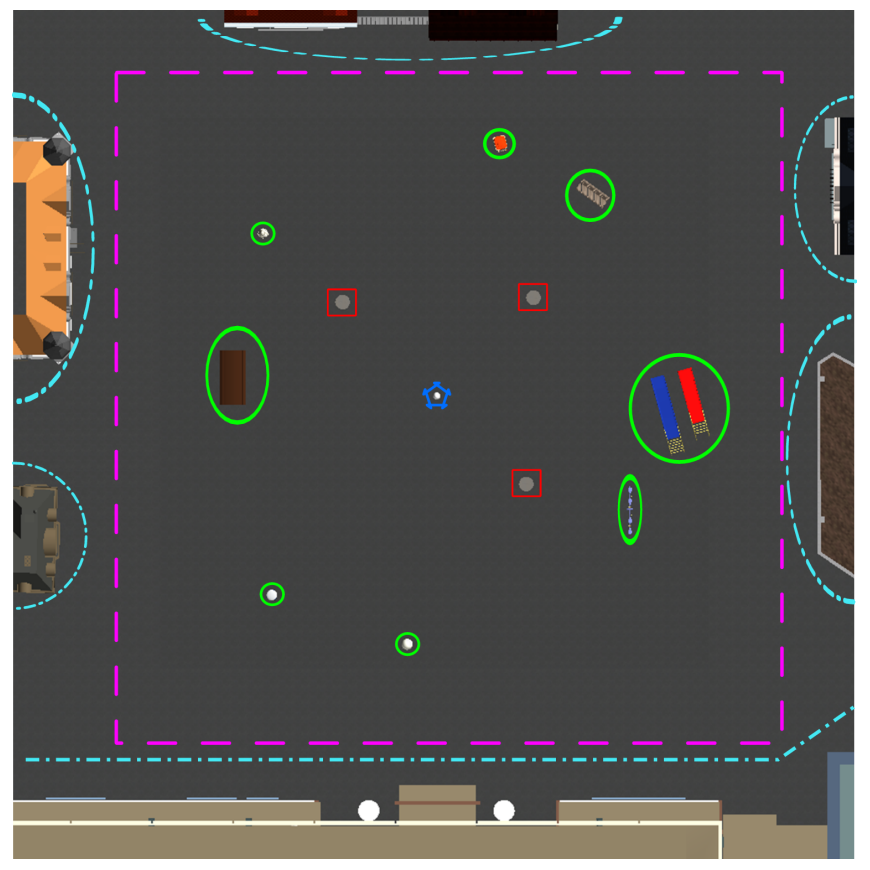

Figure 3.6: The virtual environment as seen from above. 
distracted from the main task. The 16 visual cues have colliders to prevent the child from walking through them and to look more realistic. The active environment has two principal components. The first component is the child's avatar. This avatar is a representation of the user in the virtual world. The second components are the tables. There are three tables and their position change in every level but the distance between them, and between them and the avatar, is similar in each level. The system includes all the code that allows the visualization for the virtual 3D environment. A library to create the 3D sensation for the children was also developed. This library allows us to place two cameras on the child's avatar, and each camera simulates one of the eyes of the user. The cameras are located at a standard intraocular distance $(63 \mathrm{~mm})$ (Dodgson 2004) and at a field of view of $60^{\circ}$. This value for the field of view was calculated from the real dimensions of the screen and the distance between the participant and the screen. We used Unity 3D (http://unity3d.com) as a game engine to merge all of the characteristics of the system into one application. Figure 3.7 shows the architecture of the system.

The immersive property of our system is based on the fact that the user can see the objects of the virtual environments come out of the screen as if they were real objects, creating the feeling that the user really thinks that he/she is inside the virtual environment and he/she is walking around it. The 120-inch screen acts as a window of union between the real and the virtual worlds, and the stereoscopy creates the illusion that the virtual world occupies the real world where the user is. Thus, the system creates the feeling of immersion for the user.

\section{Interaction}

One of the two types of interaction is performed using NUI. The user moves in the virtual environment by physically walking on a Wii Balance Board ${ }^{\mathrm{TM}}$. A change in direction is achieved by turning a wireless steering wheel. To compare this type of interaction with a more standard type of interaction without physical movement, we use a gamepad. These two interfaces were developed to facilitate user interaction in the application.

- NUI interaction: Wii mote ${ }^{\mathrm{TM}}$ and Wii balance board ${ }^{\mathrm{TM}}$ interaction were used. The user is placed on the Wii balance board ${ }^{\mathrm{TM}}$ and he/she holds a Wii ${ }^{\mathrm{TM}}$ mote that looks like a steering wheel. When the user raises his/her foot the avatar starts to walk. These movements were designed to be as intuitive as possible. The user can turn left or right using the 


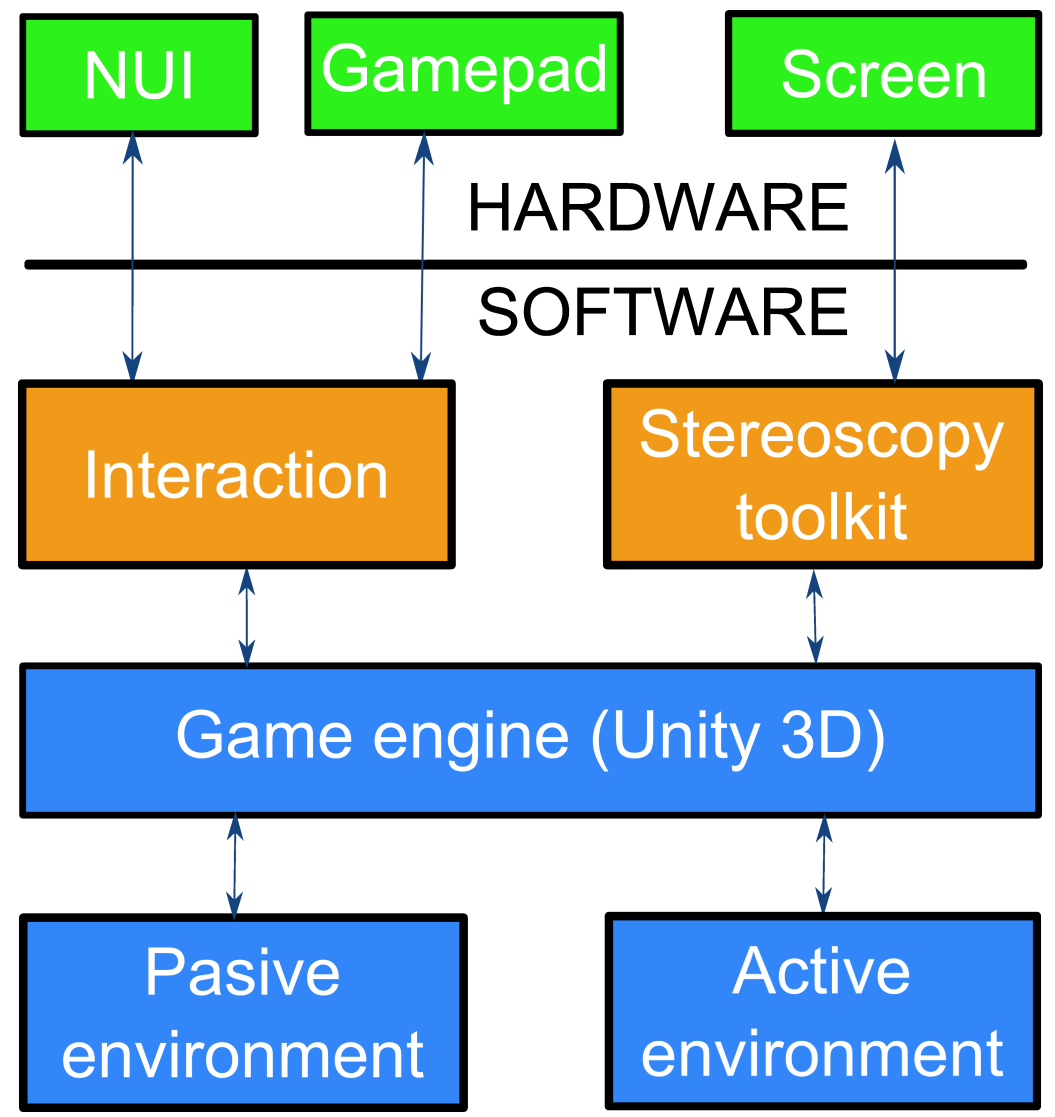

Figure 3.7: System architecture. 
steering wheel to complete the mobility of the avatar. With these two movements, the child can walk around the scene. The Wii mote ${ }^{\mathrm{TM}}$ has an action button that the children press when they want to see the object on the tables or to place the object on one of the tables.

- Gamepad interaction: To design a more standard interface that could be used in a seated or standing position, we have taken into account that children are accustomed to using their hands to interact with different devices like video game consoles, computer games with gamepads, smartphones, etc. Therefore, we selected a device that is familiar to them, a PlayStation gamepad. In our system, the movement is controlled with the left joystick of the gamepad (forward, backward, left, and right). The $\mathrm{X}$ button of the gamepad is used to see the object on the tables or to place the item on one of the tables.

To play the application, the user must stay in front of the screen and use the interaction device. Since, this application includes passive 3D, the user must wear linear polarized glasses to perceive the 3D sensation. These glasses have two vertical polarizers, one for each eye. There is a difference of $90^{\circ}$ between the directions of the two polarizers.

\section{Software and Hardware}

We used the following software to develop the MnemoCity task:

- Unity (also called Unity3D) as the game engine. This engine was chosen because it allows the completed application to be developed with the features that we needed. It supports code written in C\#, JavaScript, and Boo.

- C\# was used to program the scripts in Unity. C\# was also used for the creation of an external wrapper that allows us to work with the Wii Mote $^{\mathrm{TM}}$ and the Wii Balance Board ${ }^{\mathrm{TM}}$.

- Blender and 3DS Max were used to create and improve the 3D models, that are included in the application.

- Adobe Photoshop was used to modify the textures and images.

- The Wiilib3D (http://wiimotelib.codeplex.com) open source library was used to create the application that connected the game with the gamepad, Wii mote ${ }^{\mathrm{TM}}$, and Wii balance board ${ }^{\mathrm{TM}}$ interactions. 


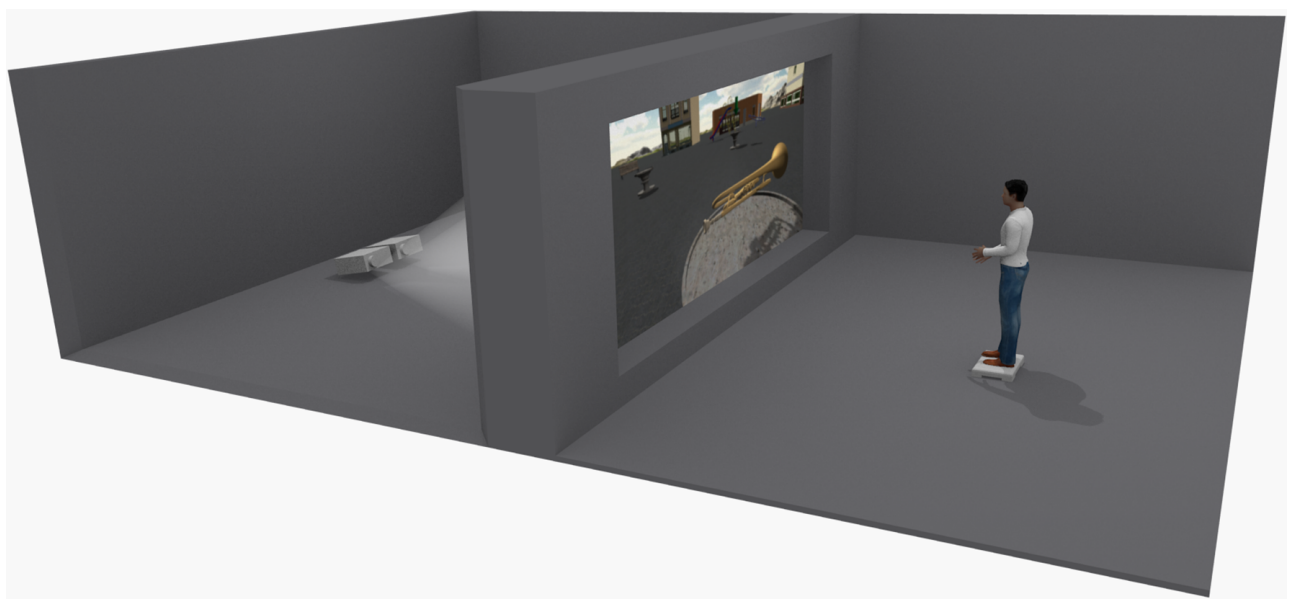

Figure 3.8: Virtual representation of the MnemoCity testing room.
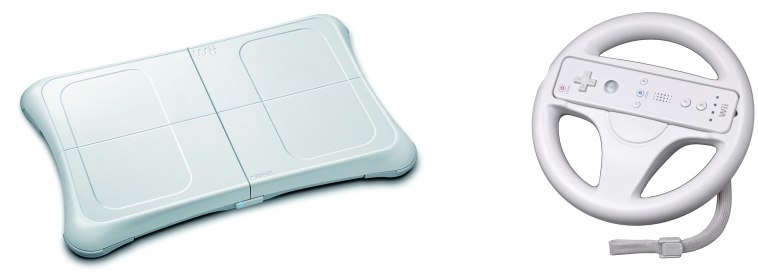

Figure 3.9: The Wii Balance Board ${ }^{\mathrm{TM}}$ and Wii Mote used ${ }^{\mathrm{TM}}$ to create the NUI interaction.

The following hardware was used:

- The testing room for the task had some special characteristics. First, it was divided into two areas (the projection area and the user area), which were divided by a wall and a translucent screen. The two projectors placed in the projection area project the two images onto the screen. These two images are polarized and a 3D image is created. The user must wear linear polarized 3D glasses in order to see the image correctly. Figure 3.8 shows a representation of this room.

- Interaction: To develop the user's interactions, three devices were needed. A Wii Balance Board ${ }^{\mathrm{TM}}$ and a Wii Mote ${ }^{\mathrm{TM}}$ with the wheel accessory were used for the NUI interaction (Figure 3.9). A "B-Move Gamepad BG Revenge" was used for the standard interface (Figure 3.10). 


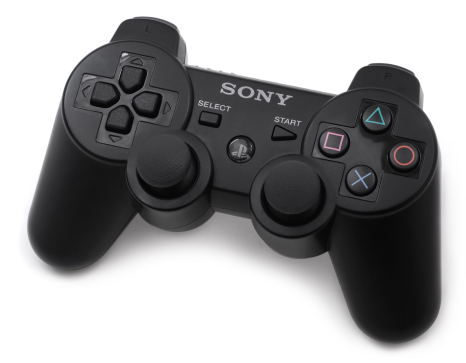

Figure 3.10: The gamepad used to create the standard interaction.

\section{Study}

In this section, we describe the participants of the study, the variables considered, and the procedure that the participants followed.

\section{Participants}

One-hundred and sixty healthy children, ranging in age from 5 to 10 years old, participated in the study. The mean age was $7.29 \pm 1.65$ years old. There were 91 boys (56.87\%) and 69 girls (43.13\%). Table 3.1 shows the children's distribution for age and gender. Their parents received written information about the objectives and characteristics of our study and they signed a written consent form on behalf of the children to allow them to participate in it. Also, the children received verbal instructions about what did the study consist at the beginning of the procedure, and where asked whether they might like to participate. This verbal consent was not recorded and the aim was to ensure that all the participants were willing to cooperate. All the participants gave verbal consent. Moreover, all clinical investigation was conducted according to the principles expressed in the Declaration of Helsinki. The Ethics Committee of the Universitat Politècnica de València, Spain, approved the study and the written consent form that the parents signed (Reference: 2014-980, approval date: $07 / 22 / 2016)$. The participants received a small reward consisting of a diploma right after the testing sessions. 
Table 3.1: Gender and age distribution of the participants.

\begin{tabular}{lccccccc}
\hline Age & 5 & 6 & 7 & 8 & 9 & 10 & Total \\
\hline Boys & 17 & 18 & 20 & 14 & 12 & 10 & 91 \\
Girls & 11 & 12 & 15 & 9 & 10 & 12 & 69 \\
\hline
\end{tabular}

\section{Measurements}

For each game of the MnemoCity task, the application stored the following variables in a remote database: the interaction type, the searching and the saving phase times for all of the levels, the table selected in each level, and the score. The table selected in each level corresponded to the place chosen by the child as the one show the object during the searching phase. This variable showed the child's ability to remember the spatial location of the object. The score of MnemoCity task was the sum of the number of objects placed correctly.

Before starting the task, the users completed the Lang-Stereo-Test (Lang 1983). The Lang-Stereo-Test is composed of easy-to-use screening tests that are designed for early detection of problems with stereoscopic vision in children. Two versions of the test plates are available, which only differ in the objects to be recognized. The Lang-Stereo-Test I displays a star, a cat, and a car; the Lang-Stereo-Test II displays a moon, a truck, and an elephant, each of these images have a different disparity. In addition, the Lang-Stereo-Test II contains a star that can be seen by only one eye. Thanks to the Lang-StereoTest, an assessment of 3D perception of the children can be performed. There are three possible results: the child sees 3D properly, the child cannot see 3D, and a doubtful result (this means that the child properly recognizes 3D in some of the objects presented, but not all).

Since the sense of presence of the user inside the virtual world is really important in applications of this type (Witmer and Singer 1998), we need to know the level of immersion of the user. Therefore, a question about the immersion of the virtual world was included in the Q2 questionnaire. In this questionnaire, we also added some satisfaction and usability questions.

To compare the MnemoCity task with existing assessment procedures, the following two test versions of the Corsi Block-Tapping Task (CBTT) were also used (Kessels et al. 2000):

- The CBTT (Direct version): The CBTT is a psychological test that assesses visuo-spatial short-term memory. It involves mimicking an evalu- 


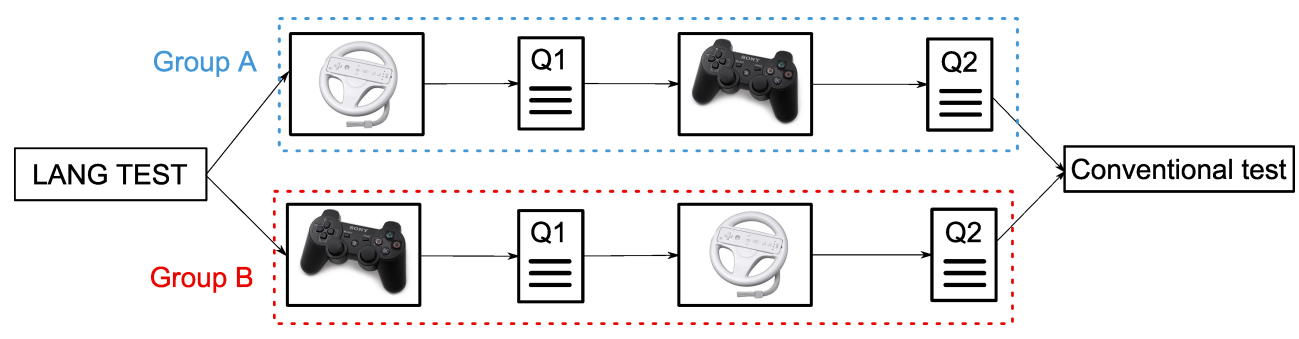

Figure 3.11: Procedure of the task.

ator as he/she taps a sequence of up to nine identical spatially separated blocks. The blocks are on a white plastic board that is on top of a table. The evaluator, who points at the blocks is in front of the subject. The sequence starts out simple (usually using two blocks) and becomes more complex until the subject's memory performance diminishes. This number is known as the CBTT Span and averages about 5 for adults (Kessels et al. 2000).

- The CBTT (Reverse version): This is a similar test, the users must not only remember the blocks, and they must also point to them in reverse order. This version assesses the ability to remember and manipulate spatial information and is related to working memory, which is a type of short-term memory that involves the mental manipulation of items.

We considered two variables that are related to performance in the CBTT (Kessels et al. 2000): the direct scores in each version of the CBTT (Direct CBTT score and Reverse CBTT score variables); and the number of blocks of the longest sequence that the child can tap correctly (Direct CBTT span and Reverse CBTT span).

\section{Procedure}

All of the children were randomly assigned to one of two groups based on the interaction used first. At the end of the procedure each child had played the MnemoCity task twice (once for each type of interaction). The different steps of the experimental procedure are shown in Figure 3.11.

- Group A: This group performed the MnemoCity task first with the NUI interaction and then performed it using the gamepad second. 
Table 3.2: Questions of the Q1 questionnaire.

\begin{tabular}{|c|c|c|}
\hline$\#$ & Question & Value \\
\hline US1 & Was the game easy to use? & $\begin{array}{l}\text { [1.Very difficult / 2.Difficult / 3.Regular / } \\
\text { 4.Easy / 5.Very easy] }\end{array}$ \\
\hline US2 & I always undestood what i have to do & $\begin{array}{l}\text { [1.Strongly disagree / 2.Disagree / 3. Nei- } \\
\text { ther agree nor disagree / 4.Agree / } \\
5 . \text { Strongly agree] }\end{array}$ \\
\hline SA1 & How much fun did you have? & $\begin{array}{l}\text { [1.Strongly disagree / 2.Disagree / 3. Nei- } \\
\text { ther agree nor disagree / 4.Agree / } \\
\text { 5.Strongly agree] }\end{array}$ \\
\hline $\mathrm{SA} 2$ & $\begin{array}{l}\text { Would you invite your friends to play } \\
\text { the game? }\end{array}$ & $\begin{array}{l}\text { [1.Strongly disagree / } 2 \text {. Disagree / } 3 \text {. Neither } \\
\text { agree nor disagree / 4.Agree / } 5 \text {.Strongly } \\
\text { agree] }\end{array}$ \\
\hline SA3 & $\begin{array}{l}\text { Would you play this game another } \\
\text { time? }\end{array}$ & $\begin{array}{l}\text { [1.Never / } 2 \text {. Hardly ever / 3.Sometimes / } \\
\text { 4.Almost every day / } 5 \text {.Everyday }]\end{array}$ \\
\hline SA4 & Score the game from 1 to 5 & $\begin{array}{l}\text { [1.Very bad / 2.Bad / 3.Regular / 4.Good } \\
\text { / } 5 \text {.Very good] }\end{array}$ \\
\hline Q3D & $\begin{array}{l}\text { At certain moments the objects came } \\
\text { out of the screen }\end{array}$ & $\begin{array}{l}\text { [1.Strongly disagree / 2.Disagree / 3.Nei- } \\
\text { ther agree nor disagree / 4.Agree / } \\
\text { 5.Strongly agree] }\end{array}$ \\
\hline
\end{tabular}

- Group B: This group performed the MnemoCity task first with the gamepad and then performed it using the NUI interaction second.

When the users had finished playing the task for the first time, they had to fill out the Q1 questionnaire (Table 3.2). Both groups filled out the Q2 questionnaire after completing the MnemoCity task with the two different interactions (Table 3.3). Finally, after completing the Q2 questionnaire, the children performed the CBTT (direct and reverse versions) conventionally. The two groups had a similar number of children (72 in Group A and 67 in Group B). The approximate duration to complete the whole procedure was one hour. The test took place Monday through Friday between 9:00 A.M. and 6:00 P.M. Each child was accompanied by a supervisor throughout the entire process. 
Table 3.3: Questions of the Q2 questionnaire.

\begin{tabular}{|c|c|c|}
\hline$\#$ & Question & Value \\
\hline SA1 & $\begin{array}{l}\text { How much fun did you } \\
\text { have? }\end{array}$ & $\begin{array}{l}\text { [1.Very boring / 2.Boring / 3.Regular } \\
\text { / 4.Fun / } 5 \text {.Very fun] }\end{array}$ \\
\hline US1 & $\begin{array}{l}\text { Was the game easy to } \\
\text { use? }\end{array}$ & $\begin{array}{l}\text { [1.Very difficult / 2.Difficult / 3.Reg- } \\
\text { ular / 4.Easy / 5.Very easy] }\end{array}$ \\
\hline PRE1 & $\begin{array}{l}\text { Which interaction was } \\
\text { more fun? }\end{array}$ & [1.NUI Interaction / 2.Gamepad] \\
\hline PRE2 & $\begin{array}{l}\text { Which interaction was } \\
\text { easier to use? }\end{array}$ & [1.NUI Interaction / 2.Gamepad] \\
\hline
\end{tabular}

\section{Results}

A statistical analysis was performed to corroborate our hypotheses. The statistical significance was set at alpha level $\alpha=0.05$. The data from the study were analyzed using the statistical open source language and environment for statistical computing and graphics R (https://www.r-project.org).

First, data normality was checked with the Levene's test (Levene 1961). Our data did not fit the normal distribution. Therefore, the tests used were nonparametric (Mann-Whitney U (Mann and Whitney 1947) and Kruskal-Wallis (Kruskal and Wallis 1952) tests).

\section{Lang-Stereo-Test outcomes}

The users performed the Lang-Stereo-Test (Lang 1983) in order to check whether or not they perceived 3D correctly. The results of the 160 users were the following: 139 passed the test correctly, 15 users had doubtful results and 6 users did not pass the test. The correlations on the Lang-Stereo-Test score were analyzed with the MnemoCity score. We performed a Mann-Whitney U test $(U=754, Z=1.78, p=0.06, r=0.15)$. There was no correlation between these two variables. The means and standard deviation of MnemoCity score indicate that the mean of the users who passed the Lang-Stereo-Test had a better score (the mean of the children who perceived 3D correctly: $2.28 \pm 1.27$, the mean of the children who did not perceive 3D correctly: $1.67 \pm 0.47)$. We selected the participants that could perceive 3D for the rest of the analyses. Thus, the final sample consisted of 139 children ( $57 \%$ boys and $43 \%$ girls). To determine if there were any differences between the users that could perceive $3 \mathrm{D}$ correctly and the users that could not perceive 3D correctly, we performed 
Table 3.4: Multifactorial Kruskal-Wallis test results for stereo vision. A multifactorial Kruskal-Wallis test was conducted on the influence of five independent variables (Gender, Interaction, Usability, Satisfaction and MnemoCity Score) for stereo vision.

"**" indicates the statistical significance at level $\alpha=0.05$.

"-" indicates that there was no statistical significance.

\begin{tabular}{lrrrr}
\hline Variable & $\chi^{2}$ & $d f$ & $p$ & Sig. \\
\hline Gender & 1.11 & 1 & 0.24 & - \\
Interaction & 1.06 & 1 & 0.30 & - \\
Usability & 6.22 & 7 & 0.52 & - \\
Satisfaction & 30.57 & 15 & 0.01 & $* *$ \\
MnemoCity Score & 7.03 & 4 & 0.14 & - \\
\hline
\end{tabular}

a Kruskal-Wallis test with the following independent variables: Gender, Interaction, Usability, Satisfaction, and MnemoCity Score. The results are shown in Table 3.4. The Satisfaction variable indicated a statistically significant difference between the two groups. The group that could see 3D correctly showed greater satisfaction than the other group.

\section{Interaction outcomes}

In order to compare the two interaction types, a Mann-Whitney U test was performed to determine whether or not there were statistically significant differences. These results indicate that there were no statistically significant differences regarding the score obtained in the MnemoCity task based on the interaction used $(U=2238.5, Z=-0.750, p=0.455, r=0.063)$. We also performed a Mann-Whitney $U$ test to find statistically significant differences in gender $(U=2471, Z=0.485, p=0.628, r=0.041)$.

Furthermore, we applied a multifactorial Kruskal-Wallis test (Table 3.5) with four independent variables (Gender, Usability, Satisfaction, and MnemoCity Score). The Satisfaction variable indicated a statistically significant difference between the users that had the gamepad interaction $(M=9.75, S D=4.30)$ and the users that had the natural interaction $(M=10.68, S D=3.08)$ in favor of the natural interaction. 
Table 3.5: A Multifactorial Kruskal-Wallis test was conducted on the influence of four independent variables (Gender, Usability, Satisfaction and MnemoCity Score) for the Type of interaction.

$" * * "$ indicates the statistical significance at level $\alpha=0.05$.

"-" indicates that there was no statistical significance.

\begin{tabular}{lrrrr}
\hline Variable & $\chi^{2}$ & $d f$ & $p$ & Sig. \\
\hline Gender & 0.04 & 1 & 0.847 & - \\
Usability & 9.88 & 6 & 0.129 & - \\
Satisfaction & 40.08 & 15 & $<0.001$ & $* *$ \\
MnemoCity score & 7.80 & 4 & 0.309 & - \\
\hline
\end{tabular}

Table 3.6: A Multifactorial Kruskal-Wallis test was conducted on the influence of four independent variables (Interaction, Usability, Satisfaction and MnemoCity Score) for gender. $" * * \|$ indicates the statistical significance at level $\alpha=0.05$.

"-" indicates that there was no statistical significance.

\begin{tabular}{lrrrr}
\hline Variable & $\chi^{2}$ & $d f$ & $p$ & Sig. \\
\hline Interaction & 0.04 & 1 & 0.848 & - \\
Usability & 12.42 & 6 & 0.050 & - \\
Satisfaction & 15.06 & 15 & 0.448 & - \\
MnemoCity score & 1.68 & 4 & 0.796 & - \\
\hline
\end{tabular}

\section{Gender outcomes}

A Mann Whitney $\mathrm{U}$ test was performed to determine if gender affected the MnemoCity score $(U=72, Z=0.864, p=0.403, r=0.184)$. The result indicated that there were no statistically significant differences in gender. Others Mann Whitney U-tests were performed with the classical test scores, regarding gender: the Direct CBTT score $(U=48, Z=-0.834, p=0.403, r=0.177)$, and the Reverse CBTT score $(U=50, Z=-0.702, p=0.516, r=0.149)$. The results of the tests indicated that there were no statistically significant differences between the performance of boys and girls in the classical method CBTT.

We also applied a multifactorial Kruskal-Wallis test (Table 3.6) with four independent variables (Interaction, Usability, Satisfaction, and MnemoCity Score). The results show that there were no statistically significant differences regarding gender. 
Table 3.7: Interaction and 3D preferences. Mann-Whitney U tests about the preferences. Group A is the one where the users played with the NUI first, and Group B is the one where the users played with the gamepad first. The PRE1 and PRE2 questions have two options (1: NUI and 2: Gamepad). The Q3D question represents the option of the user about the 3D sensation of the task.

"**" indicates the statistical significance at level $\alpha=0.05$.

"-" indicates that there was no statistical significance.

\begin{tabular}{lrrrrrrr}
\hline Variable & Group A & Group B & $U$ & $Z$ & $p$-value & $r$ & Sig. \\
\hline $\begin{array}{l}\text { PRE1- Which interac- } \\
\text { tion was more fun? }\end{array}$ & $1.54 \pm 0.50$ & $1.44 \pm 0.50$ & 3605 & 1.26 & 0.214 & 0.10 & - \\
$\begin{array}{l}\text { PRE2- Which was eas- } \\
\text { ier to use? }\end{array}$ & $1.56 \pm 0.50$ & $1.66 \pm 0.50$ & 2924 & -1.41 & 0.175 & 0.11 & - \\
$\begin{array}{l}\text { Q3D- At certain mo- } \\
\text { ments, the objects came }\end{array}$ & $3.59 \pm 1.34$ & $3.75 \pm 1.30$ & 3052 & -0.79 & 0.431 & 0.06 & - \\
out of the screen & & & & & & & \\
\hline
\end{tabular}

\section{Preference and depth perception outcomes}

In the Q2 questionnaire, two questions (PRE1-PRE2) about the preference of the interaction were included to determine which of the two interactions types the users preferred. Fifty-one percent of the users preferred the $\mathrm{Wii}^{\mathrm{TM}}$ interaction, and the rest (49\%) preferred the gamepad interaction. With regard to the ease of use, $38 \%$ of the users thought that the Wii ${ }^{\mathrm{TM}}$ interaction was easier, and the rest (62\%) thought that the gamepad interaction was easier. Two tests were performed to determine whether or not there were differences regarding the preference questions between the two groups. The results are shown in Table 3.7.

In the Q1 questionnaire, there was a question (Q3D) about the depth perception. The question had a high score 3.6 (1 - 5 scale). We also performed a multifactorial Kruskal-Wallis test (Table 3.8) with five independent variables (Gender, Type of Interaction, Usability, Satisfaction, and MnemoCity Score). The results show that there were no statistically significant differences. 
Table 3.8: Multifactorial Kruskal-Wallis test results for depth perception. Multifactorial Kruskal-Wallis test was conducted on the influence of five independent variables (Gender, Interaction, Usability, Satisfaction and MnemoCity Score) for depth perception.

$" * * "$ indicates the statistical significance at level $\alpha=0.05$.

"-" indicates that there was no statistical significance.

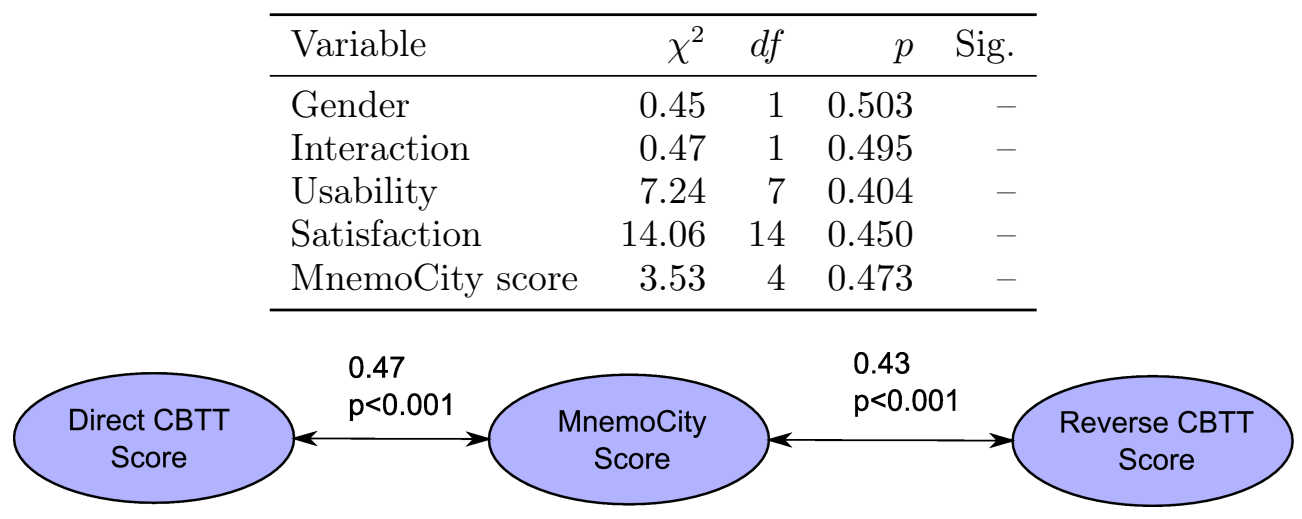

Figure 3.12: The Correlation plot.

\section{Short-term memory outcomes}

The MnemoCity score variable is a measure of short-term memory capability. The MnemoCity score can have a value between zero and four, based on the number of correct responses. Table 3.9 presents a descriptive analysis of this variable taking into account the independent variables (Age, Gender, and Type of interaction). As can be observed in Table 3.9, the task was not easy to learn for the younger children. They were not able to remember the location of all of the objects trained. Even, some of the older children did not perform the task perfectly. To compare the MnemoCity task performance level with the performance level obtained in traditional methods (the Direct and Reverse versions of the CBTT), we calculated their correlations. We did these correlations with the entire sample of 139 children. The Spearman correlation was used, and the results are shown in Figure 3.12. The Spearman correlation effect size was rho $(\rho)$. The MnemoCity score was correlated with the Direct CBTT score $(\rho=0.47, p<0.001 * *)$ and the Reverse CBTT score $(\rho=0.43, p<0.001 * *)$. The correlation between the MnemoCity score and the two traditional test scores (Direct and Reverse CBTT score) are shown graphically in Figure 3.13. It can be observed that the correlations are positive and linear in all cases. 
Table 3.9: Descriptive data of the MnemoCity score. The descriptive data of the independent variables (Age, Gender, and Type of interaction) related to the task variable for evaluating short-term memory (MnemoCity score).

\begin{tabular}{lccc}
\hline Variable & Value & Mean & Standard Deviation \\
\hline \multirow{4}{*}{ Age } & 5 years old & 1.10 & \pm 0.81 \\
& 6 years old & 1.62 & \pm 1.03 \\
& 7 years old & 2.09 & \pm 1.25 \\
& 8 years old & 2.91 & \pm 0.90 \\
\multirow{2}{*}{ Gender } & 9 years old & 3.10 & \pm 0.99 \\
& 10 years old & 3.24 & \pm 0.81 \\
\hline \multirow{2}{*}{ Type of interaction } & Girls & 2.33 & \pm 1.25 \\
& Boys & 2.20 & \pm 1.27 \\
\hline
\end{tabular}

Table 3.10: Mann-Whitney U tests for the satisfaction and usability questions. Group A is the one where the users played with the NUI first, and Group B is the one where the users played with the gamepad first. All the questions are in a Likert scale (1-5).

$" * * \|$ indicates the statistical significance at level $\alpha=0.05$.

"-" indicates that there was no statistical significance.

\begin{tabular}{lrrrrrrr}
\hline Question & Group A & Group B & $U$ & $Z$ & $p-$ value & $r$ & Sig. \\
\hline US1- Was the game easy to use? & $4.04 \pm 0.94$ & $4.25 \pm 0.90$ & 2837 & -1.59 & 0.113 & 0.13 & - \\
US2- I always undestood what i have to do & $4.73 \pm 0.52$ & $4.65 \pm 0.73$ & 3360 & 0.36 & 0.713 & 0.03 & - \\
SA1- How much fun did you have? & $4.65 \pm 0.48$ & $4.64 \pm 0.62$ & 3150 & -0.53 & 0.632 & 0.04 & - \\
SA2- Would you invite your friends to play the game? & $4.16 \pm 0.92$ & $4.16 \pm 1.11$ & 3085 & -0.70 & 0.479 & 0.06 & - \\
SA3- Would you play this game another time? & $3.89 \pm 1.01$ & $4.04 \pm 0.99$ & 2997 & -1.01 & 0.317 & 0.08 & - \\
SA4- Score the game from 1 to 5 & $4.46 \pm 0.75$ & $4.54 \pm 0.69$ & 3131 & -0.58 & 0.567 & 0.05 & - \\
\hline
\end{tabular}

\section{Usability and satisfaction outcomes}

The children answered two questions about usability and four questions about satisfaction with the MnemoCity task. All of these questions were answered in the Q1 questionnaire. In the Q2 questionnaire, the children only answered SA1 and US1. A Mann-Whitney U test for each question was performed to determine if there was any difference in the answers between the two groups. No statistically significant differences were found between the two groups. The results are shown in Table 3.10.

The users answered the SA1 and US1 question twice. Since the children answered these two questions twice, we can verify whether they changed their opinion about the first and second interaction, as they answered the two ques- 
Table 3.11: Interaction preferences. Wilcoxon Singed-rank tests for the repeated questions in the Q1 and Q2 questionaires. This table shows the differences between the views of users about how fun the game was and how easy the game was to use.

$" * * "$ indicates the statistical significance at level $\alpha=0.05$.

"-" indicates that there was no statistical significance.

\begin{tabular}{|c|c|c|c|c|c|c|c|c|}
\hline Group & Question & Q1 & Q2 & W & $\mathrm{Z}$ & p-value & $\mathrm{r}$ & Sig. \\
\hline \multirow{2}{*}{ Group A } & SA1-How much fun did you have? & $4.65 \pm 0.48$ & $4.59 \pm 0.73$ & 3311 & -0.20 & 0.875 & 0.02 & -- \\
\hline & US1-Was the game easy to use? & $4.04 \pm 0.94$ & $4.05 \pm 1.05$ & 3259 & -0.36 & 0.724 & 0.03 & -- \\
\hline \multirow{2}{*}{ Group B } & SA1-How much fun did you have? & $4.64 \pm 0.62$ & $4.62 \pm 0.64$ & 3228 & 0.12 & 0.907 & 0.01 & -- \\
\hline & US1-Was the game easy to use? & $4.25 \pm 0.90$ & $3.77 \pm 1.22$ & 3880 & 2.46 & 0.014 & 0.20 & $* *$ \\
\hline
\end{tabular}

tions twice (Table 3.11). The only difference obtained was in the question "Was the game easy to use?" and it seems that users who played with the gamepad first found it more difficult to play the game with the $\mathrm{Wii}^{\mathrm{TM}}$ second.

The general values of satisfaction and usability obtained from the questions were calculated by summing all of the values of the question and obtaining their means for usability (US1 and US2) and for satisfaction (SA1, SA2, SA3, and SA4). The children scored the task with an average of 3.49 over 5 . And the usability obtained was 4.26 over 5 .

\section{Discussion}

In this work, the capability of our MnemoCity task was tested to assess spatial short-term memory in children from 5 to 10 years old. Some applications for assessing spatial memory in humans have been developed previously (Koenig et al. 2011; Maguire, Nannery, and Spiers 2006; Cánovas et al. 2008; Cánovas, Fernández-García, and Cimadevilla 2011). These applications used basic methods of human computer interaction that could interfere with the quality of the user's immersion in the virtual environment. The quality of the immersion could affect the correct performance of the tasks (Foreman 2010; Loomis, Blascovich, and Beall 1999). Moreover, these tasks are designed to be performed by adults and not by children. A review of the literature indicates that a task that incorporates stereoscopy for the assessment of spatial short-term memory has not yet been developed. In our work, we have created a task that uses Natural User Interfaces and a large stereoscopic screen to facilitate immersion and interaction.

There have been few attempts to address spatial short-term memory through experimental tasks involving the movement of a child around an environment. 
The study by Smith, Gilchrist, and Hood (2005) presented a searching task for target locations that were hidden under a $7 \times 7$ grid. In this task, the goal was to probe the search efficiency of the child. Piccardi et al. (2013) studied shortterm memory in children with the use of the Walking Corsi Test (WalCT). This test was a larger version of the CBTT (Kessels et al. 2000) with a surface area of $2.5 \times 3$ meters. The child had to reproduce a walking sequence of the white points on the floor. In one of our previous works (Juan et al. 2014), we developed a task that incorporated augmented reality to evaluate spatial short-term memory in children. In this case, the task mixed virtual elements with the real world. Virtual elements were the objects to remember. The real elements in this work were the place and the strategically placed boxes throughout the room. The virtual elements were the objects inside the boxes. The benefit of using augmented reality was the possibility to have multiple objects that are not limited to the real world and the possibility to control the showing time of the objects. This is important because the codification time is essential in a spatial memory task. The users scored the task with high values of satisfaction and usability. Taking into account all of the abovementioned features (virtual reality, natural user interaction, and stereoscopy), to our knowledge, this is the first time that a task of these characteristics has been presented for this purpose.

The Lang-Stereo-Test (Brown et al. 2001) that was applied to our sample showed that $87 \%$ of the children could correctly perceive 3D and $13 \%$ could not perceive 3D properly. This result is consistent with other studies that indicated that between $5 \%$ and $10 \%$ of the population do not have stereo vision (Brown et al. 2001; Castanes 2003). Furthermore, the Kruskal-Wallis test corresponding to stereo vision (Table 3.4) showed that the users that perceive 3D properly have greater satisfaction when performing the task. This may be due to the fact that the application was especially designed for 3D perception of the virtual environment and the participants that cannot see 3D properly enjoy the task less than the others.

A comparison between our task with a commonly used task in neuropsychological assessment, the CBTT (Kessels et al. 2000), demonstrated that the performance of our task is related to short-term memory ability in children. The results of correlation tests indicated that the MnemoCity task shows validity for the assessment of spatial memory in children. The correlation of this task with the CBTT (Kessels et al. 2000), (Direct and Reverse CBTT) is significant. The correlation was average in both cases, with a value of 0.44 and 0.42 , respectively. This difference may be due to the fact that children handle a different type and form of information. In the CBTT the participant is in front 
of an evaluator and the participant remains in the same place throughout the entire process. In the MnemoCity task, the user is moving and seeing objects in the same way as occurs in their daily life. Therefore, the two tasks share some components of spatial short term memory, even though the procedure and features of the CBTT and the MnemoCity task are significantly different. The correlation of Direct and Reverse CBTT scores and the MnemoCity score was linear dependent, as shown in the Figure 3.13. To our knowledge, this is the first time that a virtual immersive environment has been compared directly with traditional methods for the assessment of short-term memory in children.

It should be pointed out that there is no real movement of the subject, since the participants used natural interaction to explore the virtual room. Recent studies have indicated that there are differences in the dynamics of acquisition of landmark-referenced (allocentric) knowledge relative to view-referenced (egocentric) knowledge (Zhang, Zherdeva, and Ekstrom 2014). In our task, at the end of each search phase, the child returns to the center of the scene, and the virtual world is rotated $180^{\circ}$ from the original position before starting the second phase. This means that the egocentric components of navigation did not provide any useful information and only the allocentric reference frame is valid for an adequate orientation. Previous studies (Wang and Spelke 2000; RoskosEwoldsen et al. 1998; Shelton and Mcnamara 1997) have demonstrated that some short-term memories are based on egocentric components of navigation. In the work by Wang and Spelke (2000), the users are disorientated by pivoting turns. After the disorientation, the egocentric component was eliminated from the navigation. In our task, using a virtual environment allows us to eliminate egocentric information in a way that is less annoying to the user.

With regard to user interaction, in the design phase of the MnemoCity task, we tried to find an interface that was as unobtrusive as possible so that the user could focus on the task. We also included walking motion to achieve a more realistic experience for the user while he/she was exploring the virtual environment. For this reason, we opted for a Natural User Interface. We also wanted to verify the advantages of using NUI compared to using a standard and passive motion-based interaction. Our study has shown that the use of the standard interface (gamepad) did not differ significantly for the usability and satisfaction questions or for the assessment of the task. Our explanation for this result is that most children are "digital natives" and are already familiar with standard interaction methods. Thanks to the incorporation of Wii ${ }^{\mathrm{TM}}$ and Kinect ${ }^{\mathrm{TM}}$, more and more children have also become familiar with NUI interaction. Moreover, the interaction adaptation level helped the children in our study to get used to our interface. Therefore, their mastery of current 

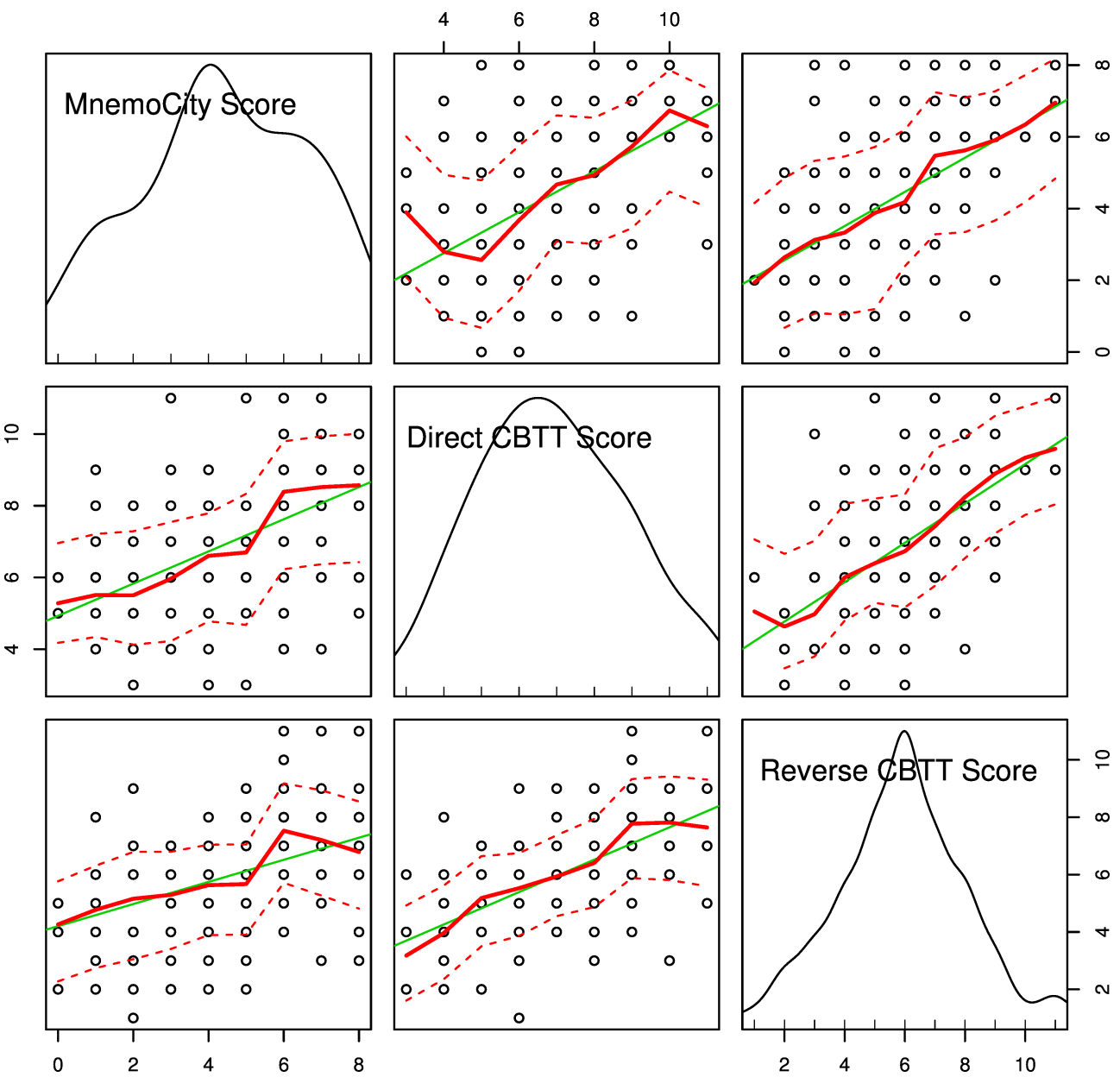

Figure 3.13: The Matrix plot for correlations between traditional tests and the

MnemoCity task. The distributions of the variables show the MnemoCity Score, the Direct CBTT Score, and the Reverse CBTT Score. The interactions between the three variables are shown in the other plots of the matrix. The red lines represent the mean and the standard deviation for each value, and the green lines represent the regression line of the correlation. 
trends, their ability to adapt to any technological change, and the different levels of our task have all contributed to making the two types of interaction were less noticeable for them. To our knowledge, previous comparisons among interaction methods in other studies (e.g., (Rauterberg 1997; Lacolina, Soro, and Scateni 2011)) have not carried out a comparison like the one proposed in this paper. The only difference between the two interactions was the preference in the PRE2 question "Which interaction was easier to use?". A total of $62 \%$ of the users thought that the gamepad was easier to use. Despite the differences between our study and Rauterberg's study (1997), it can be observed that there is a similarity between their results and ours. In Rauterberg's study, it was found that the users rated touch and mouse interactions as being easier than the custom-made Digital Playing Desk, and, in our work, the users thought that the gamepad was easier than the NUI. Our explanation for this result is that even though interaction with the NUI is more natural, users must be aware of what they are doing with their feet and hands, whereas with the gamepad they only have to think about what they are doing with their hands. Finally, as mentioned above, the type of interaction did not affect the final score for the MnemoCity task. Although unexpected, this is a good result because it means that the task is well suited for the assessment of spatial memory and that the two interaction types can be used for this purpose. Consequently, this application can also be used by children with reduced mobility (McComas, Pivik, and Laflamme 1998; Hill-Briggs et al. 2007).

With regard to gender differences in the MnemoCity score, the results indicated that there were no statistically significant differences for gender. Also, the classical task CBTT (Kessels et al. 2000) did not show any statistically significant differences. The similar performance between genders may be supported by other studies in which there were no statistically significant differences in gender when the spatial memory was tested on children (Juan et al. 2014; Alloway, Gathercole, and Pickering 2006; Piccardi et al. 2014; León, Cimadevilla, and Tascón 2014). Therefore, our results regarding gender are in line with the conclusions reached by those works and corroborate our third hypothesis (there were no statistical significant differences for the performance of the task between genders). Other studies have shown differences between genders. For example, Moffat, Hampson, and Hatzipantelis (1998) found male superiority in a study with VR environments that were developed to test the egocentric spatial orientation of adult participants. The egocentric orientation is based on one's body position in space (i.e., idiothetic information). In our task, the idiothetic information was irrelevant for the children because the virtual world was rotated before the testing phase. Therefore, the environmental cues and their arrangement in space were very important in helping children to locate 
the correct place of the object (i.e., allocentric information). The different navigational strategies promoted in each task could determine the existence or absence of gender differences, as was previously suggested (Coluccia and Louse 2004). The fact that the MnemoCity task has a low level of difficulty could explain the absence of differences between boys and girls.

\section{Conclusions}

The MnemoCity task, which incorporates stereoscopy, virtual environments, and NUI has been developed to assess spatial short-term memory in children. This task assessed children's ability to retain the position of the objects as a way to test spatial short-term memory in a natural environment. One of the main advantages of our system is that it allows the user to feel immersed in a large-scale complex virtual environment, which gives the user the sensation of being in a real environment. These sensations are not possible using traditional procedures or more basic visualization devices. Even though the system allows motion from a user-centered perspective and proves the navigational competence ecologically, the system assesses the user's short-term spatial memory in a controlled manner (i.e., it allows the user's position to be controlled to prevent an egocentric strategy). In addition, automatically stores information about the user's performance. Automatic storage of information is not possible with traditional procedures. Finally, another advantage of the system is that participation by an expert psychologist is only necessary in the design phase of the system; the task could be performed without the physical presence of an expert psychologist. The MnemoCity task could be used with more common 3D visualization devices such as HMDs (e.g., Oculus Rift). Since the interaction method did not significantly influence the assessment of short-term memory, the MnemoCity task could also be used with more traditional input devices. The MnemoCity task performance was compared with traditional neuropsychological procedures for the assessment of spatial short-term memory, and the usability and satisfaction of the participants were measured. The scores of the traditional procedures were correlated with the MnemoCity score. This means that the developed task could be used as an entertaining method to assess or train children in spatial short-term memory skills from an ecological assessment perspective, since the two types of interactions have shown that they can assess spatial memory. The MnemoCity task can potentially be used as part of an evaluation in children with and without motor problems. As future work, the possibility of using this task for the assessment of short-term spatial memory and other cognitive abilities related to spatial processing can be considered. We would also like to test this task in populations with special 
education needs, learning disabilities, or situations where cognitive impairment would likely affect spatial orientation or memory skills.

\section{Acknowledgments}

This work was funded was funded mainly by the Spanish Ministry of Economy and Competitiveness (MINECO) through the CHILDMNEMOS project (number: TIN2012-37381-C02-01) and confinanced by the European Regional Development Fund (FEDER). Other financial support was received from the Gobierno de Aragón (Departamento de Industria e Innovación), and Fondo Social Europeo for Aragón.

We would like to thank the following for their contributions:

- The "Escola d'Estiu" and especially Juan Cano and Miguelón Giménez. This work would not have been possible without their collaboration.

- Marina Vilella, Belén Santirso and Juan Fernando Martín for their collaboration in this work.

- The children who participated in the study.

- The "Área de Sistemas de Información y Comunicaciones (ASIC)" for letting us use its facilities during the testing phase.

- The reviewers and the editor for their valuable comments. 

Chapter 4

\title{
A Virtual Object-Location Task for Children: Gender and Videogame Experience Influence Navigation; Age Impacts Memory and Completion Time
}

Rodríguez-Andrés, D.; Méndez-López, M.; Juan, M.C.; Pérez-Hernández, E. (2018). A Virtual Object-Location Task for Children: Gender and Videogame Experience Influence Navigation; Age Impacts Memory and Completion Time. Frontiers in Psychology, 9:451. DOI: 10.3389/fpsyg.2018.00451, Impact Factor: 2.321 (2016)(Q1-Q2, relative position in Psychology, Multidisciplinary - SSCI: 33/129; difference with respect to Q1+0.75)

\begin{abstract}
The use of virtual reality-based tasks for studying memory has increased considerably. Most of the studies that have looked at child population factors that influence performance on such tasks have been focused on cognitive variables. However, little attention has been paid to the impact of non-cognitive skills. In the present paper, we tested 52 typically-developing children aged 5-12 years in a virtual object-location task. The task assessed their spatial short-term
\end{abstract}


memory for the location of three objects in a virtual city. The virtual task environment was presented using a 3D application consisting of a 120" stereoscopic screen and a gamepad interface. Measures of learning and displacement indicators in the virtual environment, 3D perception, satisfaction, and usability were obtained. We assessed the children's videogame experience, their visuospatial span, their ability to build blocks, and emotional and behavioral outcomes. The results indicate that learning improved with age. Significant effects on the speed of navigation were found favoring boys and those more experienced with videogames. Visuospatial skills correlated mainly with ability to recall object positions, but the correlation was weak. Longer paths were related with higher scores of withdrawal behavior, attention problems, and a lower visuospatial span. Aggressiveness and experience with the device used for interaction were related with faster navigation. However, the correlations indicated only weak associations among these variables.

\section{Introduction}

Loomis, Blascovich, and Beall (1999) reviewed the potential of immersive virtual environment (VE) technology for experimental psychology. They described its value as a tool in research on spatial cognition. They highlighted its advantages in terms of methodological issues, that are difficult to achieve in practice without this type of technological support (e.g., facilitating the control of the delivered stimuli, manipulating variables, recording measurements and allowing exposure to complex and natural-appearing environments). VEs have also become quite popular for their contributions to neuropsychological assessment. Measures of performance (e.g., correct responses and completion time) derived from tasks using VEs have shown moderate sensitivity in detecting cognitive impairments in clinical populations, especially in the assessment of visuospatial and memory skills (see the review of Negut et al. (2016). Some VEs have been used to study children's performance, reporting differences between typically-developing children and children with developmental issues (Bioulac et al. 2012; Broadbent, Farran, and Tolmine 2015; Courbois et al. 2013; Erez et al. 2013; Farran et al. 2015; Kalyvioti and Mikropoulos 2013). Therefore, virtual reality-based tasks currently play an important role in the field of child psychological assessment as an adjunct to standardized classical tests.

The study of human spatial cognition using VEs became quite popular by emulating virtual tasks based on animal mazes (e.g., Cánovas et al. 2008; Astur et al. 2004). Other virtual tasks simulated familiar places for humans 
(Maïano, Therme, and Mestre 2011; Purser et al. 2012; Burles et al. 2014). The VEs can be viewed on a computer screen (e.g., Astur et al. 2004; Merrill et al. 2016) or other virtual reality platforms, such as head-mounted displays (HMDs), which can provide a full $360^{\circ}$ view (Siemerkus et al. 2012). In a typical spatial task, the person controls their movements in the virtual space to memorize places, objects, or routes using a joystick (e.g., Astur et al. 2004; Siemerkus et al. 2012; Walkowiak, Foulsham, and Eardley 2015) or a keyboard (e.g., Purser et al. 2012; Merrill et al. 2016).

Virtual environments used for researching spatial navigation abilities in children have been very similar to those used for adult research (e.g., Hamilton et al. 2003; León, Cimadevilla, and Tascón 2014; Broadbent, Farran, and Tolmine 2015; Nys et al. 2015). Children have been asked to navigated the VE and then were tested on their ability to retrace routes or to memorize places or objects. The results found can be extrapolated to results obtained within real environments (e.g., Schmelter, Jansen, and Heil 2009). Also, these virtual tasks have been used to draw conclusions about difficulties in orientation in children with developmental disorders (e.g., Hamilton et al. 2003; Courbois et al. 2013; Fornasari et al. 2013; Broadbent, Farran, and Tolmine 2015).

Most of the studies looking at factors influencing children's performance in spatial tasks have been focused on cognitive variables such as visuospatial abilities (e.g., Nys et al. 2015), memory (e.g., Purser et al. 2012; Nys et al. 2015), executive functions (e.g., Purser et al. 2012), or navigational strategies (e.g., Bullens et al. 2010; León, Cimadevilla, and Tascón 2014). The impact of children's non-cognitive skills on spatial task performance has been less studied. van den Brink and Janzen (2013) considered the effects of self-care skills measured using the Vineland Screener. The authors found that there was a significant relation between adaptive functioning and the performance of 2 to 3-year-olds on a VR spatial task used for the assessment of orientation skills. They suggested that independence in everyday activities presented by some of the children was critical in improving their spatial knowledge because of a greater number of opportunities for exploring their spatial surroundings. Also, exploratory behavior was related to emotional factors in a study that tested children with autism (Fornasari et al. 2013) who were less active during free exploration of a virtual town. Children suffering from anxiety disorder also performed more poorly than control participants in a virtual Morris water maze (Mueller et al. 2009). They showed thigmotaxis behavior (i.e., the adaptive tendency to avoid exploring the central zone of a novel place) at the beginning of the test and higher numbers of heading errors and unsuccessful 
trials. Psychometrical measures of anxiety, but not depression, were related to the number of heading errors.

To our knowledge, there are no published studies about relationships between emotional factors and spatial performance in VEs in healthy children. We suggest that affective components and adaptive behavior could influence the performance of typically-developing children in a spatial task involving exploration of a VE. Previous studies performed in adults found that thigmotaxis behavior was positively correlated with affective components (Kallai et al. 2007). These results were obtained after controlling for gender differences in the levels of fear (i.e., women scored higher than men). Also, neuroticism and psychoticism traits had a negative impact on spatial performance (Burles et al. 2014; Walkowiak, Foulsham, and Eardley 2015). These studies yielded conclusions for young adults, but little is known about the relationships between these psychological variables and performance in the child population.

In the present study, we aimed to determine if the performance of typicallydeveloping children in an emotionally neutral virtual-based spatial task is related to their behavioral and emotional outcomes. To do this, we used a basic short-term memory test in which children were to learn the spatial locations of objects (i.e., the learning phase) and later were asked about the correct position of one of these objects (i.e., the testing phase). The VE of this virtual object-location (VOL) task consisted of a city square. To provide visual guidance, the square was surrounded by distal cues and proximal cues. The objects were associated to a place holder and located in the central area of the VE. The VE was presented using a 3D application consisting of a 120 " stereoscopic screen. The children could actively explore details required for orientation by traveling across the interaction area taking a first-person perspective. We chose a gamepad as the device for interaction because it has been preferred by children due to its playability (Rodríguez-Andrés et al. 2016). We tried to reduce the potential influence of individual differences in the experience with videogames and gamepads. For this reason, the participants were trained with the gamepad and performed a tutored trial of the task.

The VOL task was similar to the task used in Rodríguez-Andrés et al. (2016) in terms of the visual and procedural aspects; however, in the present study, we aimed to obtain information about how children's exploratory behaviors were. The present task assessed not only the ability of the children to recall the place of the objects, but also their way of exploring the interaction area of the VE. The aims of the study by Rodríguez-Andrés et al. (2016) were mainly to present the task, to validate the task for the assessment of spatial shortterm memory, and to examine the influence of the type of interaction used on 
the ability to recall the place of the objects, and the perceived usability and satisfaction of the children with the task.

We obtained objective performance measures of the participating children on the VOL task (i.e., learning and displacement indicators). We assessed their perception about the task (3D perception, satisfaction, and usability) and previous videogame experience. We also considered participant individual differences in the performance of small-scale visuospatial tasks (building blocks and visuospatial span), emotional outcomes (i.e., anxiety, depression, and aggressiveness), and behavioral outcomes (i.e., hyperactivity, withdrawal, and attention problems), which were obtained with a psychometric rating scale. We also considered the age and gender of the participants. The research questions are:

- Does age, gender, or previous videogame experience of the children affect their performance on the VOL task?

- Are there any significant relationships among performance of the VOL task and the user's variables (i.e., videogame experience, ratings about the experience with the VOL task, visuospatial skills, emotional and behavioral outcomes)?

We hypothesized that age would affect performance in the VOL task. We studied a wide age range, as the values of the learning indicators would be lower in children younger than 6 years. We did not expect to find an effect of gender on VOL task performance because of its low level of difficulty. The task involved remembering the locations of three objects that were shown sequentially with several proximal visual cues aiding orientation. Both boys and girls might use specific orientation strategies to solve the task. We did not expect to find an effect of videogame experience on task execution because the participants were trained before being tested. Finally, a higher ability for recalling objects in the VE would be linked with higher visuospatial skills on small-scale tests. The displacements made across the interaction area of the VE during performance of the task would be related to emotional and behavioral outcomes. Specifically, higher scores on anxiety would be related to a higher tendency to explore the boundaries of the VE. 


\section{Materials and Methods}

\section{Participants}

The participants were 52 right-handed, typically-developing children from 5 to 12 years old (22 girls and 30 boys; $\left.M_{a g e} \pm S D=8.06 \pm 1.60\right)$. They were divided into three age groups: preschool ( $5-6$ year olds; 5 boys and 4 girls); the first cycle of primary school (7-9 year olds; 18 boys and 13 girls); and the second cycle of primary school (10-12 year olds; 7 boys and 5 girls). They were recruited from a summer school. This final sample was selected after applying the inclusion criteria to a larger sample composed of 66 children. None of the participating children had visual or hearing impairments or had had a breech birth, required neonatal resuscitation, had a body temperature higher than $40^{\circ}$ in the first 5 years of life, had suffered a brain injury, had any impairment in motor performance, or were treated with a medication that could potentially impair their cognitive functioning. A questionnaire was completed by their parents concerning their development and medical history. The parents also completed the Movement ABC-2 Checklist (Henderson, Sugden, and Barnett 2012) to discard any motivational or emotional difficulty related to motor tasks. We used the Lang-Stereo-Test (Lang 1983) to check that the children could perceive 3D properly. All parents gave written informed consent before their children's participation. The study was conducted in accordance with the European Directive 2001/20/EC and the Helsinki Declaration for biomedical research involving humans. The University Ethics Committee approved the research protocol.

\section{The Testing Room and Instrumentation for the VOL Task}

The testing room consisted of a square room of about 20 square meters (Figure 4.1). The child was placed in the middle of the room facing one of the walls on which was mounted a 120-inch screen. We used two projectors to send two images to the screen from the back. Each of the two projectors had a linear vertical polarizer. There was a difference of $90^{\circ}$ between the directions of the two polarizers. The children wore linear polarized glasses to perceive the 3D sensation. These glasses had two vertical polarizers, one for each eye, that were aligned to match the directions of the projectors' polarizers. The interface used to control the child's movements in the VE was a PlayStation gamepad. We used Unity 3D as the game engine. 


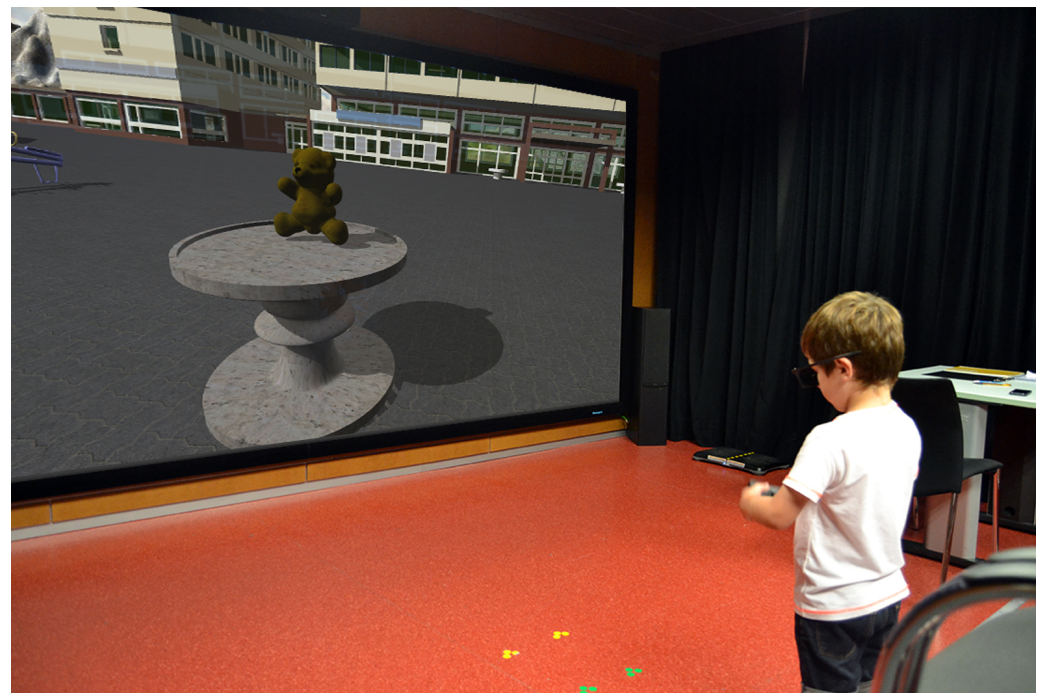

Figure 4.1: The testing room for the VOL task.

To run the application, we used a PC with an i7-4770k processor, 16 GB RAM memory, and a graphic card NVIDIA GTX770. The software and hardware used to develop the VOL task were described in Rodríguez-Andrés et al. (2016).

\section{The VOL Task}

The task consisted of a short-term memory test for object location. Briefly, the participant had to search for objects that were placed on tables distributed in certain locations of a VE. Then, he/she had to remember their locations in order to place them in their correct positions later. There was a narrator who guided the participant through all phases of the task with her voice. She told the child what to do each time (e.g., "Remember the location of the objects that you are going to see now"; "Approach it and push the button when its color changes"; "You have to put this object in its correct position"). In Section "Training Phases and VOL Trials," we briefly describe the phases of the VOL task. More details about the VOL task can be found in Rodríguez-Andrés et al. (2016). 


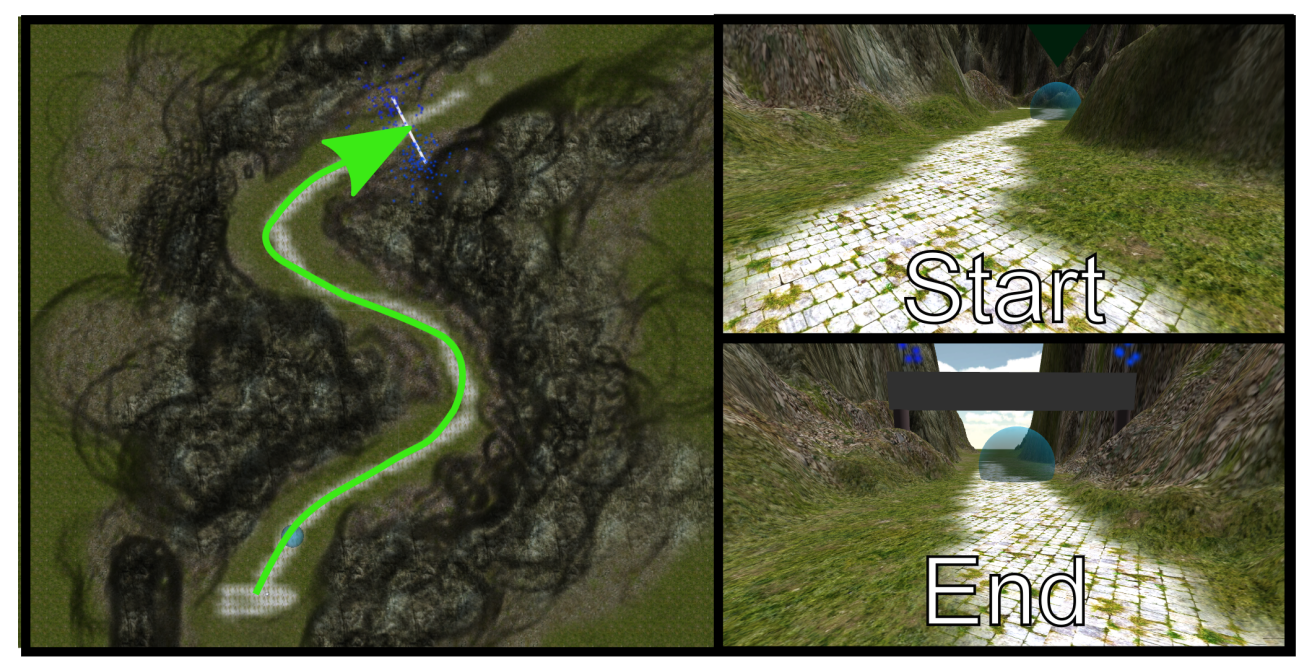

Figure 4.2: The VE in the mountains in the adaptation phase.

\section{Training Phases}

Before starting the trials of the VOL task, each child completed two separate phases: the adaptation phase and the tutorial phase. The aim of the adaptation phase was to familiarize the child with the interaction method. The child learned how to move inside a VE using the gamepad. In this phase, the participant was transported to a VE in mountainous terrain (Figure 4.2). Then, he/she had to follow a path across the mountains to arrive at a goal at the end of the path. Some arrows and bubbles showed the child which direction to follow. In the tutorial phase, each child completed a short tutorial about how to perform the VOL task. He/she learned what the goal of the task was and how to achieve it. This phase was like a trial of the VOL task (see section Vol trials) except for the fact that the child received a visual indication of the position of the object during the testing phase. The visual indication consisted of a vertical green arrow pointing to the position of the object. 


\section{The VOL Trials}

The VE of the VOL task was simulated as a city square. The square was surrounded by several buildings (Figure 4.3). The child could move within the limits of an interaction area of the city square (Figure 4.3A). The buildings were outside of the interaction area of the child and worked as visual cues to help orient the participant with spatial orientation (distal cues). Inside the square, there were eight common objects of a city (proximal cues), which also served as guidance (Figures 4.3A,B). We defined two separate areas within the interaction area: the peripheral area, and the central area (Figure $4.3 \mathrm{C}$ ). The peripheral area included a zone that was three meters away from the tables, whereas the central area included the area where objects were placed on tables (Figure 4.3C).

There were four VOL trials in the VOL task (see Figure 4.4). Each child completed these trials consecutively. The goal of these trials was to assess the children's short-term memory for object location. Each trial was divided into two separate phases: the learning phase, and the testing phase.

Short-term memories for visuospatial items were formed in the learning phase. In this phase, the child searched three gray tables with the aim of finding three hidden objects. These objects were shown one by one. The system guided the search process using a green arrow that pointed to one of the gray tables. The child had to walk to the table, and, when the child was close enough, the table changed color from gray to green, and the child could see the object on that table for $5 \mathrm{~s}$. The child had to repeat this process two more times to discover all of the objects. It is important to note that the children had to remember the objects they saw and where the objects were placed. At the end of each learning phase, the child returned to the center of the scene, and the $\mathrm{VE}$ was rotated $180^{\circ}$ from the original position before starting the testing phase. Therefore, idiothetic information could not be used as a reference for orientation.

The testing phase consisted of the retrieval of the short-term memories for the visuospatial items that were formed in the learning phase. In this phase, the system showed an object on the screen and the narrator asked the participant for the position of that object. The participant had to put the object in its correct position to complete the trial. The position of the tables and the objects varied in the four different trials of the VOL task as shown in Figure 4.4. We included a score screen to keep the children motivated. They received a star when they finished the tutorial phase and each of the four VOL trials, regardless of the quality of their responses. 


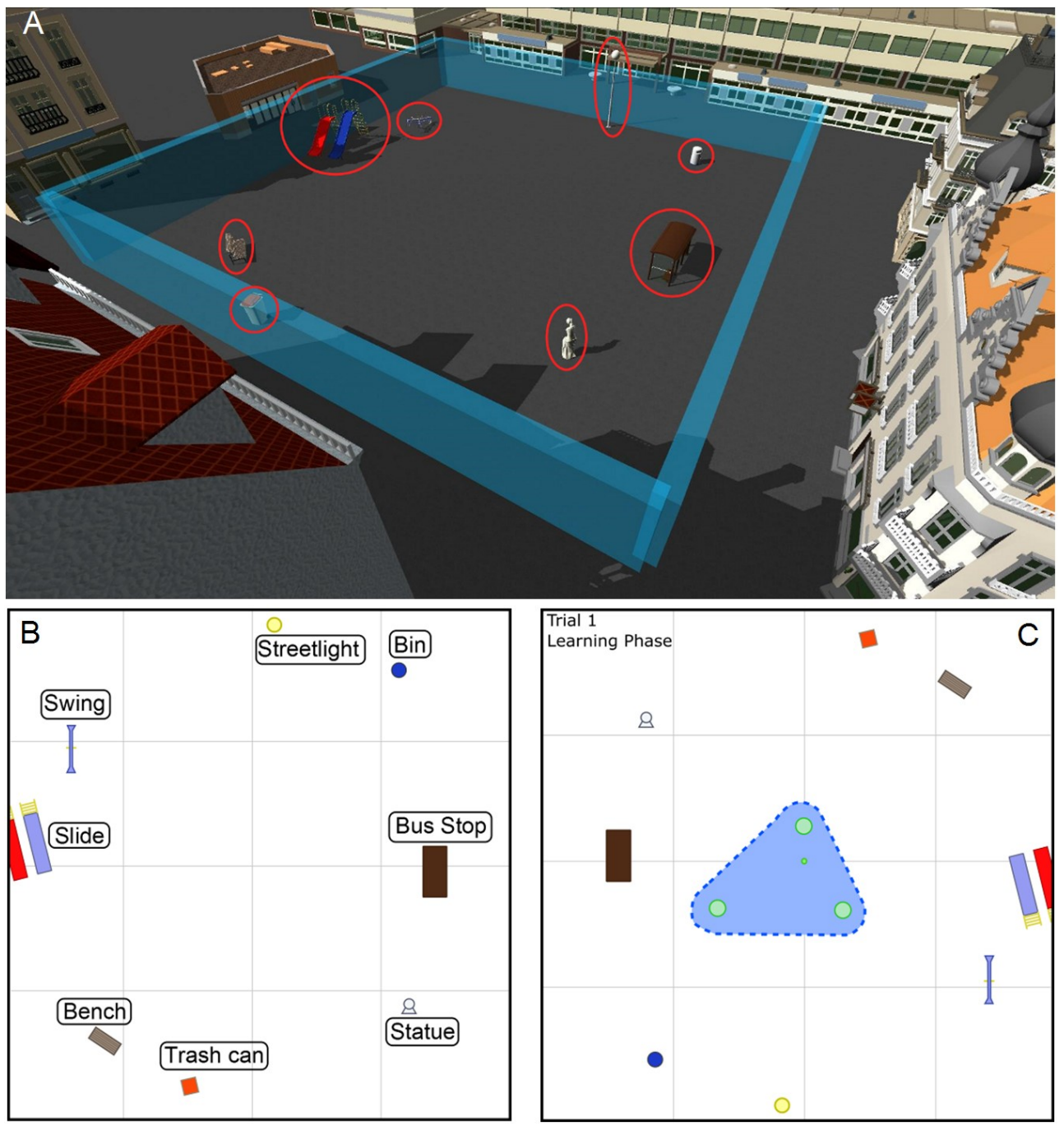

Figure 4.3: (A) The interaction area of the VOL task is delimited within imaginary blue walls, which are not visible to the participant. The objects that worked as proximal cues for orientation are indicated with red circles. (B) A schematic top view of the interaction area and the location of the proximal cues. (C) A schematic top view of the learning phase of Trial 1. An example showing the two separate areas: the peripheral area in white, and the central area in blue. The dashed blue line delimits the peripheral area. 


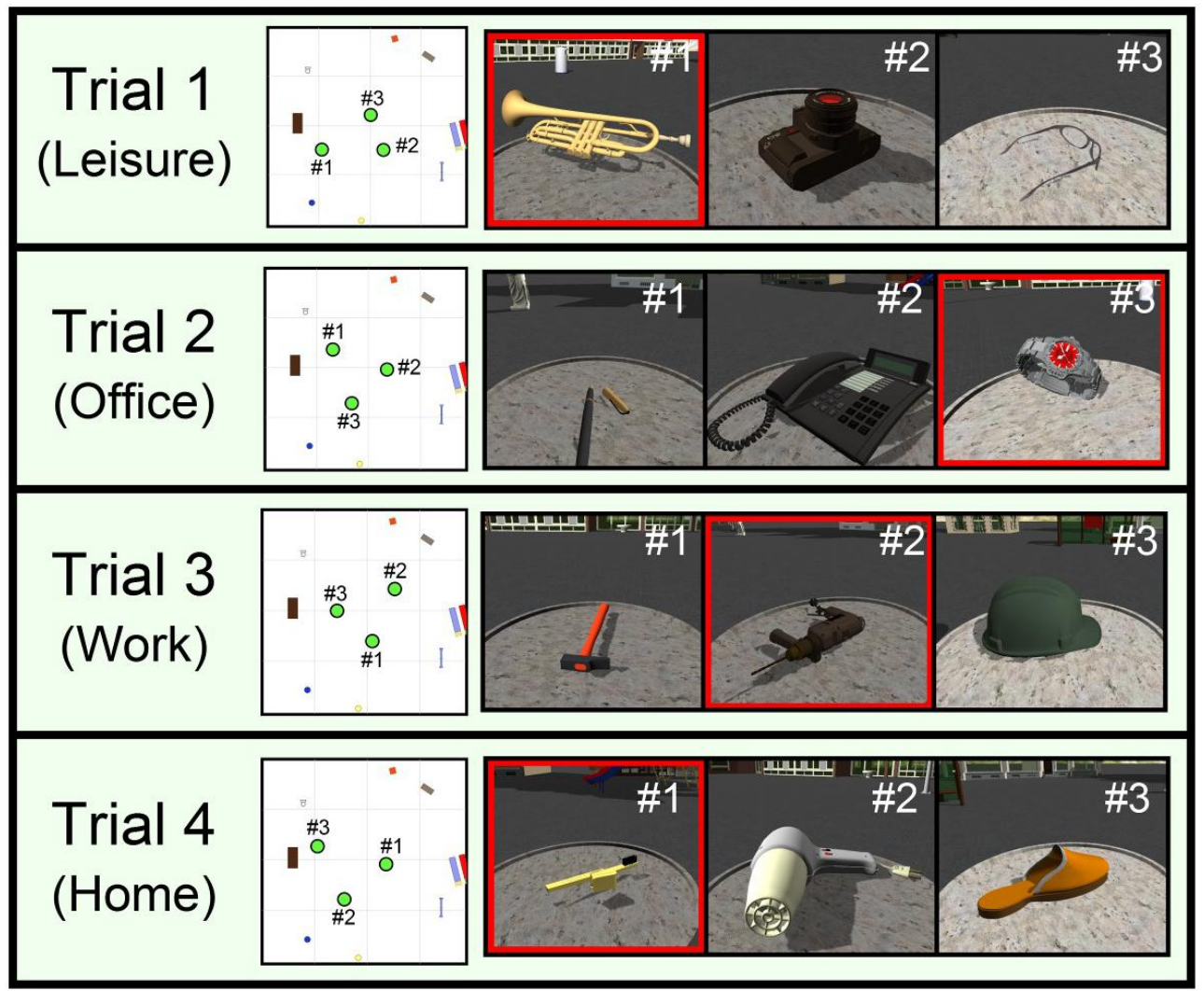

Figure 4.4: A general scheme of the four trials of the VOL task (Trials: 1-4), which shows the following information (from left to right): a schematic top view of the interaction area, and the location of the tables and the objects; an image of the objects numbered in order of appearance during the learning phase; and an image of the object asked about during the testing phase. 
Videogame Experience, 3D Perception, Satisfaction, and Usability Questionnaires

We designed a questionnaire to determine the participants' videogame experience, consisting of two items:

- "How often do you play with videogames on a PC or smartphone?"

- "How often do you play videogames with a gamepad?"

The children answered the two items using a five-point Likert scale ranging from "(1) Never" to "(5) Everyday". Also, the children gave their opinion about 3D perception during the performance on the VOL task by answering the statement.

- "At certain moments, the objects came out of the screen" using a fivepoint Likert scale ranging from "(1) Strongly disagree" to "(5) Strongly agree".

The questionnaires were adapted to children. The items of the questionnaires were filled in using text labels that were accompanied by graphical icons (Read 2008).

We collected information about the satisfaction and usability perceived by the children by using two questionnaires with five-point Likert scale items. The satisfaction questionnaire was made up of four items:

- "How much fun did you have?" response scale: "(1) None" to "(5) A lot"

- "I would invite my friends to play the game" response scale: "(1) Never" to "(5) Every day"

- "Would you play this game another time?" response scale: "(1) Never" to "(5) Every day"

- "Score the game from 1 to 5" response scale: "(1) Very bad" to "(5) Very good"

Finally, a usability questionnaire had two items:

- "Was the VOL task easy to play?" response scale: "(1) Very difficult" to "(5) Very easy" 
- "I always understood what I had to do" response scale: "(1) Strongly disagree" to "(5) Strongly agree"

\section{Spatial Ability Tests}

We used two classical psychometric tests to assess the children's basic visuospatial abilities. We obtained an index of their visuospatial span with the forward version of the Corsi Block Tapping Test (CBTT), and we used the backward version of the CBTT to collect a measure of their visuospatial working memory capacity (Kessels et al. 2000). We also assessed their visuospatial and visuomotor ability with the Block Construction subtest (BC) from the Nepsy-II battery (Korkman, Kirk, and Kemp 2014).

\section{Emotional and Behavioral Rating Scale}

We used the Parent Report form of the Behavioral Assessment Scale for Children (PRfBASC) (Reynolds and Kamphaus 1992) to assess their emotional and behavioral outcomes. PRfBASC is one of the most widely used behavior rating scales for the assessment of behavioral problems, emotional symptoms, and adjustment patterns in children across the following domains of functioning: Internalizing, Externalizing, and Adaptive Behavior. The PRfBASC consists of 130 items (3-6 years old) or 134 items (6-12 years old) about a child's behavior at home and in the community measured on a four-point Likert scale. In this study, we considered the following subscales of the PRfBASC: Anxiety, Depression, Hyperactivity, Aggressiveness, Withdrawal, and Attention Problems.

\section{Procedure}

The participants were tested individually in sessions of approximately $55 \mathrm{~min}$, which took place on the same day and between 9:00 A.M. and 2:00 P.M. They were randomly assigned to one of the following experimental conditions: Condition I and Condition II. In Condition I, the participants were tested with the Lang-Stereo-Test and then completed the questionnaire about videogame experience. Afterward, they performed the VOL task and then completed the questionnaires about 3D perception, satisfaction, and usability. Finally, they performed the CBTT and the BC. In Condition II, the participants performed the CBTT and the BC first and were then assessed with the remaining tests and questionnaires in the same order as described in Condition I. In the recruitment phase of the study (see section "Participants"), the parents completed 
the PRfBASC to obtain the emotional and behavioral measures. Before the child started, the child and his/her parents met the person responsible for the procedure, who accompanied the child during the whole session. The child and the experimenter talked for about $5 \mathrm{~min}$, until the child felt comfortable with the situation. Then, the parents left the room and the session began.

\section{Data Analysis}

We considered two variables that are related to the videogame experience questionnaire: (item 1) the child's previous experience in playing videogames, and (item 2) child's previous experience using the interaction method of the VOL task. We used the direct scores of these two items to calculate these variables. Similarly, we used the direct score of the 3D perception statement. For the satisfaction and usability questionnaires, we calculated the mean of the children's direct scores for each item of these two questionnaires in order to obtain a general measure of satisfaction and usability in performing the VOL task.

We considered five variables that are related to the performance of the VOL task: VOL Task Score, Total Distance, Total Time Average Speed, and Peripheral Distance. The VOL Task score is an indicator of visuospatial memory and involved the sum of the trials of the VOL task that were correctly performed (range: $0-4$ ). The Total Time consists of the time (in seconds) taken to complete the four trials of the VOL task. The Total Distance is the total distance (in virtual meters) traveled by the child in the four trials of the VOL task. The Average Speed is an indicator of the velocity (in virtual meters/sec) with which the child explored the VE. We calculated this variable by dividing the Total Distance traveled by the Total Time spent to perform the task. The Peripheral Distance consists of the distance traveled by the child in the peripheral zone of the interaction area in the four trials of the VOL task. For the variables: Total Distance, Total Time, Average Speed, and Peripheral Distance, we also calculated the values obtained by the sum of each phase of the VOL task separately (learning and testing).

For the measures of the visuospatial ability, we used the direct scores of the CBTT (forward and backward versions) and BC. Finally, the scores of the subscales measured with the PRfBASC-2 (Anxiety, Depression, Hyperactivity, Aggressiveness, Withdrawal, and Attention Problems) are reported as T-scores $(M=50, S D=10)$.

We applied the Shapiro-Wilk test (Shapiro and Wilk 1965) to check the normality distribution of the dataset variables. This test is especially powerful for 
samples of small size. The tests showed that only the Anxiety variable followed a normal distribution. We decided to perform non-parametric tests with the entire data-set which are more suitable with distributions of this kind. All analyses were done using the free Software R-Studio (Version 0.98.1079). The results were considered to be statistically significant if $p<0.05$.

\section{Results}

Table 4.1 shows descriptive statistics for the five variables that are related to performance in the VOL task. In the case of time, speed, path length and peripheral path length, we present descriptive statistics for both the learning and testing phases of the VOL task. Figure 4.5 shows the paths made by the children in the testing phases. Table 4.1 also shows the descriptive statistics for the participants' experience in playing videogames and using the interaction method, their 3D perception during the VOL task, and their perceived satisfaction and usability. Table 4.2 shows the descriptive statistics for the children's visuospatial abilities assessed with CBTT and CB, and their scores on the emotional and behavioral subscales of the PRfBASC-2.

\section{Effects of Age, Gender, and Previous Videogame Experience on Performance in the VOL Task}

The task performance variables were analyzed using the Kruskal-Wallis test with four factors: Gender, Age, Experience in Videogames, and Interaction Method Experience. Table 4.3 shows the results of the statistical analyses. The Kruskal-Wallis test revealed a significant effect of Age group on the VOL Task Score. The older children had higher scores than the younger ones $\left[\chi^{2}(2)=\right.$ 15.8, $p<0.01]$. A post hoc test showed significant differences between Age $5-6$ and $7-9(r=0.49, p<0.001)$, and between Age 5-6 and $10-12$ $(r=0.84, p<0.001)$. The test also indicated that the younger children spent more time completing the task $\left[\chi^{2}(2)=13.98, p<0.01\right]$. Figure 4.6A shows the influence of Gender and Age on the VOL Task Score. The gray and white boxes of the same age group are placed at the same height. The boxes are closer to the maximum score in the oldest group.

The Kruskal-Wallis tests also revealed that there was a significant effect of Age on the Total time spent to complete the task. The younger children required more time than the older ones $\left[\chi^{2}(2)=13.98, p<0.01\right]$. There are statistically significant differences related to the Gender factor. The girls spent more time than the boys to complete the task in all age groups (Figure 4.6B). 
Table 4.1: Mean scores (standard deviations) for the variables of the VOL task, videogame experience, 3D perception, satisfaction, and usability questionnaires $(N=52)$.

\begin{tabular}{lrr}
\hline Type of measure (range/unit) & $\mathrm{M}$ & $\mathrm{SD}$ \\
\hline Performance on the VOL task & 2.63 & 1.23 \\
VOL Task Score (0-4) & 498.12 & 219.67 \\
Total Time (seconds) & 337.80 & 132.54 \\
Total Time - learning phase (seconds) & 120.32 & 105.87 \\
Total Time - testing phase (seconds) & 5.16 & 1.92 \\
Average Speed (meters/second) & 4.67 & 1.39 \\
Average Speed - learning phase (meters/second) & 6.13 & 3.43 \\
Average Speed - testing phase (meters/second) & 2352.70 & 747.51 \\
Total Distance (meters) & 1598.73 & 452.03 \\
Total Distance - learning phase (meters) & 520.27 & 256.08 \\
Total Distance - testing phase (meters) & 712.43 & 753.31 \\
Peripheral Distance (meters) & 197.21 & 254.82 \\
Peripheral Distance - learning phase (meters) & 53.70 & 99.47 \\
Peripheral Distance - testing phase (meters) & & \\
\hline Videogame experience & 3.44 & 0.93 \\
Experience in Videogames (1-5) & 2.08 & 1.00 \\
Interaction Method Experience (1-5) & 3.56 & 1.41 \\
\hline Perception about VOL task & 3.39 & 1.09 \\
3D perception (1-5) & 4.44 & 0.48 \\
Satisfaction (1-5) & & \\
Usability (1-5) & & \\
\hline
\end{tabular}


Table 4.2: Mean scores (standard deviations) for the spatial ability tests and the subscales of the Parent Report form of the BASC-2 used in the study $(N=52)$. CBTT $=$ Corsi Block Tapping Test. $\mathrm{BC}=$ Block Construction subtest from the Nepsy-II. PRfBASC $=$ Parent Report form of the Behavioural Assessment Scale for Children.

\begin{tabular}{lrr}
\hline Test/Subscale & $M$ & $S D$ \\
\hline Visuospatial abilities & & \\
CBTT forward & 5.21 & 1.01 \\
CBTT backward & 4.62 & 1.00 \\
BC & 14.75 & 4.46 \\
Emotional and behavioral outcomes & & \\
PRfBASC-2 subscales: & & \\
Anxiety & 44.25 & 8.88 \\
Depression & 47.77 & 8.07 \\
Hyperactivity & 46.77 & 8.08 \\
Aggressiveness & 49.33 & 9.00 \\
Withdrawal & 48.48 & 9.22 \\
Attention Problems & 48.65 & 8.22 \\
\hline
\end{tabular}

This difference was especially high in the 5 to 6 year-old group. The girls in this group spent a mean of 16 min to complete the entire task.

To check if previous experience in videogames or previous experience with the interaction method influenced performance on the VOL task, we included these variables in the analyses. The Kruskal-Wallis tests show that only the average speed in the task is influenced by previous experience with videogames $\left[\chi^{2}(4)=\right.$ $12.25, p<0.01]$; the children who had more experience with videogames completed the task faster than those who did not have as much experience. Previous experience with the interaction method did not influence any of the variables considered $(p>0.05)$.

\section{Usability, Satisfaction and 3D Perception}

We performed one Kruskal-Wallis test for each VOL task measure of performance, using Usability, Satisfaction, and 3D perception as dependent variables. The results of these tests are shown in Table 4.4. The tests indicated that there were no statistically significant differences in the measures of the VOL task performance in relation to these variables. These results reflect that the users' perception of the task and the system did not influence the way users performed the task. 
Table 4.3: The results of the Kruskal Wallis tests for the variables related to the performance of the VOL task. The tests that reached significance are displayed in bold type.

\begin{tabular}{|c|c|c|c|c|}
\hline Variable & Factor & $\chi^{2}$ & $d f$ & $p-$ value \\
\hline \multicolumn{5}{|c|}{ VOL Task Score } \\
\hline & Age Group & 15.79 & 2 & $<0.001$ \\
\hline & Gender & 0.33 & 1 & 0.57 \\
\hline & Experience in Videogames & 3.37 & 4 & 0.50 \\
\hline & Interaction Method Experience & 7.85 & 3 & 0.05 \\
\hline \multicolumn{5}{|c|}{ Total Distance } \\
\hline & Age Group & 3.45 & 2 & 0.18 \\
\hline & Gender & 0.73 & 1 & 0.39 \\
\hline & Experience in Videogames & 0.96 & 4 & 0.91 \\
\hline & Interaction Method Experience & 1.64 & 3 & 0.65 \\
\hline \multicolumn{5}{|c|}{ Total Time } \\
\hline & Age Group & 13.98 & 2 & $<0.001$ \\
\hline & Gender & 7.11 & 1 & 0.007 \\
\hline & Experience in Videogames & 7.87 & 4 & 0.10 \\
\hline & Interaction Method Experience & 4.54 & 3 & 0.21 \\
\hline \multicolumn{5}{|c|}{ Average Speed } \\
\hline & Age Group & 3.67 & 2 & 0.16 \\
\hline & Gender & 4.08 & 1 & 0.04 \\
\hline & Experience in Videogames & 12.25 & 4 & $<0.01$ \\
\hline & Interaction Method Experience & 6.34 & 3 & 0.10 \\
\hline \multicolumn{5}{|c|}{ Peripheral Distance } \\
\hline & Age Group & 2.88 & 2 & 0.24 \\
\hline & Gender & 0.66 & 1 & 0.41 \\
\hline & Experience in Videogames & 1.44 & 4 & 0.84 \\
\hline & Interaction Method Experience & 0.65 & 3 & 0.88 \\
\hline
\end{tabular}


Table 4.4: Multifactorial Kruskal Wallis tests for the Usability, Satisfaction, and 3D Perception variables.

\begin{tabular}{llrrr}
\hline Variable & Factor & $\chi^{2}$ & $d f$ & $p$-value \\
\hline Usability & & & \\
& VOL Task Score & 0.05 & 3 & 0.99 \\
& Total Distance & 3.30 & 3 & 0.65 \\
& Total Time & 0.16 & 3 & 0.98 \\
& Average Speed & 2.95 & 3 & 0.40 \\
& Peripheral Distance & 2.75 & 3 & 0.43 \\
Satisfaction & & & \\
& VOL Task Score & 3.13 & 13 & 0.99 \\
& Total Distance & 10.41 & 13 & 0.66 \\
& Total Time & 9.97 & 13 & 0.70 \\
& Average Speed & 19.63 & 13 & 0.10 \\
& Peripheral Distance & 13.64 & 13 & 0.40 \\
3D perception & & & \\
& VOL Task Score & 7.02 & 4 & 0.13 \\
& Total Distance & 20.01 & 4 & 0.73 \\
& Total Time & 5.89 & 4 & 0.21 \\
& Average Speed & 1.84 & 4 & 0.76 \\
& Peripheral Distance & 3.61 & 4 & 0.46 \\
\hline
\end{tabular}




\section{Relationship between Performance on the VOL Task and the Participant's Outcomes}

To determine the relations between the different performance outcomes in the VOL task and the different scores obtained depending on videogame experience, perception of the VOL task, visuospatial ability, and emotional and behavioral variables, we performed a partial Spearman correlation extracting the influence of Age (Table 4.5).

Some displacement indicators in the VE showed significant correlations. There were significant direct correlations between the score obtained on the VOL task and two variables of visuospatial abilities in small-scale real space: the visuospatial span backward (CBTT backward; Spearman's $r=0.29, p=0.04$ ), and blocks construction (BC; Spearman's $r=0.43, p<0.01$ ). Furthermore, there were relations between the Total Distance $($ Spearman's $r=-0.27$, $p=0.04$ ) and Peripheral Distance (Spearman's $r=-0.31, p=0.03$ ) with the CBTT forward score. We also found that with for those with the less experience with gamepads, the completion time for the VOL task was longer (Spearman's $r=-0.29, p=0.04)$.

There were significant direct correlations between the Average Speed of navigation in the VE and experience with the gamepad interaction (Spearman's $r=$ $0.30, p=0.03)$. The same type of meaningful relationship was found between the Average Speed and the score on the Aggressiveness subscale (Spearman's $r=0.30, p=0.04)$. Longer navigation paths were related to higher scores on the Withdrawal (Spearman's $r=0.31, p=0.03$ ) and Attention Problem subscales (Spearman's $r=0.32, p=0.02$ ). In addition, longer navigation paths in the peripheral area of the VE were related to higher scores on the Withdrawal subscale (Spearman's $r=0.31, p=0.03$ ). Shorter path lengths in both the whole interaction area and in the peripheral area of the VE were related to higher visuospatial span scores measured with the CBTT forward (Spearman's $r=-0.31, p=0.03)$.

\section{Discussion}

We studied the performance of typically-developing boys and girls in a VE that was designed to test short-term memory for the location of objects placed in specific places in a city square (i.e., the VOL task). The VE worked as an open field, which included proximal and distal cues that are common in a city. The area of interaction was divided into two areas (i.e., central and peripheral). The VE was actively explored using a gamepad. We considered participants' 

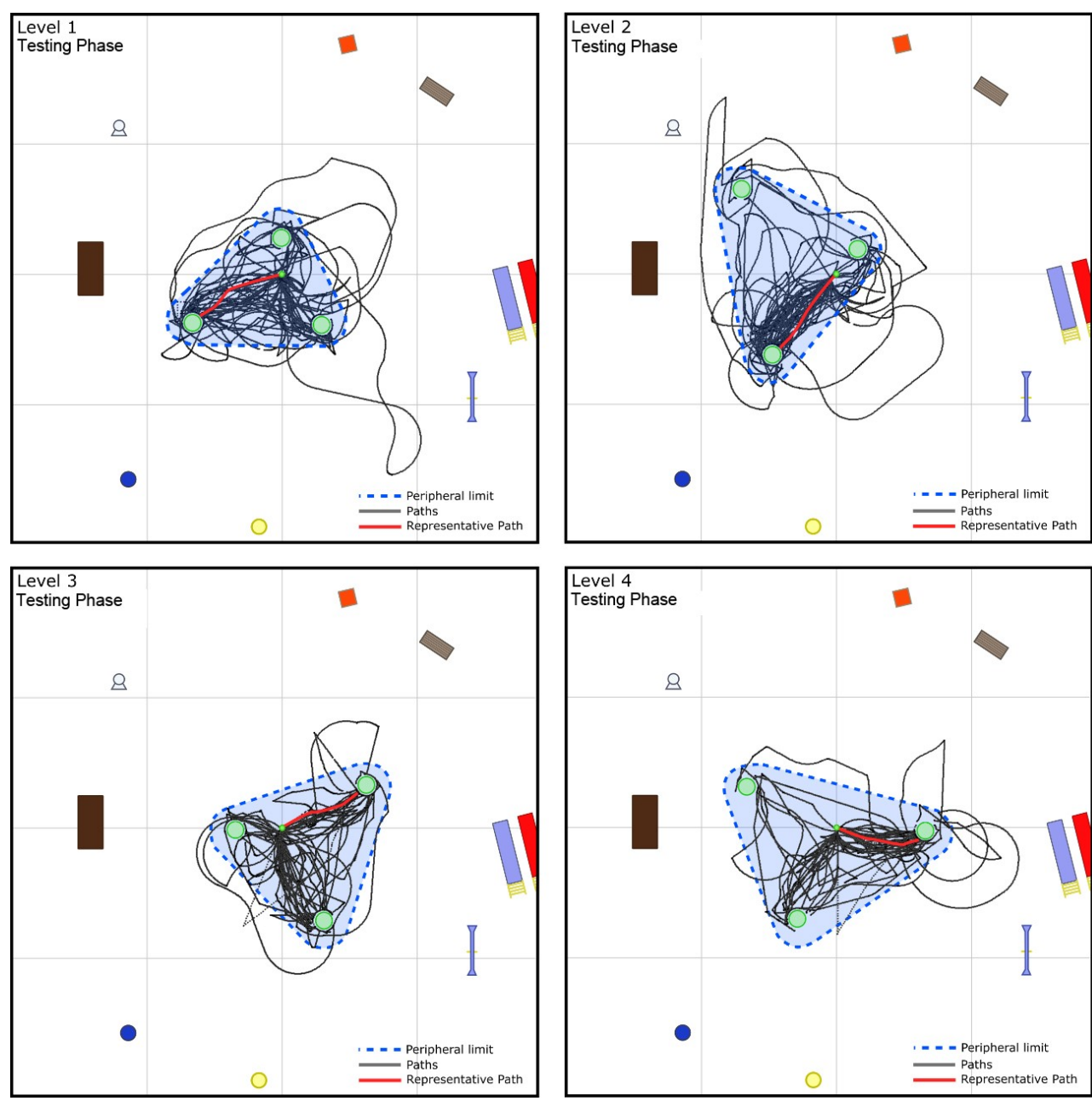

Figure 4.5: The paths made by the children in the testing phases of the four levels. 
Table 4.5: Partial Spearman correlations $(N=52)$. CBTT, Corsi Block Tapping Test; BC, Block Construction subtest from the Nepsy-II. The correlation coefficients that reached significance are displayed in bold type. The values are shown as $r(p)$.

\begin{tabular}{|c|c|c|c|c|c|}
\hline VOL task variables: & VOL Score & Total Time & Average Speed & Total Distance & Peripheral Distance \\
\hline $\begin{array}{l}\text { Videogame experience variables: } \\
\text { Experience in Videogames } \\
\text { Interaction Method Experience }\end{array}$ & $\begin{array}{l}0.06(0.06) \\
0.08(0.67)\end{array}$ & $\begin{array}{r}0.05(0.72) \\
-0.29(0.04)\end{array}$ & $\begin{array}{r}-0.07(0.63) \\
\mathbf{0 . 3 0}(\mathbf{0 . 0 3})\end{array}$ & $\begin{array}{l}0.00(0.99) \\
0.04(0.76)\end{array}$ & $\begin{array}{l}0.04(0.78) \\
0.08(0.57)\end{array}$ \\
\hline $\begin{array}{l}\text { Perception about VOL task: } \\
\text { 3D Perception } \\
\text { Satisfaction } \\
\text { Usability }\end{array}$ & $\begin{array}{r}-0.13(0.37) \\
-0.07(0.59) \\
0.00(0.94) \\
\end{array}$ & $\begin{array}{r}0.02(0.89) \\
0.02(0.90) \\
-0.15(0.29) \\
\end{array}$ & $\begin{array}{r}-0.07(0.63) \\
0.00(0.97) \\
-0.04(0.79) \\
\end{array}$ & $\begin{array}{l}-0.14(0.33) \\
-0.01(0.93) \\
-0.25(0.07)\end{array}$ & $\begin{array}{r}0.05(0.71) \\
-0.04(0.78) \\
-0.21(0.14) \\
\end{array}$ \\
\hline $\begin{array}{l}\text { Visuospatial ability variables: } \\
\text { CBTT forward score } \\
\text { CBTT backward score } \\
\text { BC score }\end{array}$ & & $\begin{array}{r}-0.14(0.31) \\
0.03(0.86) \\
0.01(1.00)\end{array}$ & $\begin{array}{r}-0.18(0.22) \\
0.14(0.33) \\
0.10(0.50)\end{array}$ & $\begin{array}{r}-0.28(0.04) \\
0.08(0.57) \\
-0.02(0.87)\end{array}$ & $\begin{array}{r}-0.31(0.03) \\
0.05(0.72) \\
0.05(0.71)\end{array}$ \\
\hline $\begin{array}{l}\text { Emotional and behavioral variables: } \\
\text { Anxiety } \\
\text { Depression } \\
\text { Hyperactivity } \\
\text { Aggressiveness } \\
\text { Withdrawal } \\
\text { Attention Problems }\end{array}$ & $\begin{array}{r}-0.10(0.47) \\
-0.08(0.56) \\
-0.05(0.71) \\
0.03(0.83) \\
-0.01(0.96) \\
-0.17(0.23)\end{array}$ & $\begin{array}{r}-0.18(0.19) \\
0.04(0.79) \\
-0.12(0.41) \\
-0.18(0.21) \\
0.11(0.43) \\
0.00(0.98)\end{array}$ & $\begin{array}{r}-0.01(0.92) \\
0.03(0.82) \\
0.09(0.52) \\
0.30(0.04) \\
0.11(0.44) \\
0.20(0.15)\end{array}$ & $\begin{array}{r}-0.02(0.87) \\
0.23(0.10) \\
-0.02(0.87) \\
0.21(0.13) \\
\mathbf{0 . 3 1}(0.03) \\
\mathbf{0 . 3 2}(0.02)\end{array}$ & $\begin{array}{r}0.05(0.71) \\
0.11(0.44) \\
-0.09(0.51) \\
0.10(0.49) \\
0.31(0.03) \\
0.10(0.49)\end{array}$ \\
\hline
\end{tabular}
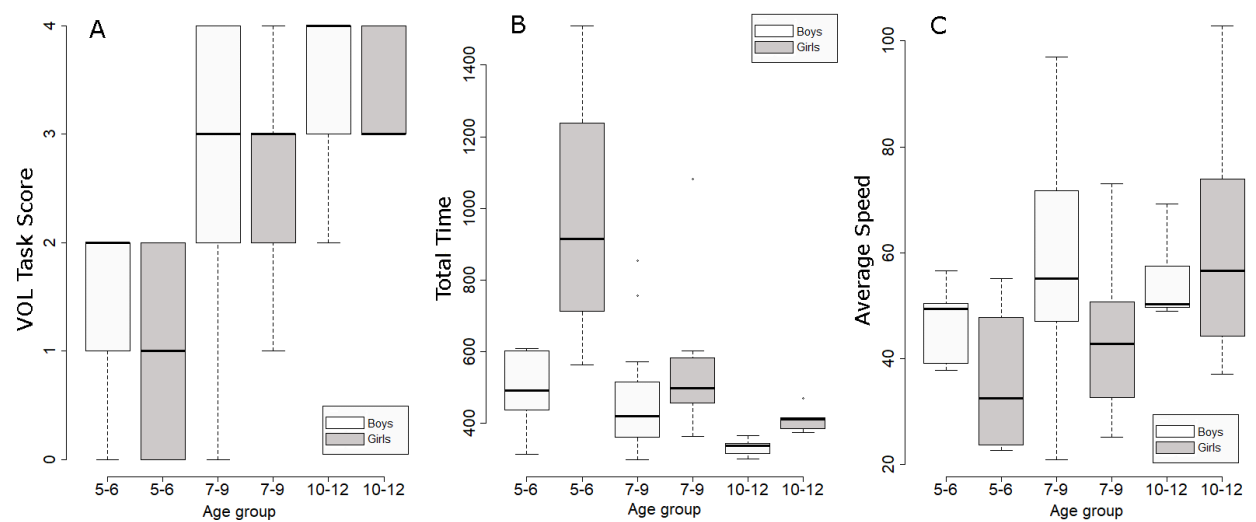

Figure 4.6: (A) Boxplots of the VOL Task Score; (B) Total Time; and (C) Average Speed of the three age groups separated by gender. 
age, gender, and previous videogame experience as potential variables that could influence success on the VOL task and the way of exploring the VE. We also examined relationships among the variables in performance on the VOL task and visuospatial, emotional, and behavioral outcomes.

The children's performance on the VOL task and their visuospatial skills correlated. The task also obtained high values of usability and satisfaction by the children. Hence, we considered that the task was appropriate for studying the spatial performance in a child population without disabilities.

As we hypothesized, the participants' age affected their performance on the VOL task. The task involved the retrieval of short-term memories of three visuospatial items. Also, the proximal and distal cues were important for orientation. The children could not use a strategy based on routes since their point-of-view position was rotated between the learning and testing phases. Their success was dependent on the creation and use of a mental map of the city square and/or links between the target and its surrounding cues. The lower scores of the youngest participants suggest that their visuospatial short-term memory and/or their spatial strategies were relatively weaker during this developmental period. This result is consistent with previous studies (Bullens et al. 2010; Purser et al. 2012; Nys et al. 2015; Mendez-Lopez, Perez-Hernandez, and Juan 2016; Merrill et al. 2016) and with the results found by RodríguezAndrés et al. (2016). They performed descriptive analyses taking into account the age of the participants and the VOL task score. They found a trend toward a better score on the task by the older children than the younger ones.

Age and gender also affected the total time spent on the task. This time was especially longer in the youngest group studied and was related to gender differences found in navigation speed (Figure 4.6C) and amount of previous experience with videogames. Children who played videogames frequently were found to navigate with greater speed, precision, and agility. The amount of experience with technological devices increases with the age (Sayers 2004). Also, girls play videogames less frequently (Terlecki and Newcombe 2005). Interestingly, experience with playing videogames influenced only performance variables that reflected the way in which the participant explored the VE but did not affect the score obtained. The VOL score was a measure of the visuospatial abilities of the children based on the correlations found between this outcome and the score obtained on the paper-pencil spatial tests. This result suggests that being less skilled in videogames does not influence the visuospatial ability of the user obtained in a virtual spatial task, but it does influence the speed of exploration of the VE. 
Familiarity with the interaction method used in the VOL task did not impair how the way the children explored the space; however, there was a trend toward a lower ability to locate the objects by the less experienced participants. Also, those more skilled with the gamepad were faster in the completion of the task and the navigation of the VE, but the strength of the correlation was weak. Our sample was not very familiar with the gamepad overall. The gamepad was the preferred device of interaction by children from 5 to 10 years old when compared with a device based on a natural user interface in a previous study (Rodríguez-Andrés et al. 2016). As noted by the mean score, our participants had played with a gamepad occasionally, but their frequency of use was less than once a week. Based on our informal notes, they played more frequently using touch-based interfaces in mobile devices, including tablets. We gave them training to reduce the possibility of differences in experience-based performance (Sandamas, Foreman, and Coulson 2009). The VOL task included two phases for practice with the interface (i.e., adaptation and tutorial). The first one involved practicing in a VE which was more difficult to explore than the VE of the learning trials. The $\mathrm{VE}$ of the adaptation phase required strong fine motor skills. These two phases gave the users training in the procedural aspects of the virtual navigation. In this way, we attempted to reduce any potential bias due to experiential factors in the interpretation of children's ability to locate objects.

The children's perception of the task experience and with overall system was very positive, especially for its usability aspects. The children gave a score close to maximum on the usability questionnaire; he means were 4 on a scale from 1 to 5. This result shows that the task was easy for them to perform. Three reasons for the high usability level include (1) the procedure aimed to facilitate the familiarity and comprehension of task phases, (2) the users were habituated to the interaction system prior to being tested, and (3) the children appreciated the innovative nature of the system. For example, the 120-inch stereoscopic screen, wearing polarized glasses, and the sense of immersion in the virtual city were novelties for most if not all of the children (Wells et al. 2010). However, we suggest that novelty alone is unlikely to influence the positive scores. If that were the case, the children would have given the maximum score on the satisfaction and 3D perception questionnaires. All of the children had stereoptic vision, but their 3D perception was not highly positive considering their mean rating of the experience (3.56 out of a maximum of 5). Similarly, the children were satisfied with the task, but some aspects of the task might have increased the perceived satisfaction more than others. The task provided motivating feedback after the completion of each trial regardless of the quality of execution. This was to prevent any frustration that might have been caused 
by a feeling of inadequacy and to keep the children engaged throughout the task. Despite this, the children gave the task a relatively high score (3.39 out of 5).

As we mentioned above, boys were more skilled than girls in the exploring the VE. However, contrary to what we expected, boys did not outperform girls in their ability to locate the virtual objects. The similar performance between boys and girls was also found in several studies in which children were trained in a navigational short-term memory task (Juan et al. 2014; León, Cimadevilla, and Tascón 2014; Piccardi et al. 2014; Méndez-López et al. 2009). Also, Rodríguez-Andrés et al. (2016) did not find significant differences between 5 and 10-year old boys and girls in their ability to locate the objects in the task. They performed similarly regardless of the type of interaction used (i.e., natural interaction or gamepad). The level of difficulty of the VOL task was low in terms of its VE and the memory load required. The spatial layout of the VE had proximal and distal cues guiding orientation. All of these cues could be seen from any viewpoint of the interaction area by the rotation of the VE during the exploration. In addition, the task requirement was to store three spatial locations temporarily that had been sequentially presented. The results agree with those of León, Cimadevilla, and Tascón (2014) who suggested that gender differences emerge only in spatial tasks that are more challenging.

We found significant correlations between task performance and children's visuospatial abilities in some paper and pencil spatial tests. The moderate strength of the correlation found between the VOL score and the score on the BC subtest indicates that the success in object location in our task is related to the general ability to calculate position and directionality (Korkman, Kirk, and Kemp 2014). It is also related to spatial working memory, but to a lesser extent as indicated by the weak correlation found between the VOL score and the score on the CBTT backward subtest. High scores on this subtest reveal good skill in holding in mind and manipulating a large number of visuospatial items (Kessels et al. 2000; Korthauer et al. 2017). We suggest that the mental manipulation of spatial representations is a key factor in solving our virtual task because there was no correlation with the simple ability to maintain spatial information in short-term memory. This supports the relevance of executive functions in working memory tasks involving spatial relations (Purser et al. 2012; Korthauer et al. 2017). It is also interesting to note that those participants with lower spatial spans executed longer path lengths in the VE, but the strength of the correlation was weak. The spatial span measure is affected by attentional capacity (Kessels et al. 2000), thus the result could also be interpreted as reflecting the relation between execution of longer paths and 
increased attentional difficulties. Those children that are more prone to distraction might be less able to navigate efficiently to a spatial target. Thus, the level of the participants' attentional capacity could be an important factor to be considered in spatial task performance, as discussed by Farran et al. (2015).

Contrary to what we expected, we did not find correlations between anxiety measures and displacements within the peripheral area of the VE. We propose three possible explanations for this result:

- The children scored within the normal limits in all emotional and behavioral outcomes considered, whereas previous studies were conducted using samples with clinical symptoms (Burles et al. 2014; Mueller et al. 2009).

- Our VE was emotionally neutral, and we gave children the optimal conditions to reduce anxiety regarding the testing situation (i.e., an initial familiarization with the experimenter and positive reinforcement during the task).

- Our VE target items were all in the same space. A more complex environment with several spaces that are not accessible at first sight might be more prone to reveal significant correlations with anxious behavioral traits.

Nevertheless, withdrawal behaviors were related to an increase in the exploratory behaviors in our sample, but they did not affect spatial learning or the time spent on the task. It might be suggested that the children withdraw made an intense exploration of the VE in order to achieve a good spatial representation. Fornasari et al. (2013) found an effect of withdrawal on the exploration of a virtual city. Contrary to what we found, this behavior was related to a reduction in the exploration of the $\mathrm{VE}$, but the differences between these results could be explained by the populations studied. In the case of Fornasari et al. (2013), they studied a clinical population of children with autism. Based on levels of withdrawal within the normal limits, we can speculate that withdrawal might have a negative impact on social outdoor games. This result partially supported the relevance of previous experiences in spatial behaviors proposed by other authors (e.g., Lawton and Kallai 2002).

Finally, those children who are more prone to aggressive behaviors navigated the VE faster, but there was no significant correlation with time savings. This result is in line with studies confirming that the feeling of anger predicts faster motor behavior (e.g., Deffenbacher et al. 2003; Roidl, Frehse, and Hoger 2014). 
The present research has some limitations. First, our task tests spatial shortterm memory learning for three locations in a VE that works like an open field. The level of difficulty is low. It would have been interesting to compare results with those obtained in a task that was more difficult and a VE that was more complex. The second problem is related to the sample. It would have been desirable to increase the number of participants in each age group, especially in the youngest group.

The VOL task presents a VE in which participants use their navigational competencies and their spatial short-term memory for the location of objects. The key factor in an object-location task is the possibility to mentally represent a spatial configuration of interrelated objects. We used three objects because previous research has tested adults in spatial tasks with three or four objects (Zimmer et al., 2003; Iachini et al., 2009), and, from 5 years of age, a person is able to recall the location of 2-3 objects (Mendez-Lopez, Perez-Hernandez, and Juan 2016). The VOL task is attractive for children and is also challenging for adults. We considered that this is a positive aspect of this task because the VOL task provides an opportunity to increase knowledge about spatial memory and navigation and to directly compare these skills in participants of all ages. However, this aspect also puts us at a disadvantage in determining the effects of individual factors in spatial performance. If the task had incorporated more objects that would make it more difficult to perform, there might have been gender effects in favor of the boys. As we have discussed above, the difficulty of a spatial task is a key factor in the existence of gender differences (León, Cimadevilla, and Tascón 2014). Also, we hypothesize that an increase in the number of objects to recall would have negatively affected the scores on satisfaction and usability given by the younger children because it would be very difficult for them to perform it. In addition, their exploratory behavior would have been more prone to reveal significant correlations with anxiety or withdrawal behaviors.

\section{Conclusion}

Age affected the spatial short-term memory for the location of three objects in a virtual city in children between the ages of 5 and 12 years. Three factors contributed positively to improving the accuracy of the children's performance during the navigation: age, being male, and having more experience with videogames. There were weak associations among variables which showed that the individual differences in visuospatial skills correlated mainly with the ability to recall objects' positions. Behavioral and emotional variables were 
not related to object location memory. However, three variables were associated with differences in the exploration of the VE, namely: levels of attention, aggressiveness, and withdrawal.

\section{Funding}

This work was funded mainly by the Spanish Ministry of Economy, Industry and Competitiveness (MINECO) through the CHILDMNEMOS project (TIN2012-37381-C02-01) and co-financed by the European Regional Development Fund (FEDER). Other financial support was received from the Generalitat Valenciana (Conselleria d'Educació, Investigació, Cultura i Esport) through the grant for consolidable research groups (AICO/2017/041), the Gobierno de Aragón (Departamento de Innovación, Investigación y Universidad), and the FEDER "Construyendo Europa desde Aragón".

\section{Acknoledgments}

We would like to thank the following for their contributions James F. Juola, the "Escola d'Estiu" and the ETSInf for letting us use their facilities. 
Part III

Discussion 



\title{
Chapter 5
}

\section{Discussion}

\author{
"Success is a science; if you have the conditions, you get the \\ result" -Oscar Wilde
}

\section{VR system for the assessment of spatial memory}

The work of this thesis related to the assessment of spatial memory is part of the CHILDMNEMOS project. As mentioned in the introduction section, the main objective of CHILDMNEMOS was the design, development and validation of different AR/VR systems to assess spatial memory. All the tasks developed in CHILDMNEMOS included an important difference with respect to the tasks that had been used to date and it is the user's physical movement in the real environment. In one of those works, AR was used (Juan et al. 2014; Mendez-Lopez, Perez-Hernandez, and Juan 2016). In another work (Loachamín-Valencia et al. 2017; Loachamín-Valencia et al. 2018), auditory stimuli were used. The work most related to this thesis (Cárdenas-Delgado et al. 2017b; Cárdenas-Delgado et al. 2017a) used different devices to those used to date (visualization system and the device for the physical movement), the virtual environment was different (a maze), the visuospatial cues were different (proximal cues) and the sample was also different (adults).

VR has already been used for the same purpose. However, those VR systems often introduce the users into an environment in which they can move and interact by using traditional devices (e.g., computer screens, mouses or keyboards) (Maguire, Nannery, and Spiers 2006; Koenig et al. 2011; Cáno- 
vas, Fernández-García, and Cimadevilla 2011; Cimadevilla et al. 2011). This not natural interaction could affect the correct performance on the task (Foreman 2010; Loomis, Blascovich, and Beall 1999). However, as computer-based systems, those systems offers several benefits:

- The presentation of stimuli, the time of appearance and its duration can be controlled. Those aspects are very important for assessment.

- The system can assess the user in an objective way (i.e., path, response time and accuracy).

Therefore, our VR system for the assessment of spatial memory is different to previous works:

- It combines stereoscopy and user's physical movement.

- It uses a different visualization system and a different device for the physical movement not used to date.

In the design phase, we tried to design an interface that was as unobtrusive as possible so that the user could focus on the task. We decided not to include an avatar of the child in the virtual environment to avoid distracting the child from the main objective of the task. As the target group were children, we discarded the use of HMDs. Some manufacturers of HMDs show health and safety recommendations that suggest an age limit $(13+)$ for their use. HMDs are physically designed for adults. They are not ergonomic (big and heavy). The distance between the user's eyes (pupils) is also important for a good VR experience and it can be adjust in most of the HMDs. With the aim of selecting the visualization system as ergonomic as possible, we discarded HMDs and chose a large stereoscopic screen (with passive glasses). We decided to include walking motion to induce a more realistic experience for the users while they were exploring the virtual environment. Recent studies have indicated that there are differences in the dynamics of acquisition of landmark-referenced (allocentric) knowledge relative to view-referenced (egocentric) knowledge (Zhang, Zherdeva, and Ekstrom 2014). We designed the system to ensure that all children used a landmark-referenced acquisition. At the end of each search phase, the child returned to the centre of the scene, and the virtual world was rotated $180^{\circ}$ from the original position before starting the second phase. This implies that the egocentric components of navigation did not provide any useful information and only the allocentric reference frame was valid for an adequate orientation. 
For the validation, two studies were carried involving healthy children. A total of 160 children ( 5 to 10 years old) participated in the first study. A total of 52 typically-developing children aged 5-12 years participated in the second study. The participants performed our task and a traditional test, the Corsi Block Tapping Test, was also administered (Kessels et al. 2000). The general conclusions for these two studies are discussed below.

Correlations were found between our task and traditional methods (the Corsi Block Tapping Test (backward and forward versions) and the Bock Construction subtest from the Nepsy-II), indicating that our task has proven to be a valid tool for assessing spatial memory and the ability to calculate distances and positions in children by combining stereoscopy and user's physical movement. These correlations are in line with our previous works for assessing spatial memory using only visual cues (Juan et al. 2014; Mendez-Lopez, PerezHernandez, and Juan 2016; Cárdenas-Delgado et al. 2017b) or auditory stimuli (Loachamín-Valencia et al. 2017; Loachamín-Valencia et al. 2018) that also obtained correlations between our previous tasks and traditional methods. This result is also in line with other previous works that have demonstrated that VR can be used as assessment tool (e.g., Vallejo et al. 2017) or for diagnosis (e.g., Tarnanas et al. 2014).

With regard to the interaction type, our second study showed that there were no statistically significant differences regarding the score obtained in our task based on the interaction used (inactive condition vs. physical active condition). Although unexpected, this is a good result because it means that the task is well suited for the assessment of spatial memory and that the two interaction types can be used for this purpose. Moreover, our task can also be used by children with reduced mobility (McComas, Pivik, and Laflamme 1998; HillBriggs et al. 2007). In another of our works (Cárdenas-Delgado et al. 2017b), the result was different. In that work (Cárdenas-Delgado et al. 2017b), the performance on the task was better in the participants who used a gamepad (inactive condition) than in the physical active condition (pedaling in a bike). That result could be influenced by the difficulty when pedaling with the HMD on and also having to handle the handlebar. Besides, these studies underline the relevance of considering and comparing different types of interaction based on active conditions. Not only the type of interaction used influences the performance of the task, but also the procedure by which the user interacts during the task.

With regard to gender differences in the task score, the results indicated that there were no statistically significant differences for gender. Moreover, the classical test, the Corsi Block Tapping Test, did not show any statistically sig- 
nificant difference. The similar performance between genders may be supported by other studies in which there were no statistically significant differences in gender when the spatial memory was tested on children (Alloway, Gathercole, and Pickering 2006; Juan et al. 2014; Piccardi et al. 2014; León, Cimadevilla, and Tascón 2014). Also, our results pointed out the importance of the level of difficulty of a spatial task when studying gender differences. The difficulty of our task is low in terms of memory load. The user had to remember the location of three objects. The score obtained by boys and girls in the task supported the previous findings obtained with spatial tasks of low load (León, Cimadevilla, and Tascón 2014; Mendez-Lopez, Perez-Hernandez, and Juan 2016). In addition, our results showed two facts related to gender differences in spatial tasks. The first, the importance of considering different factors in the spatial performance. The second, the importance of research into how these factors influenced differently depending of the variables of spatial performance considered. The speed of navigation was lower in the girls, especially in the youngest. The difference was modulated by the gender differences found in the experience with playing videogames, which negatively affect the girls. This result is in line with Terlecki and Newcombe (2005). Based on our studies, the experience with playing videogames is a factor that influenced navigation but no spatial memory ability. Therefore, our results regarding gender are in line with the conclusions reached by those works and highlight the importance of a detailed analysis of the performance of the user.

With regard to usability and satisfaction, our studies have shown that the use of the inactive condition (gamepad) did not differ significantly from the physical active condition for the usability and satisfaction questions. Our explanation for this result is that most children are "digital natives" and are already familiar with standard interaction methods. Thanks to the incorporation of Wii and Kinect ${ }^{\mathrm{TM}}$, more and more children have also become familiar with NUI interaction. Therefore, their mastery of current trends, their ability to adapt to any technological change, and the design of our task have all contributed to making the two types of interaction were less noticeable for them. However, $62 \%$ of the participants indicated that the gamepad was easier to use. The results obtained by Rauterberg (1997) are in line with our results. Rauterberg (1997) found that the users rated touch and mouse interactions as being easier than the custom-made digital playing desk. Our explanation for our result is that even though interaction with the NUI is more natural, users must be aware of what they are doing with their feet and hands, whereas with the gamepad they only have to think about what they are doing with their hands. 

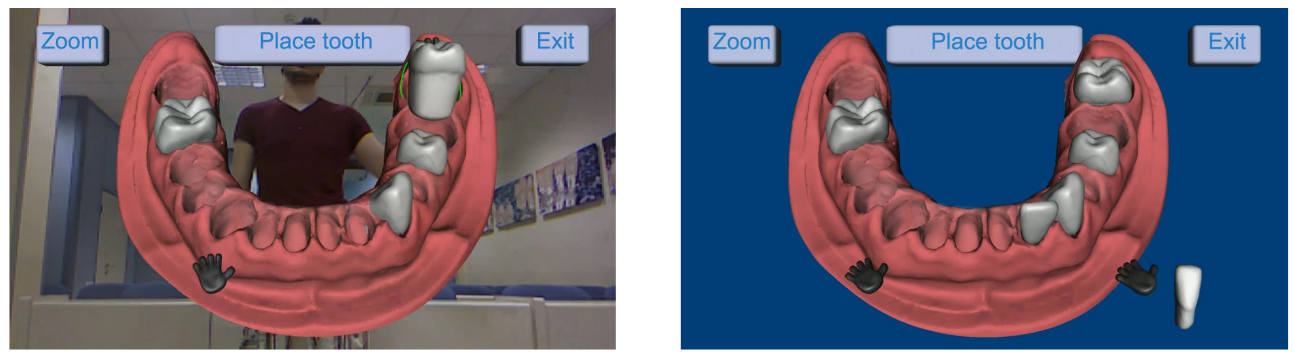

Figure 5.1: Left, the real-world background version. Right, the neutral background version.

This thesis supports studies that showed the influence of emotional variables in the assessment of spatial performance (Mueller et al. 2009; Burles et al. 2014; Walkowiak, Foulsham, and Eardley 2015). As far as we know, it is the first time that emotional outcomes and their relationships with spatial performance in an emotionally neutral VR task were studied in typically developing children. We concluded that the levels of aggressiveness and withdrawal affect negatively the exploration of a virtual environment, even when these levels are within the non-clinical range. This conclusion has direct implications on the design of future research about VR and navigation in healthy populations. It will be particularly essential to accustom the user to the testing condition to minimize the impact of emotional traits on overall outcomes.

\section{VR system for dental learning}

As mentioned in the introduction section, this VR system is not the core of the thesis. However, with it, the required knowledge for facing the main development was acquired. In this case, a VR system with two different backgrounds for learning teeth morphology was designed, developed and validated. Figure 5.1 shows the real world and the neutral backgrounds. For the validation, a total of 33 dentistry students participated in the study.

With regard to the improvement of knowledge, we compared students' initial knowledge about tooth morphology and their knowledge after using our system. The results showed statistically significant improvement in knowledge that corroborate that students increase their knowledge about teeth morphology using our system. On another of our previous works, we demonstrated that the improvement in knowledge is also statistically significant when the students play in pairs and also in large groups (up to 12 children) (Martín-SanJosé et al. 2015). These results are in line with previous works that have argued for 
the immense potential of educational computer games in helping students to improve their learning performance (e.g., Hwang and Wu 2012; Martí-Parreño, Méndez-Ibáñez, and Alonso-Arroyo 2016).

The real-world background did not offer statistically significant differences with regard to the neutral background. Although unexpected, it is an excellent result because it means that the game is well suited for learning outcomes and that the two backgrounds can be used for this purpose. The results of the $\chi^{2}$ test also indicated that the students preferred the neutral background for learning activities. Even though there were no statistically significant differences between the two backgrounds, the students' comments gave us information about a key fact: The background distracted them from their main task. These data, the opinion of the professors, and the comments of the students indicated that the real-world background was identified as being more suitable for leisure activities and that the neutral background distracted less from the main task.

In relation to the depth perception, the autostereoscopy screen gave the students the feeling of being able to touch the 3D elements. The main problem in the experience was that when the users were perceiving the 3D and they moved a little, they lose the focus and they had to move the head to find it again. This fact caused a strange sensation and influenced in the loss of concentration in the task and in the perceived quality of the experience. This problem is solved in current headsets such as Microsoft HoloLens or Magic Leap. Promising 3D imaging methods that improve the 3D experience are light-field imaging and electroholographic imaging. These methods provide a continuous parallax which is a core requirement of fulfilling the natural viewing condition, and a large focusable image depth (Son et al. 2017). Therefore, with these or new methods, and current and new headsets, for sure that can be developed very interesting systems for learning as well as for many other purposes. 
Part IV

Conclusions 



\section{Chapter 6}

\section{Conclusions}

\section{Conclusions}

In this thesis, two systems that combine VR and NUI have been designed, developed and tested. The first system used an autostereoscopic display and Kinect ${ }^{\mathrm{TM}}$ for gesture interaction. With the development of this first system, we acquired the necessary knowledge to develop the second system for the assessment of spatial memory in children. In the second VR system, we combined a large stereo screen with NUI (using a Wii Remote ${ }^{\mathrm{TM}}$ control and a Wii Balance Board ${ }^{\mathrm{TM}}$ ). The user moved in the virtual environment by physically walking on a Wii Balance Board ${ }^{\mathrm{TM}}$. A change in direction was achieved by turning a wireless steering wheel with a built-in Wii Remote ${ }^{\mathrm{TM}}$ control. The task was displayed on a large screen with 120 inches. Passive 3D was used for the visualization. The user had to wear linear polarized glasses to have the depth perception.

The virtual environment consisted of a city square that was surrounded by several buildings (distal cues), and eight visual cues inside the city square (proximal cues). The cognitive task comprised six levels: an interaction adaptation level, a habituation level, and four levels for the main task. The goal of the levels for the main task was to assess children short-term memory for object location in the virtual environment. Each level was divided into two phases. In 
the first phase, called the searching phase, the users should move through the environment looking for three objects that had to remember as well as their positions. In the second phase, the saving phase, the screen showed an object and the child had to find it.

In this thesis, two studies were carried out that focused on studying and comparing different factors and performance measures between data collected with the task and classical methods for testing memory skills. We also assessed other aspects such as usability and satisfaction with the task. To our knowledge, this is the first work in which is combined a large stereo screen and physical movement for the assessment of spatial memory. The development of new tasks for neuropsychological assessment represents an alternative for the assessment of spatial memory. Our task and other similar tools can be used for the assessment of the spatial memory as well as for training.

The conclusions of the three studies are described as follow:

Study 1. Dental Learning in Higher Education.

- The students showed statistically significant improvement in knowledge about teeth morphology using the two background modes. Result that corroborates the first hypothesis.

- The real-world background did not offer statistically significant differences with regard to the neutral background. Result that does not corroborate the second hypothesis. As explained above, this unexpected result indicates that our system is well suited for learning teeth morphology using the two background modes.

Study 2. MnemoCity Task for assessing spatial memory.

- There were no statistically significant differences regarding the task score when using the two types of interaction (inactive condition vs. physical active condition). Result that does not corroborate the third hypothesis. As in the previous study, this unexpected result implies that the task is well suited for the assessment of spatial memory using the two interaction types.

- There were no statistically significant differences regarding the task score for gender. Result that corroborates the fourth hypothesis.

- Correlations were found between our task and traditional methods (the Corsi Block Tapping Test (backward and forward versions)), indicating 
that our task has proven to be a valid tool for assessing spatial memory. Result that corroborates the fifth hypothesis.

Study 3. MnemoCity Task. Gender and videogame experience influence navigation; Age impacts memory and completion time.

- Age affected the spatial short-term memory for the location of three objects. The task was not easy to learn for the younger children. They were not able to remember the location of all of the objects trained. Result that corroborates our sixth hypothesis.

- The ability for recalling objects in the large-scale environment of the task area was related with the visuospatial skills on small-scale tests. Specifically, it was related with the spatial short-term memory retrieval and the ability to calculate distances and directions. Results that corroborate the seventh hypothesis.

- The displacements made across the interaction area of the task were related to the levels of aggressiveness and withdrawal. Results that corroborates our eighth hypothesis.

From the developments and studies carried out, we can present the following general conclusions:

\section{Learning:}

- Autostereoscopic VR systems, with different background modes and NUI, have proven to be effective tools for learning teeth morphology.

- With this type of systems, children can learn and at the same time, they can have a good time.

- Stereoscopy and NUI are appropriated for developing educational games and they can be exploited in their development.

\section{Spatial memory:}

- VR systems, with stereoscopy and two different user interfaces (inactive and physical active conditions), have proven to be reliable and effective tools to assess spatial memory in children.

- With this type of systems, the children can be assessed meanwhile are having a good time. 
- Our task and similar tasks could be used for assessment and training of spatial memory in children and adults.

\section{Future works}

Our task for the assessment of spatial memory has some limitations that can be improved in different aspects, it can be used for different purposes and for different collectives. First, as aspects of improvement, our task tests spatial short-term memory for the location of three objects in the virtual environment. The task could be improved adding more objects, more levels and design more complex environments. Second, as possibilities of use with other purposes or different collectives, our task can potentially be used:

- For the assessment in adults and children with and without motor problems.

- To detect learning difficulties in samples of people with academic problems or neurological disorders.

- To assess other cognitive abilities related to spatial processing.

- To train people with cognitive impairment who could probably have affected spatial orientation or memory skills.

\section{Scientifc contributions}

The publications derived from this thesis are the following:

\section{Papers in journals indexed in JCR}

- Rodríguez-Andrés, D.; Juan, M.C.; Méndez-López, M.; Pérez-Hernández, E.; Lluch, J. (2016). MnemoCity Task: assessment of children's spatial memory using stereoscopy and virtual environments. PLoS ONE, 11(8): e0161858. DOI: 10.1371/journal.pone.0161858, Impact Factor: 2.806 (in the year of publication) (Q1, relative position in Multidisciplinary Sciences - SCIE: 15/64)

- Rodríguez-Andrés, D.; Méndez-López, M.; Juan, M.C.; Pérez-Hernández, E. (2018). A Virtual Object-Location Task for Children: Gender 
and Videogame Experience Influence Navigation; Age Impacts Memory and Completion Time. Frontiers in Psychology, 9:451. DOI: 10.3389/fpsyg.2018.00451. Impact Factor: 2.321 (2016) (Q1-Q2, relative position in Psychology, Multidisciplinary - SSCI: 33/129; difference with respect to $\mathrm{Q} 1+0.75)$

Papers in conferences indexed in CORE 2017

- Rodríguez-Andrés, D.; Juan, M.C.; Mollá, R.; Méndez-López, M. (2017). A 3D Serious Game for Dental Learning in Higher Education. The 17th IEEE International Conference on Advanced Learning Technologies (ICALT2017), pp. 106-110 (CORE 'B')

\section{Papers in other conferences}

- Rodríguez-Andrés, D.; Cárdenas-Delgado, S.; Juan, M.C.; Pérez-Hernández, E., Méndez-López, M., Lluch, J. (2015). Stereoscopic visualization systems: Comparison between a Large Passive Display and a Head Mounted Display. XXV Spanish Computer Graphics Conference (CEIG 2015). pp. 39-42. DOI:10.2312/ceig.20151198

- Rodríguez-Andrés, D.; Cárdenas-Delgado, S.; Pérez-Hernández, E.; Juan, M.C.; Méndez-López, M. (2015). Nueva tarea virtual para evaluar la memoria espacial en niños. VII Congreso de Neuropsicología. Neuropsicología 3.0. Communication: 9.

\section{Other difusions}

- Rodríguez-Andrés, D. (2014). Nuevos métodos para facilitar el aprendizaje en odontología. I Encuentro de Estudiantes de Doctorado. Universitat Politècnica de València. Poster: 124.

- Rodríguez-Andrés, D. (2014). Aplicaciones de la realidad aumentada, autoestereocopía e interfaces naturales. United Nations Day. The United Nations Support Base in Valencia.

- Juan, M.C.; Martín-SanJosé, J.F.; Cárdenas-Delgado, S.; LoachamínValencia, M.; Rodríguez-Andrés, D. (2014). Aplicaciones de la Realidad Aumentada, Autoestereoscopía e Interfaces Naturales en Educación y Psicología. I Jornada de Aplicaciones Industriales de la Investigación. Valencia. 
- Rodríguez-Andrés, D. (2014). AutoestereoNUI: Un sistema que combina una pantalla autoestereoscópica y tecnología Kinect para ayudar en la formación de odontólogos. Salón Internacional de Equipos, Productos y Servicios Dentales. Madrid.

- Rodríguez-Andrés, D. (2015). MemoCity: Ciudad virtual visualizada en el Power Wall de la UPV. II Encuentro de Estudiantes de Doctorado. Universitat Politècnica de València. Poster: 118. 


\section{Bibliography}

Aggarwal, B. B. and S. Shishodia (2006). "Molecular targets of dietary agents for prevention and therapy of cancer". In: Biochemical Pharmacology 71.10, pp. 1397-1421 (cit. on p. 5).

Ahlberg, G. et al. (2007). "Proficiency-based virtual reality training significantly reduces the error rate for residents during their first 10 laparoscopic cholecystectomies". In: The American Journal of Surgery 193.6, pp. 797804. ISSN: 0002-9610. DOI: 10.1016/j . amjsurg. 2006.06.050 (cit. on p. 5).

Alloway, T. P. (2012). Automated Working Memory Assessment-2 (AWMA-2). London: The Psychological Corporation (cit. on p. 36).

Alloway, T. P. and R. G. Alloway (2010). "Investigating the predictive roles of working memory and IQ in academic attainment". In: Journal of Experimental Child Psychology 106.1, pp. 20-29. ISSN: 0022-0965. DOI: 10. 1016/j.jecp.2009.11.003 (cit. on p. 36).

Alloway, T. P., S. E. Gathercole, and S. J. Pickering (2006). "Verbal and visuospatial short-term and working memory in children: Are they separable?" In: Child Development 77.6, pp. 1698-1716 (cit. on pp. 61, 98).

Anacleto, J., S. Fels, and R. Silvestre (2012). "Transforming a paper based process to a natural user interfaces process in a chronic care hospital". 
In: Procedia Computer Science 14, pp. 173-180. ISSN: 1877-0509. DOI: 10.1016/j.procs.2012.10.020 (cit. on p. 17).

Arino, J. J., M. C. Juan, J. A. Gil-Gómez, and R. Mollá (2014). "A comparative study using an autostereoscopic display with augmented and virtual reality". In: Behaviour \& Information Technology 33.6, pp. 646-655 (cit. on pp. 17, 26).

Astur, R. S., J. Tropp, S. Sava, R. T. Constable, and E. J. Markus (2004). "Sex differences and correlations in a virtual Morris water task, a virtual radial arm maze, and mental rotation". In: Behavioural Brain Research 151.1-2, pp. 103-115. ISSN: 0166-4328. DOI: 10.1016/j.bbr.2003.08.024 (cit. on pp. 66, 67).

Baddeley, A. (1992). "Working memory". In: Science 255.5044, pp. 556-559. ISSN: 0036-8075. DOI: 10.1126/science.1736359 (cit. on p. 36).

Balram, N. (2016). "Fundamentals of Light Field Imaging and Display Systems". In: Short Course. https://bit.ly/2MRZK2Q, (last access: july 2018) (cit. on p. 4).

Bioulac, S., S. Lallemand, A. Rizzo, P. Philip, C. Fabrigoule, and M. P. Bouvard (2012). "Impact of time on task on ADHD patient's performances in a virtual classroom". In: European Journal of Paediatric Neurology 16.5, pp. 514-521. ISSN: 1090-3798. DOI: 10.1016/j . ejpn. 2012.01 .006 (cit. on p. 66).

Botella, C., J. Osma, A. Garcia-Palacios, S. Quero, and R. M. Baños (2004). "Treatment of flying phobia using virtual reality: data from a 1-year followup using a multiple baseline design". In: Clinical Psychology 83 Psychotherapy: An International Journal of Theory \& Practice 11.5, pp. 311-323 (cit. on p. 7).

Bowman, D. A. and R. P. McMahan (2007). "Virtual Reality: How Much Immersion Is Enough?" In: Computer 40.7, pp. 36-43. ISSN: 0018-9162. DOI: 10.1109/MC. 2007.257 (cit. on p. 3).

Broadbent, H. J., E. K. Farran, and A. Tolmine (2015). "Sequential egocentric navigation and reliance on landmarks in Williams syndrome and typical 
development". In: Frontiers in Psychology 6.216. ISSN: 1664-1078. DOI: 10.3389/fpsyg. 2015.00216 (cit. on pp. 66, 67).

Brown, S., L. Weih, N. Mukesh, C. McCarty, and H. Taylor (2001). "Assessment of adult stereopsis using the Lang 1 Stereotest: a pilot study". In: Binocular Vision ES Strabismus Quarterly 16.2, pp. 91-97 (cit. on p. 58).

Bullens, J., K. Igloi, A. Berthoz, A. Postma, and L. Rondi-Reig (2010). "Developmental time course of the acquisition of sequential egocentric and allocentric navigation strategies". In: Journal of Experimental Child Psychology 107.3, pp. 337-350. ISSN: 0022-0965. DOI: 10.1016/j. jecp. 2010. 05.010 (cit. on pp. 67, 87).

Burgess, N. and G. Hitch (2005). "Computational models of working memory: putting long-term memory into context". In: Trends in Cognitive Sciences 9.11, pp. 535-541. ISSN: 1364-6613. DOI: $10.1016 /$ j.tics.2005.09.011 (cit. on pp. 6, 30, 36).

Burgess, N., E. A. Maguire, H. J. Spiers, and J. O'Keefe (2001a). "A temporoparietal and prefrontal network for retrieving the spatial context of lifelike events". In: NeuroImage 14.2, pp. 439-453. ISSN: 1053-8119. DOI: 10.1006/nimg. 2001.0806 (cit. on p. 6).

Burgess, N., S. Becker, J. A. King, and J. O'Keefe (2001b). "Memory for events and their spatial context: models and experiments". In: Philosophical Transactions of the Royal Society of London B: Biological Sciences 356.1413, pp. 1493-1503. ISSN: 0962-8436. DOI: 10.1098/rstb. 2001.0948 (cit. on p. 30).

Burles, F., V. Guadagni, F. Hoey, A. E. G. F. Arnold, R. M. Levy, T. O'Neill, and G. Iaria (2014). "Neuroticism and self-evaluation measures are related to the ability to form cognitive maps critical for spatial orientation". In: Behavioural Brain Research 271, pp. 154-159. ISSN: 1872-7549. DOI: 10. 1016/j.bbr.2014.06.002 (cit. on pp. 67, 68, 90,99).

Byrne, P., S. Becker, and N. Burgess (2007). "Remembering the past and imagining the future: A neural model of spatial memory and imagery". In: Psychological Review 114.2, pp. 340-375. ISSN: 1939-1471. DOI: 10.1037/ 0033-295X.114.2.340 (cit. on p. 36). 
Cánovas, R., R. Fernández-García, and J. M. Cimadevilla (2011). "Effect of reference frames and number of cues available on the spatial orientation of males and females in a virtual memory task". In: Behavioural Brain Research 216.1, pp. 116-121. ISSN: 1872-7549. DOI: $10.1016 / \mathrm{j} . \mathrm{bbr}$. 2010.07.026 (cit. on pp. 33, 36, 57, 95).

Cánovas, R., M. Espínola, L. Iribarne, and J. M. Cimadevilla (2008). "A new virtual task to evaluate human place learning". In: Behavioural Brain Research 190.1, pp. 112-118. ISSN: 0166-4328. DOI: 10.1016/j.bbr. 2008. 02.024 (cit. on pp. 30, 33, 35, 36, 57, 66).

Cantoni, V., M. Cellario, and M. Porta (2004). "Perspectives and challenges in e-learning: towards natural interaction paradigms". In: Journal of Visual Languages $\&$ Computing 15.5, pp. 333-345. ISSN: 1045-926X. DOI: 10 . 1016/j.jvlc.2003.10.002 (cit. on p. 35).

Cárdenas-Delgado, S., M. C. Juan, M. Méndez-López, and E. Pérez-Hernández (2017a). "Could People with Stereo-Deficiencies Have a Rich 3D Experience Using HMDs?" In: IFIP Conference on Human-Computer Interaction, pp. 97-116 (cit. on pp. 8, 95).

Cárdenas-Delgado, S., M. Méndez-López, M. C. Juan Lizandra, E. PérezHernández, J. Lluch, and R. Vivó (2017b). "Using a Virtual Maze Task to Assess Spatial Short-term Memory in Adults". In: VISIGRAPP, pp. 46-57 (cit. on pp. 8, 95, 97).

Carlin, A. S., H. G. Hoffman, and S. Weghorst (1997). "Virtual reality and tactile augmentation in the treatment of spider phobia: a case report". In: Behaviour Research and Therapy 35.2, pp. 153-158. ISSN: 0005-7967. DOI: 10.1016/S0005-7967 (96)00085-X (cit. on p. 5).

Castanes, M. S. (2003). "Major review: The underutilization of vision screening (for amblyopia, optical anomalies and strabismus) among preschool age children". In: Binocular Vision EJ Strabismus Quarterly 18.4, pp. 217-232. ISSN: 1088-6281 (cit. on p. 58).

Chang, Y.-J., S.-F. Chen, and A.-F. Chuang (2011a). "A gesture recognition system to transition autonomously through vocational tasks for individuals with cognitive impairments". In: Research in Developmental Disabilities 
32.6, pp. 2064-2068. ISSN: 0891-4222. DOI: 10.1016/j.ridd.2011.08.010 (cit. on p. 16).

- (2011b). "A gesture recognition system to transition autonomously through vocational tasks for individuals with cognitive impairments". In: Research in Developmental Disabilities 32.6, pp. 2064-2068 (cit. on p. 17).

Cimadevilla, J. M., R. Cánovas, L. Iribarne, A. Soria, and L. López (2011). "A virtual-based task to assess place avoidance in humans". In: Journal of Neuroscience Methods 196.1, pp. 45-50. ISSN: 1872-678X. DOI: 10.1016/ j.jneumeth.2010.12.026 (cit. on pp. 30, 34, 96).

Cimadevilla, J. M., L. Roldán, M. París, M. Arnedo, and S. Roldán (2014). "Spatial learning in a virtual reality-based task is altered in very preterm children". In: Journal of Clinical and Experimental Neuropsychology 36.9, pp. 1002-1008. ISSN: 1380-3395. DOI: 10.1080/13803395 . 2014.963520 (cit. on pp. 7, 30).

Coluccia, E. and G. Louse (2004). "Gender differences in spatial orientation: A review". In: Journal of Environmental Psychology 24.3, pp. 329-340. ISSN: 0272-4944. DOI: $10.1016 / j$.jenvp. 2004.08 .006 (cit. on p. 62).

Corsi, P. (1972). "Human Memory and the Medial Temporal Region of the Brain (Doctoral dissertation, McGill University, 1972)". In: Dissertation Abstracts International 34.819-B (cit. on p. 6).

Courbois, Y., E. K. Farran, A. Lemahieu, M. Blades, H. Mengue-Topio, and P. Sockeel (2013). "Wayfinding behaviour in Down syndrome: A study with virtual environments". In: Research in Developmental Disabilities 34.5, pp. 1825-1831. ISSN: 0891-4222. DOI: $10.1016 /$ j . ridd . 2013.02 .023 (cit. on pp. 66, 67).

da Silva Cameirão, M., S. Bermúdez i Badia, E. Duarte, and P. F. M. J. Verschure (2011). "Virtual reality based rehabilitation speeds up functional recovery of the upper extremities after stroke: A randomized controlled pilot study in the acute phase of stroke using the Rehabilitation Gaming System". In: Restorative Neurology and Neuroscience 29.5, pp. 287-298. ISSN: 0922-6028. DOI: 10.3233/RNN-2011-0599 (cit. on p. 5). 
Deffenbacher, J. L., D. M. Deffenbacher, R. S. Lynch, and T. L. Richards (2003). "Anger, aggression, and risky behavior. A comparison of high and low anger drivers". In: Behaviour Research and Therapy 41.6, pp. $701-$ 718. ISSN: 0005-7967. DOI: https://doi.org/10.1016/S0005-7967(02) 00046-3 (cit. on p. 90).

Dodgson, N. A. (2004). "Variation and extrema of human interpupillary distance". In: Electronic Imaging 2004. Ed. by A. J. Woods, J. O. Merritt, S. A. Benton, and M. T. Bolas. Vol. 5291. International Society for Optics and Photonics, pp. 36-46. DOI: 10.1117/12.529999 (cit. on p. 43).

Emmelkamp, P. M., M. Krijn, A. M. Hulsbosch, S de Vries, M. J. Schuemie, and C. A. van der Mast (2002). "Virtual reality treatment versus exposure in vivo: a comparative evaluation in acrophobia". In: Behaviour Research and Therapy 40.5, pp. 509-516 (cit. on p. 7).

Emmelkamp, P. M., M. Bruynzeel, L. Drost, and C. A. van der Mast (2001). "Virtual reality treatment in acrophobia: a comparison with exposure in vivo". In: CyberPsychology \& Behavior 4.3, pp. 335-339 (cit. on p. 6).

Erez, N., P. L. Weiss, R. Kizony, and D. Rand (2013). "Comparing performance within a virtual supermarket of children with traumatic brain injury to typically developing children: A pilot study". In: OTJR-Occupation Participation and Health 33.4, pp. 218-227. ISSN: 1539-4492. DOI: 10.3928/ 15394492-20130912-04 (cit. on p. 66).

Farran, E. K., H. R. M. Purser, Y. Courbois, M. Balle, P. Sockeel, D. Mellier, and M. Blades (2015). "Route knowledge and configural knowledge in typical and atypical development: a comparison of sparse and rich environments". In: Journal of Neurodevelopmental Disorders 7.37. ISSN: 18661947. DOI: 10.1186/s11689-015-9133-6 (cit. on pp. 66, 90).

Fishkin, K. P. (2004). "A taxonomy for and analysis of tangible interfaces". In: Personal and Ubiquitous Computing 8.5, pp. 347-358. ISSN: 1617-4909. DOI: $10.1007 / \mathrm{s} 00779-004-0297-4$ (cit. on p. 16).

Foreman, N. (2010). "Virtual reality in psychology". In: Themes in Science and Technology Education 2, pp. 225-252 (cit. on pp. 5, 33, 57, 96). 
Fornasari, L. et al. (2013). "Navigation and exploration of an urban virtual environment by children with autism spectrum disorder compared to children with typical development". In: Research in Autism Spectrum Disorders 7.8, pp. 956-965. DOI: 10.1016/j.rasd.2013.04.007 (cit. on pp. 67, 90).

Grantcharov, T. P., V. B. Kristiansen, J. Bendix, L. Bardram, J. Rosenberg, and P. Funch-Jensen (2004). "Randomized clinical trial of virtual reality simulation for laparoscopic skills training". In: British Journal of Surgery 91.2, pp. 146-150. ISSN: 0007-1323. DOI: 10.1002/bjs. 4407 (cit. on p. 35).

Grigg, P. and C. D. Stephens (1998). "Computer-assisted learning in dentistry a view from the UK". In: Journal of Dentistry 26.5-6, pp. 387-395. ISSN: 0300-5712. DOI: 10.1016/S0300-5712 (98)00012-8 (cit. on p. 17).

Gurusamy, K., R. Aggarwal, L. Palanivelu, and B. R. Davidson (2008). "Systematic review of randomized controlled trials on the effectiveness of virtual reality training for laparoscopic surgery". In: British Journal of Surgery 95.9, pp. 1088-1097. ISSN: 00071323. DOI: 10.1002/bjs. 6344 (cit. on p. 5).

Halle, M. (1997). "Autostereoscopic displays and computer graphics". In: $A C M$ SIGGRAPH Computer Graphics (SIGGRAPH) 31.2, pp. 58-62. ISSN: 00978930. DOI: $10.1145 / 271283.271309$ (cit. on p. 17).

Hamilton, D. A., I. Driscoll, and R. J. Sutherland (2002). "Human place learning in a virtual Morris water task: some important constraints on the flexibility of place navigation". In: Behavioural Brain Research 129.1-2, pp. 159-170. ISSN: 0166-4328. DOI: 10 . 1016/S0166-4328(01) 00343-6 (cit. on pp. 33, 35).

Hamilton, D. A., P. Kodituwakku, R. J. Sutherland, and D. D. Savage (2003). "Children with Fetal Alcohol Syndrome are impaired at place learning but not cued-navigation in a virtual Morris water task". In: Behavioural Brain Research 143.1, pp. 85-94. ISSN: 0166-4328. DOI: 10.1016/S01664328(03)00028-7 (cit. on pp. 34, 67).

Hartley, T., I. Trinkler, and N. Burgess (2004). "Geometric determinants of human spatial memory". In: Cognition 94.1, pp. 39-75. ISSN: 0010-0277. DOI: $10.1016 /$ j.cognition.2003.12.001 (cit. on p. 38). 
Hays, R. T., J. W. Jacobs, C. Prince, and E. Salas (1992). "Flight simulator training effectiveness: A meta-analysis". In: Military Psychology 4.2, pp. 63-74. ISSN: 1532-7876. DOI: $10.1207 /$ s15327876mp0402_1 (cit. on p. 5).

Heilig, M. L. (1960). Stereoscopic-Television Aparatus for Individual Use. United States Patent 2955156. (Cit. on p. 4).

Henderson, S. E., D. A. Sugden, and A. L. Barnett (2012). Batería de evaluación del movimiento para niños-2 (MABC-2). Madrid, Pearson Educación. (Cit. on p. 70).

Hill-Briggs, F., J. G. Dial, D. A. Morere, and A. Joyce (2007). "Neuropsychological assessment of persons with physical disability, visual impairment or blindness, and hearing impairment or deafness". In: Archives of Clinical Neuropsychology 22.3, pp. 389-404. ISSN: 0887-6177. DOI: 10.1016/j. acn. 2007.01 .013 (cit. on pp. 61,97).

Holden, M. K. (2005). "Virtual environments for motor rehabilitation: review". In: CyberPsychology $\&$ Behavior 8.3, pp. 187-211. ISSN: 1094-9313. DOI: $10.1089 / \mathrm{cpb} .2005 .8 .187$ (cit. on p. 33).

Hwang, G.-J. and P.-H. Wu (2012). "Advancements and trends in digital gamebased learning research: a review of publications in selected journals from 2001 to 2010". In: British Journal of Educational Technology 43.1, E6E10. ISSN: 0007-1013. DOI: 10.1111/j.1467-8535.2011.01242.x (cit. on pp. 24, 100).

Jack, D., R. Boian, A. S. Merians, M. Tremaine, G. C. Burdea, S. V. Adamovich, M. Recce, and H. Poizner (2001). "Virtual reality-enhanced stroke rehabilitation". In: IEEE Transactions on Neural Systems and Rehabilitation Engineering 9.3, pp. 308-318. ISSN: 1534-4320. DOI: 10.1109/7333.948460 (cit. on p. 5).

Juan, M. C. and J. Calatrava (2011). "An augmented reality system for the treatment of phobia to small animals viewed via an optical see-through HMD. Comparison with a similar system viewed via a video see-through HMD". In: International Journal of Human-Computer Interaction 27.5, pp. 436-449 (cit. on p. 30). 
Juan, M. C., M. Alcañiz, C. Monserrat, C. Botella, R. M. Baños, and B. Guerrero (2005). "Using augmented reality to treat phobias". In: IEEE Computer Graphics and Applications 25.6, pp. 31-37. ISSN: 0272-1716. DOI: 10.1109/MCG.2005.143 (cit. on pp. 30,35).

Juan, M. C., R. Baños, C. Botella, D. Pérez, M. Alcañiz, and C. Monserrat (2006). "An augmented reality system for the treatment of acrophobia: The sense of presence using immersive photography". In: Presence: Teleoperators and Virtual Environments 15.4, pp. 393-402. ISSN: 1054-7460. DOI: $10.1162 /$ pres.15.4.393 (cit. on p. 30).

Juan, M. C., M. Mendez-Lopez, E. Perez-Hernandez, and S. Albiol-Perez (2014). "Augmented reality for the assessment of children's spatial memory in real settings". In: PLoS ONE 9.12, e113751. ISSN: 1932-6203. DOI: 10.1371/ journal.pone.0113751 (cit. on pp. 8, 30, 36, 58, 61, 89, 95, 97, 98).

Kallai, J et al. (2007). "Cognitive and affective aspects of thigmotaxis strategy in humans". In: Behavioral Neuroscience 121.1, pp. 21-30. ISSN: 0735-7044. DOI: $10.1037 / 0735-7044.121 .1 .21$ (cit. on p. 68).

Kalyvioti, K. and T. A. Mikropoulos (2013). "A virtual reality test for the identification of memory strengths of dyslexic students in higher education". In: Journal of Universal Computer Science 19.18, pp. 2698-2721. ISSN: 0948-695X (cit. on p. 66).

Kessels, R. P. C., M. J. E. van Zandvoort, A. Postma, L. J. Kappelle, and E. H. F. de Haan (2000). "The Corsi Block-Tapping Task: standardization and normative data". In: Applied Neuropsychology 7.4, pp. 252-258. ISSN: 0908-4282. DOI: 10.1207/S15324826AN0704_8 (cit. on pp. 6, 36, 48, 49, $58,61,77,89,97)$.

Kim, H., G. A. Lee, U. Yang, T. Kwak, and K.-H. Kim (2012). "Dual autostereoscopic display platform for multi-user collaboration with natural interaction". In: ETRI Journal 34.3, pp. 466-469. ISSN: 1225-6463. DOI: 10.4218/etrij.12.0211.0331 (cit. on p. 17).

Koenig, S. T., G. P. Crucian, A. Dünser, C. Bartneck, and J. C. DalrympleAlford (2011). "Validity evaluation of a spatial memory task in virtual environments". In: International Journal of Design and Innovation Research 6.1, pp. 1-13 (cit. on pp. 30, 33, 57, 95). 
Korkman, M., U. Kirk, and S. Kemp (2014). NEPSY-II. Madrid: Pearson Ediciones. (Cit. on pp. 77, 89).

Korthauer, L. E., N. T. Nowak, M. Frahmand, and I. Driscoll (2017). "Cognitive correlates of spatial navigation: Associations between executive functioning and the virtual Morris Water Task". In: Behavioural Brain Research 317, pp. 470-478. ISSN: 1872-7549. DOI: $10.1016 /$ j . bbr. 2016.10.007 (cit. on p. 89).

Kruskal, W. H. and W. A. Wallis (1952). "Use of ranks in one-criterion variance analysis". In: Journal of the American Statistical Association 47.260, pp. 583-621. ISSN: 0162-1459. DOI: 10.1080/01621459.1952.10483441 (cit. on p. 51).

Lacolina, S. A., A. Soro, and R. Scateni (2011). "Natural exploration of 3D models". In: Proceedings of the 9th ACM SIGCHI Italian Chapter International Conference on Computer-Human Interaction Facing Complexity - CHItaly. ACM Press, pp. 118-121. DOI: 10 .1145/2037296 . 2037326 (cit. on pp. 34, 35, 61).

Lam, W. J. and L. de Vries (1983). Flight simulator. US Patent 4,398,889 (cit. on p. 5).

Lang, J. (1983). "Microtropia". In: International Ophthalmology 6.1, pp. 33-36. ISSN: 0165-5701. DOI: 10.1007/BF00137371 (cit. on pp. 48, 51, 70).

Lawton, C. A. and J. Kallai (2002). "Gender differences in wayfinding strategies and anxiety about wayfinding: A cross-cultural comparison". In: Sex Roles 47, pp. 380-401 (cit. on p. 90).

León, I., J. M. Cimadevilla, and L. Tascón (2014). "Developmental gender differences in children in a virtual spatial memory task". In: Neuropsychology 28.4, pp. 485-495. ISSN: 1931-1559. DOI: $10.1037 /$ neu0000054 (cit. on pp. $61,67,89,91,98)$.

Levene, H. (1961). "Robust tests for equality of variances". In: Contributions to Probability and Statistics: Essays in Honor of Harold Hotelling 2, pp. 279 292 (cit. on p. 51). 
Loachamín-Valencia, M., M. C. Juan, M. Méndez-López, and E. Pérez-Hernández (2017). "Auditory and Spatial Assessment in Inattentive Children Using Smart Devices and Gesture Interaction". In: 2017 IEEE 17th International Conference on Advanced Learning Technologies (ICALT), pp. 106110. DOI: 10.1109/ICALT.2017.28 (cit. on pp. 8, 95, 97).

- (2018). "Using a Serious Game to Assess Spatial Memory in Children and Adults". In: International Conference on Advances in Computer Entertainment Technology (ACE 2017). LNCS 10714, pp. 809-829. DOI: 10 . 1007/978-3-319-76270-8_55 (cit. on pp. 8, 95, 97).

Loomis, J. M., J. J. Blascovich, and A. C. Beall (1999). "Immersive virtual environment technology as a basic research tool in psychology". In: $B e-$ havior Research Methods, Instruments, 83 Computers 31.4, pp. 557-564. ISSN: 0743-3808. DOI: 10.3758/BF03200735 (cit. on pp. 33, 35, 57, 66, 96).

Maguire, E. A., R. Nannery, and H. J. Spiers (2006). "Navigation around London by a taxi driver with bilateral hippocampal lesions". In: Brain 129.11, pp. 2894-2907. ISSN: 1460-2156. DOI: 10.1093/brain/aw1286 (cit. on pp. $30,57,95)$.

Maïano, C., P. Therme, and D. Mestre (2011). "Affective, anxiety and behavioral effects of an aversive stimulation during a simulated navigation task within a virtual environment: A pilot study". In: Computers in Human Behavior 27.1, pp. 169-175. ISSN: 0747-5632. DOI: 10.1016/j.chb. 2010. 07.020 (cit. on p. 67).

Maimone, A., J. Bidwell, K. Peng, and H. Fuchs (2012). "Enhanced personal autostereoscopic telepresence system using commodity depth cameras". In: Computers 85 Graphics 36.7, pp. 791-807. ISSN: 0097-8493. DOI: 10.1016/ j.cag.2012.04.011 (cit. on p. 17).

Manetta, C. and R. Blade (2015). "Glossary of Virtual Reality Terminology". In: International Journal of Virtual Reality (IJVR) 01.2, pp. 35-39 (cit. on p. 3).

Mann, H. B. and D. R. Whitney (1947). "On a test of whether one of two random variables is stochastically larger than the other". In: The Annals of Mathematical Statistics 18.1, pp. 50-60. ISSN: 0003-4851. DOI: 10.1214/ aoms/1177730491 (cit. on p. 51). 
Markets and Markets (2016). "Virtual Reality Market by Component (Hardware and Software), Technology (Non-Immersive, Semi- \& Fully Immersive), Device Type (Head-Mounted Display, Gesture Control Device), Application and Geography - Global Forecast to 2022". Report Code: SE 3528. Available in: http://www.marketsandmarkets.com/Market-Reports/reality-applications-market-458.html (last access: july 2018) (cit. on p. 4).

- (2017). "Augmented and Virtual Reality in Healthcare Market by Offering (Hardware and Software), Device Type, End User, Application (Patient Care Management, Medical Training \& Education, Pharmacy Management, Surgery), and Geography - Global Forecast to 2023". Available in: http://www.marketsandmarkets.com/Market-Reports/augmented-realityvirtual-reality-healthcare-market-220832469.html (last access: july 2018). (Cit. on p. 4).

Martí-Parreño, J., E. Méndez-Ibáñez, and A. Alonso-Arroyo (2016). "The use of gamification in education: a bibliometric and text mining analysis". In: Journal of Computer Assisted Learning 32.6, pp. 663-676 (cit. on p. 100).

Martín-SanJosé, J. F., M. C. Juan, M. Giménez, and J. Cano (2013). "A Computer-Based Learning Game for Studying History". In: XXIII Spanish Computer Graphics Conference - CEIG'13, pp. 177-186 (cit. on p. 35).

Martín-SanJosé, J. F., M. C. Juan, E. Torres, and M. J. Vicent (2014). "Playful interaction for learning collaboratively and individually". In: Journal of Ambient Intelligence and Smart Environments 6.3, pp. 259-311. DOI: 10. 3233/AIS-140257 (cit. on pp. 20, 35).

Martín-SanJosé, J. F., M. C. Juan, I. Seguí, and I. García-García (2015). "The effects of computer-based games and collaboration in large groups vs. collaboration in pairs or traditional methods". In: Computers $\& 3$ Education 87, pp. 42-54 (cit. on p. 99).

Martín-SanJosé, J. F., M. C. Juan, R. Mollá, and R. Vivó (2017). "Advanced displays and natural user interfaces to support learning". In: Interactive Learning Environments 25.1, pp. 17-34. DOI: 10.1080/10494820.2015. 1090455 (cit. on pp. 30, 34). 
McComas, J., P. Pivik, and M. Laflamme (1998). "Current uses of virtual reality for children with disabilities". In: Studies in Health Technology and Informatics 58, pp. 161-169 (cit. on pp. 33, 61, 97).

Meckfessel, S. et al. (2011). "Introduction of e-learning in dental radiology reveals significantly improved results in final examination". In: Journal of Cranio-Maxillofacial Surgery 39.1, pp. 40-48 (cit. on p. 17).

Mendez-Lopez, M., E. Perez-Hernandez, and M. C. Juan (2016). "Learning in the navigational space: Age differences in a short-term memory for objects task". In: Learning and Individual Differences 50.C, pp. 11-22. ISSN: 10416080. DOI: https://doi.org/10.1016/j.lindif.2016.06.028 (cit. on pp. 8, 87, 91, 95, 97, 98).

Méndez-López, M., M. Méndez, L. López, and J. L. Arias (2009). "Spatial working memory learning in young male and female rats: involvement of different limbic system regions revealed by cytochrome oxidase activity". In: Neuroscience Research 65.1, pp. 28-34. ISSN: 1872-8111. DOI: 10.1016/ j.neures.2009.05.001 (cit. on p. 89).

Merchant, Z., E. T. Goetz, L. Cifuentes, W. Keeney-Kennicutt, and T. J. Davis (2014). "Effectiveness of virtual reality-based instruction on students' learning outcomes in K-12 and higher education: A meta-analysis". In: Computers \& Education 70, pp. 29-40. ISSN: 03601315. DOI: 10.1016/ j.compedu.2013.07.033 (cit. on p. 5).

Merrill, E. C., Y. Yang, B. Roskos, and S. Steele (2016). "Sex differences in using spatial and verbal abilities influence route learning performance in a virtual environment: a comparison of 6- to 12-year old boys and girls". In: Frontiers in Psychology 7.258. ISSN: 1664-1078. DOI: 10.3389/fpsyg. 2016.00258 (cit. on pp. 67, 87).

Mestre, D. and J. L. Vercher (2011). "Glossary of Virtual Reality Terminology". In: Virtual Reality Concepts and Technologies. Chapter 5: Immersion and Presence. CRC Press (cit. on p. 3).

Michael, D. and S. L. Chen (2006). Serious games: games that educate, train and inform. Thomson Course Technology. ISBN: 15920-06221 (cit. on p. 5). 
Moffat, S. D., E. Hampson, and M. Hatzipantelis (1998). "Navigation in a "virtual" maze: sex differences and correlation with psychometric measures of spatial ability in humans". In: Evolution and Human Behavior 19.2, pp. 73-87. ISSN: 1090-5138. DOI: 10.1016/S1090-5138(97)00104-9 (cit. on pp. 33, 35, 61).

Mueller, S. C., V. Temple, B. Cornwell, C. Grillon, D. S. Pine, and M. Ernst (2009). "Impaired spatial navigation in pediatric anxiety". In: Journal of Child Psychology and Psychiatry and Allied Disciplines 50.10, pp. 12271234. ISSN: 0021-9630. DOI: $10.1111 / \mathrm{j} .1469-7610.2009 .02112 . \mathrm{x}$ (cit. on pp. $67,90,99)$.

Negut, A., S.-A. Matu, F. A. Sava, and D. David (2016). "Virtual reality measures in neuropsychological assessment: a meta-analytic review". In: Clinical Neuropsychologist 30.2, pp. 165-184. ISSN: 1385-4046. DOI: 10.1080/ 13854046.2016.1144793 (cit. on p. 66).

North, M. M., S. M. North, and J. R. Coble (2002). "Virtual reality therapy: An effective treatment for psychological disorders". In: Handbook of Virtual Environments. Design, Implementation and Applications, Kay M. Stanney (Ed.). pp 1065-1077 (cit. on p. 6).

Nys, M., V. Gyselinck, E. Orriols, and M. Hickmann (2015). "Landmark and route knowledge in children's spatial representation of a virtual environment". In: Frontiers in Psychology 5.1522. ISSN: 1664-1078. DOI: 10.3389/ fpsyg.2014.01522 (cit. on pp. 67, 87).

Oades, R. D. and R. L. Isaacson (1978). "The development of food search behavior by rats: The effects of hippocampal damage and haloperidol". In: Behavioral Biology 24.3, pp. 327-337. ISSN: 0091-6773. DOI: 10.1016/ S0091-6773(79)90184-6 (cit. on p. 33).

Piccardi, L., F. Bianchini, O. Argento, A. de Nigris, A. Maialetti, L. Palermo, and C. Guariglia (2013). "The Walking Corsi Test (WalCT): standardization of the topographical memory test in an Italian population". In: Neurological Sciences 34.6, pp. 971-978. ISSN: 1590-1874. DOI: 10.1007/s10072012-1175-x (cit. on p. 58).

Piccardi, L., L. Palermo, M. Leonzi, M. Risetti, L. Zompanti, S. D'Amico, and C. Guariglia (2014). "The Walking Corsi Test (WalCT): a normative 
study of topographical working memory in a sample of 4- to 11-year-olds". In: The Clinical Neuropsychologist 28.1, pp. 84-96. ISSN: 1744-4144. DOI: 10.1080/13854046.2013.863976 (cit. on pp. 61, 89, 98).

Picucci, L., A. O. Caffò, and A. Bosco (2011). "Besides navigation accuracy: Gender differences in strategy selection and level of spatial confidence". In: Journal of Environmental Psychology 31.4, pp. 430-438. DOI: 10.1016/ j.jenvp. 2011.01 .005 (cit. on p. 7).

Purser, H. R. M., E. K. Farran, Y. Courbois, A. Lemahieu, D. Mellier, P. Sockeel, and M. Blades (2012). "Short-term memory, executive control, and children's route learning". In: Journal of Experimental Child Psychology 113.2, pp. 273-285. ISSN: 0022-0965. DOI: 10.1016/j. jecp. 2012.06.005 (cit. on pp. 67, 87, 89).

Rauterberg, M. (1997). "Natural User Interface (NUI): a case study of a video based interaction technique for a computer game". In: HCI (2), pp. 253256 (cit. on pp. 34, 61, 98).

Read, J. C. (2008). "Validating the Fun Toolkit: an instrument for measuring children's opinions of technology". In: Cognition, Technology $\&$ Work 10.2, pp. 119-128 (cit. on p. 76).

Rego, P., P. Moreira, and L. Reis (2011). "Natural user interfaces in serious games for rehabilitation". In: Information Systems and Technologies (CISTI), 2011 6th Iberian Conference on, pp. 1-4 (cit. on p. 35).

Reynolds, C. R. and R. W. Kamphaus (1992). Behavior Assessment System for Children: Manual. Circle Pines, MN: American Guidance Service (cit. on p. 77).

Reynolds, C. R. and E. D. Bigler (2001). TOMAL Test of memory and learning: Examiner's manual. Ed. by E. Goikoetxea and D. I+D. TEA Ediciones. Madrid, Spain (cit. on p. 36).

Rodríguez-Andrés, D., M. C. Juan, M. Méndez-López, E. Pérez-Hernández, and J. Lluch (2016). "MnemoCity task: assessment of childrens spatial memory using stereoscopy and virtual environments". In: PLOS ONE 11.8. e0161858. ISSN: 1932-6203. DOI: 10.1371/journal . pone. 0161858 (cit. on pp. $17,68,71,87-89)$. 
Roidl, E., B. Frehse, and R. Hoger (2014). "Emotional states of drivers and the impact on speed, acceleration and traffic violations. A simulator study". In: Accident Analysis and Prevention 70.C, pp. 282 -292. ISSN: 0001-4575. DOI: https://doi.org/10.1016/j.aap. 2014.04 .010 (cit. on p. 90).

Roman, D. (2010). "Interact naturally". In: Communications of the ACM 53.6, p. 12. ISSN: 0001-0782. DOI: 10.1145/1743546.1743552 (cit. on p. 16).

Rosenberg, H., H. A. Grad, and D. W. Matear (2003). "The effectiveness of computer-aided, self-instructional programs in dental education: a systematic review of the literature". In: Journal of Dental Education 67.5, pp. 524-532 (cit. on p. 18).

Roskos-Ewoldsen, B., T. P. McNamara, A. L. Shelton, and W. Carr (1998). "Mental representations of large and small spatial layouts are orientation dependent". In: Journal of Experimental Psychology: Learning, Memory, and Cognition 24.1, pp. 215-226 (cit. on p. 59).

Rothbaum, B. O., L. Hodges, S. Smith, J. H. Lee, and L. Price (2000). "A controlled study of virtual reality exposure therapy for the fear of flying." In: Journal of Consulting and Clinical Psychology 68.6, p. 1020 (cit. on p. 6).

Rothbaum, B. O., L. Hodges, P. L. Anderson, L. Price, and S. Smith (2002). "Twelve-month follow-up of virtual reality and standard exposure therapies for the fear of flying." In: Journal of Consulting and Clinical Psychology 70.2 , p. 428 (cit. on p. 7).

Ruddle, R. A. and S. Lessels (2006). "For efficient navigational search, humans require full physical movement, but not a rich visual scene". In: Psychological Science 17.6, pp. 460-465 (cit. on p. 7).

Sandamas, G., N. Foreman, and M. Coulson (2009). "Interface familiarity restores active advantage in a virtual exploration and reconstruction task in children". In: Spatial Cognition and Computation 9.2, pp. 96-108. ISSN: 1387-5868. DOI: http://dx.doi.org/10.1080/13875860802589202 (cit. on p. 88).

Sandin, D. J., T. Margolis, J. Ge, J. Girado, T. Peterka, and T. A. DeFanti (2005). "The Varrier TM autostereoscopic virtual reality display". In: $A C M$ 
SIGGRAPH 2005. Vol. 24. 3, pp. 894-903. DOI: $10.1145 / 1186822$. 1073279 (cit. on p. 17).

Sayers, H. (2004). "Desktop virtual environments: A study of navigation and age". In: Interacting with Computers 16.5, pp. 939-956. ISSN: 0953-5438. DOI: $10.1016 /$ j.intcom. 2004.05 .003 (cit. on p. 87).

Schmelter, A., P. Jansen, and M. Heil (2009). "Empirical evaluation of virtual environment technology as an experimental tool in developmental spatial cognition research". In: European Journal of Cognitive Psychology 21.5, pp. 724-739. ISSN: 0954-1446. DOI: 10.1080/09541440802426465 (cit. on p. 67).

Shapiro, S. S. and M. B. Wilk (1965). "An Analysis of Variance Test for Normality (Complete Samples)". In: Biometrika 52.3/4, pp. 591-611. ISSN: 0006-3444. DOI: $10.2307 / 2333709$ (cit. on p. 78 ).

Shelton, A. L. and T. P. Mcnamara (1997). "Multiple views of spatial memory". In: Psychonomic Bulletin 83 Review 4.1, pp. 102-106. ISSN: 1069-9384. DOI: 10.3758/BF03210780 (cit. on p. 59).

Siemerkus, J., E. Irle, C. Schmidt-Samoa, P. Dechent, and G. Weniger (2012). "Egocentric spatial learning in schizophrenia investigated with functional magnetic resonance imaging". In: NeuroImage: Clinical 1.1, pp. 153-163. ISSN: 22131582 . DOI: $10.1016 / \mathrm{j}$.nicl.2012.10.004 (cit. on p. 67).

Smith, A. D., I. D. Gilchrist, and B. M. Hood (2005). "Children's search behaviour in large-scale space: Developmental components of exploration". In: Perception 34.10, pp. 1221-1229. ISSN: 0301-0066. DOI: 10.1068/p5270 (cit. on p. 58).

Son, J.-Y., H. Lee, B.-R. Lee, and K.-H. Lee (2017). "Holographic and LightField Imaging as Future 3-D Displays". In: Proceedings of the IEEE 105.5, pp. 789-804 (cit. on p. 100).

Stanton, D., N. Foreman, and P. N. Wilson (1997). "Uses of virtual reality in clinical training: developing the spatial skills of children with mobility impairments". In: Studies in Health Technology and Informatics 58, pp. 219232 (cit. on p. 33). 
Sturz, B. R. and K. D. Bodily (2010). "Encoding of variability of landmarkbased spatial information". In: Psychological Research 74.6, pp. 560-567. ISSN: 1430-2772. DOI: 10.1007/s00426-010-0277-4 (cit. on pp. 33, 35).

Tarnanas, I., M. Tsolaki, T. Nef, R. M. Müri, and U. P. Mosimann (2014). "Can a novel computerized cognitive screening test provide additional information for early detection of Alzheimer's disease?" In: Alzheimer's 8 Dementia 10.6, pp. 790-798 (cit. on p. 97).

Terlecki, M. S. and N. S. Newcombe (2005). "How important is the digital divide? The relation of computer and videogame usage to gender differences in mental rotation ability". In: Sex Roles 53.5, pp. 433-441. ISSN: 1573-2762. DOI: $10.1007 /$ s11199-005-6765-0 (cit. on pp. 87, 98).

Vallejo, V., P. Wyss, A. Chesham, A. V. Mitache, R. M. Müri, U. P. Mosimann, and T. Nef (2017). "Evaluation of a new serious game based multitasking assessment tool for cognition and activities of daily living: Comparison with a real cooking task". In: Computers in Human Behavior 70, pp. 500506 (cit. on p. 97).

Valverde, H. H. (1973). "A review of flight simulator transfer of training studies". In: Human Factors 15.6, pp. 510-522 (cit. on p. 5).

van den Brink and G. Janzen (2013). "Visual spatial cue use for guiding orientation in two-to-three-year-old children". In: Frontiers in Psychology 4. ISSN: 1664-1078. DOI: 10.3389/fpsyg. 2013.00904 (cit. on p. 67).

van der Staay, F. J., J. van Nies, and W. Raaijmakers (1990). "The effects of aging in rats on working and reference memory performance in a spatial holeboard discrimination task". In: Behavioral and Neural Biology 53.3, pp. 356-370. ISSN: 0163-1047. DOI: 10 . 1016/0163-1047 (90 ) 90226-V (cit. on p. 33).

Walkowiak, S., T. Foulsham, and A. F. Eardley (2015). "Individual differences and personality correlates of navigational performance in the virtual route learning task". In: Computers in Human Behavior 45, pp. 402-410. DOI: 10.1016/j.chb.2014.12.041 (cit. on pp. 7, 67, 68, 99). 
Walmsley, D. (2003). "Computer-aided learning programmes in teaching dental students". In: Evidence-Based Dentistry 4.81. ISSN: 1462-0049. DOI: 10. 1038/sj.ebd.6400219 (cit. on p. 18).

Wang, R. F. and E. S. Spelke (2000). "Updating egocentric representations in human navigation". In: Cognition 77.3, pp. 215-250. ISSN: 00100277. DOI: 10.1016/S0010-0277(00)00105-0 (cit. on p. 59).

Welk, A, C. Splieth, E. Wierinck, R. Gilpatrick, and G. Meyer (2006). "Computer-assisted learning and simulation systems in dentistry-a challenge to society". In: International Journal of Computerized Dentistry 9.3, pp. 253265 (cit. on p. 18).

Wells, J. D., D. E. Campbell, J. S. Valacich, and M. Featherman (2010). "The Effect of Perceived Novelty on the Adoption of Information Technology Innovations: A Risk/Reward Perspective". In: Decision Sciences 41.4, pp. 813-843. ISSN: 1540-5915. DOI: 10.1111/j.1540-5915.2010.00292.x (cit. on p. 88).

Witmer, B. G. and M. J. Singer (1998). "Measuring presence in virtual environments: A presence questionnaire". In: Presence: Teleoperators and virtual environments 7.3 , pp. 225-240 (cit. on p. 48).

Wu, H.-K., S. W.-Y. Lee, H.-Y. Chang, and J.-C. Liang (2013). "Current status, opportunities and challenges of augmented reality in education". In: Computers \& Education 62, pp. 41-49. ISSN: 03601315. DOI: $10.1016 / \mathrm{j}$. compedu.2012.10.024 (cit. on p. 5).

Xie, L., A. N. Antle, and N. Motamedi (2008). "Are tangibles more fun?" In: Proceedings of the 2nd International Conference on Tangible and Embedded Interaction - TEI '08, pp. 191-198. ISBN: 9781605580043. DOI: 10. 1145/1347390.1347433 (cit. on p. 34).

Zhang, H., K. Zherdeva, and A. D. Ekstrom (2014). "Different "routes" to a cognitive map: dissociable forms of spatial knowledge derived from route and cartographic map learning". In: Memory $\&$ Cognition 42.7, pp. 11061117. ISSN: 1532-5946. DOI: 10.3758/s13421-014-0418-x (cit. on pp. 59, 96). 